PARENTS' PERSPECTIVES ON BOTULINUM TOXIN TREATMENT 


\title{
EFFECTS OF BOTULINUM TOXIN TREATMENT IN NON-AMBULATORY CHILDREN AND ADOLESCENTS WITH CEREBRAL PALSY: UNDERSTANDING PARENTS' PERSPECTIVES
}

\author{
BY: LINDA NGUYEN, B.H.Sc.
}

\author{
A Thesis \\ Submitted to the School of Graduate Studies \\ In Partial Fulfillment of the Requirements \\ for the Degree of \\ Master of Science \\ McMaster University \\ C Copyright by Linda Nguyen, August 2017
}


McMaster University

MASTER OF SCIENCE (2017)

Hamilton, Ontario

(Rehabilitation Science)

TITLE: Effects of Botulinum Toxin Treatment in Non-ambulatory Children and Adolescents with Cerebral Palsy: Understanding Parents' Perspectives

AUTHOR: Linda Nguyen, B.H.Sc. (McMaster University)

SUPERVISOR: Dr. Jan Willem Gorter

NUMBER OF PAGES: xiii, 100 


\section{LAY ABSTRACT}

Children diagnosed with cerebral palsy $(\mathrm{CP})$ receive botulinum toxin (BoNT-A) as a treatment to reduce muscle tone. Current research on the use of BoNT-A injections in non-ambulatory children with $\mathrm{CP}$ is scarce and may not incorporate the perspectives of the family about their goals for treatment. This study interviewed parents to ask about the effects that they observed in their child after BoNT-A treatment. Fifteen parents were interviewed and all parents spoke about their journey of "finding the right path to do what is best for my child" as they learned about the possible effects of BoNT-A treatment for their child. By learning about parents' journey, informational resources can be developed and shared with other parents about the effects of BoNT-A treatment. It is important to help parents understand these effects, which would allow them to discuss and identify appropriate goals with healthcare professionals in future BoNT-A treatment sessions. 


\begin{abstract}
Children and adolescents with cerebral palsy (CP) often receive botulinum toxin (BoNT-A) to manage spasticity. Our 2014 study developed an inventory of parents' goals for BoNT-A treatment, but reasons for selecting these goals were unclear. The current study aimed to describe and categorize the effects of BoNT-A that parents observed according to WHO's International Classification of Functioning, Disability and Health (ICF) framework.
\end{abstract}

This qualitative study used interpretive description. Fifteen parents of non-ambulatory young people with CP (mean age 10.2 years, SD 3.9, 7 males) who received BoNT-A were recruited through McMaster Children's Hospital's Spasticity Management Clinic. Interviews were conducted in-person or by telephone for 20-60 minutes. The research team read the initial transcript, identified codes, and finalized the coding framework. Member checking was conducted to enhance trustworthiness.

The key theme was that parents needed to find the right path to do what is best for their child. Parents described how they learned about both positive and negative effects of BoNT-A treatment: some parents emphasized the child's pain during BoNT-A injections (negative), but also felt that BoNT-A was helpful for their child (positive). Most effects of BoNT-A were coded at the ICF activity level, such as dressing These observations helped inform parents' decision to continue with BoNT-A and identify future goals.

This study provides insight into parents' journey of learning about BoNT-A and goal-setting for their child. Parents' perspectives will be used to refine the 2014 inventory of goals to facilitate collaborative goal-setting for BoNT-A treatment. 


\section{ACKNOWLEDGEMENTS}

First, I want to thank Dr. Jan Willem Gorter, my supervisor, for his ongoing support and guidance throughout my Masters graduate studies. He always encouraged me to ask questions, propose new ideas, and collaborate with researchers and families.

I would also like to thank my thesis committee members: Drs. Peter Rosenbaum, Briano Di Rezze, and Ronit Mesterman. I am thankful for the opportunity to work with Dr. Rosenbaum, and he shared unique insights that forced me to critically think about the implications of my research. He is an exceptional mentor who always responded to emails within minutes, but more than that, I can always ask him for advice about anything, whether it is research work or future career opportunities. I am also very thankful to work with Dr. Di Rezze, who was always willing to meet with me in-person to further discuss my research work. Little did I know at the time when I first met Dr. Di Rezze, but he mentioned that my research could take place over the time span of a decade. I also feel fortunate to have continued working with Dr. Mesterman, who mentored me from when I was in fourth year of my undergraduate program and continued to support me during my Masters thesis. I would also like to extend my sincere gratitude to Dr. Sandra Moll for her incredible insight and patience in supporting me with my data analysis. She asked the questions that needed to be asked and forced me to think beyond my data.

Thank you to the members of CanChild, and every single individual has made an impact on my perspective in conducting research with families. I want to give my special thanks to Pranay Jindal for his thoughtfulness to share his resources and knowledge when I was conducting my study. I would also like to thank the families who participated in my study and took the time to share their inspiring stories with me.

I also could never have imagined that I would continue my graduate studies here at McMaster University, without the guidance of my mentors in the Child Health Specialization, Bachelor of Health Sciences (Honours) Program - Ms. Margaret Secord, Ms. Lorna Colli, and Dr. Stelios Georgiades. You have each made an impact on my personal and academic journey by encouraging me to critically think, inspiring me about the importance of research and collaboration, and challenging me to take on new opportunities.

Thank you to Michael Wong and Mark Lee for always listening to my stories and sharing your experiences. Your level of knowledge about any topic is incredible! After every single one of our conversations, I have to go home and do more research. Sometimes, this was the level of "distraction" that I needed. And of course, your sense of humour always made our conversations enjoyable.

I would also like to thank my friends who graduated with me from the Bachelor of Health Sciences (Honours) Program - Megan Schlorff, Rida Tul-Zuhra, and Mathura Mahendren. Distance clearly did not affect our friendships, because you always took the time to reach out to me. 
I am grateful for the friends that I made during graduate studies, because you made my graduate school experience so much more fun and enjoyable! Thank you to Isabel Rodriguez and Karam Noel for pushing me to work harder during our gym sessions. Tram Nguyen, Silvana Choo, Sung Ha Kim, and Young Heo - I am thankful for our friendship. You all pulled me out of my "shell" by encouraging me to share my jokes, hobbies, and interests. While spending time with you, I felt like I could simply be myself.

Last but not least, I would like to thank my family for their love, guidance, and support throughout my journey. I am especially thankful to my niece, Jennifer To, for always listening without judgment and encouraging me to relax. 


\section{TABLE OF CONTENTS}

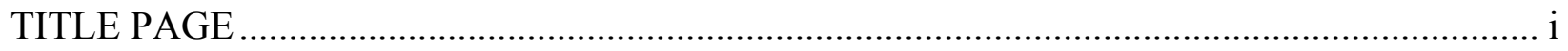

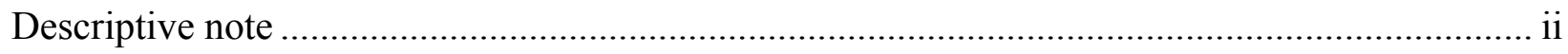

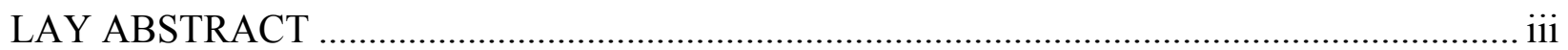

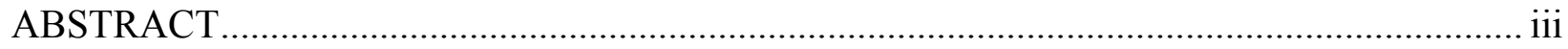

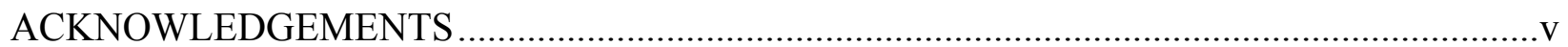

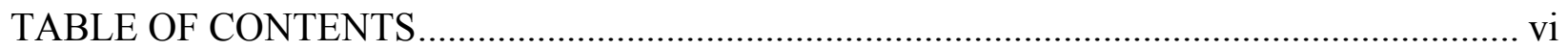

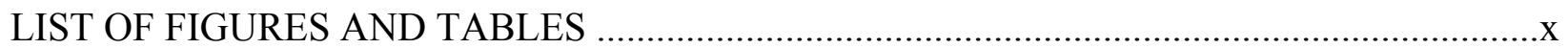

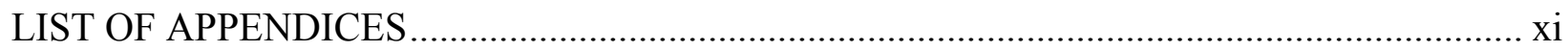

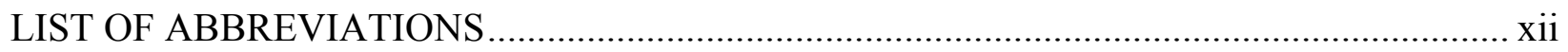

DECLARATION OF ACADEMIC ACHIEVEMENT ….......................................................

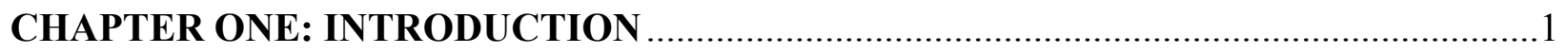

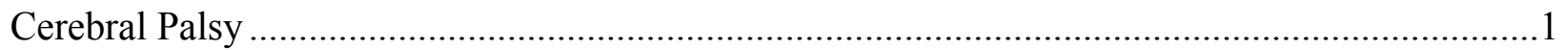

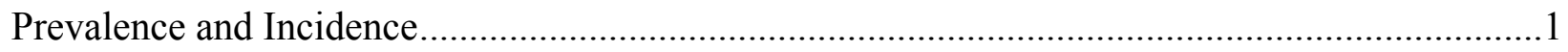

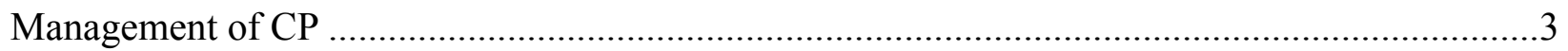

International Classification of Functioning, Disability and Health .....................................

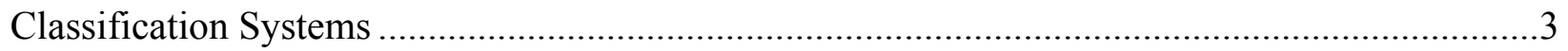

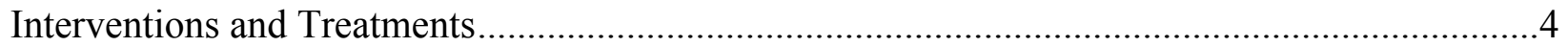

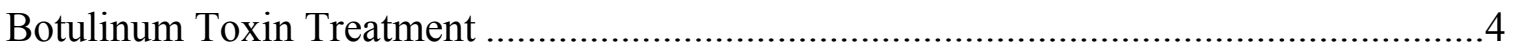

Goals and Effects of Botulinum Toxin Treatment...........................................................

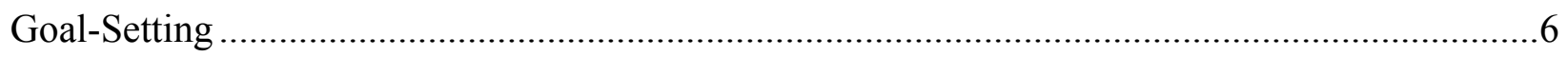

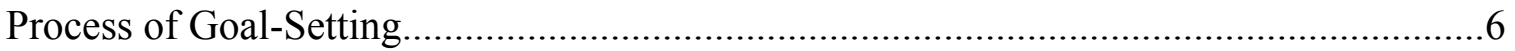

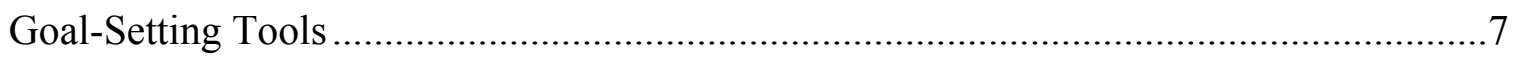

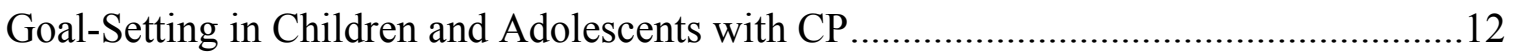

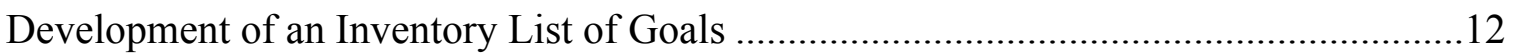

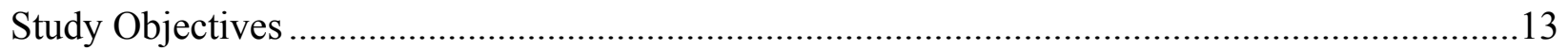

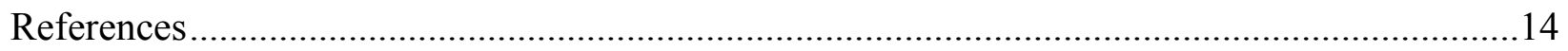

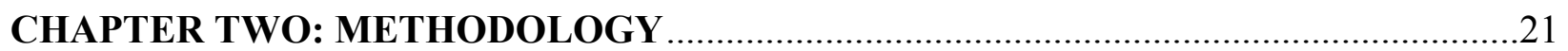

Importance of Qualitative Research in Pediatric Therapy .........................................................21

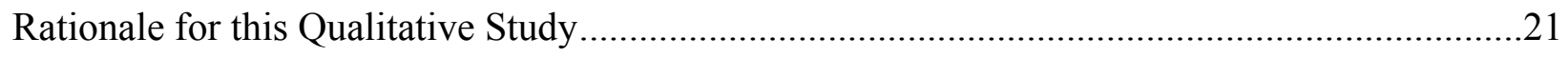

Types of Qualitative Approaches.....................................................................................2

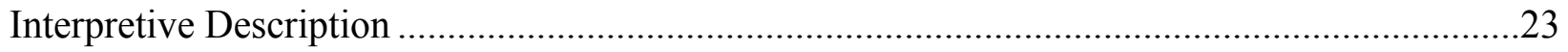

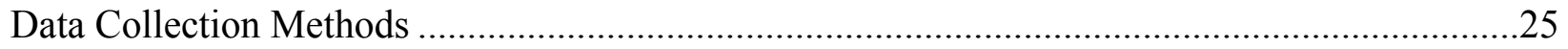

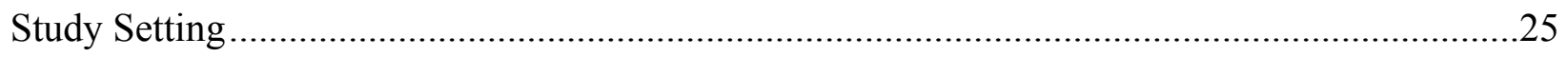

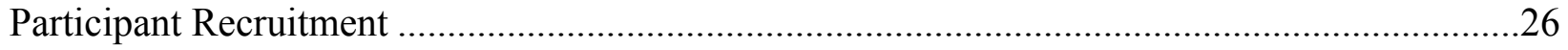

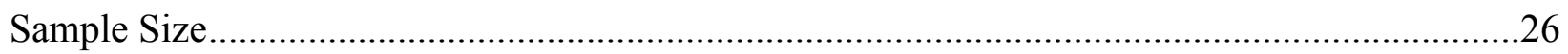


Ethics. .26

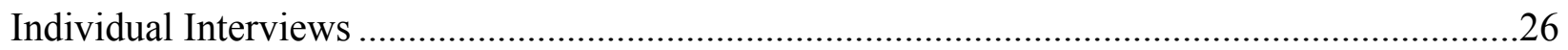

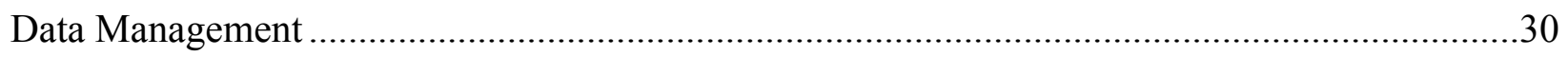

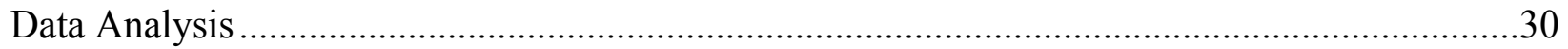

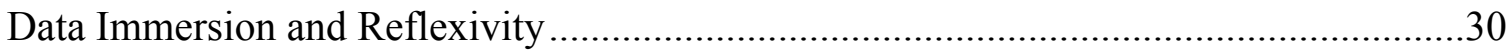

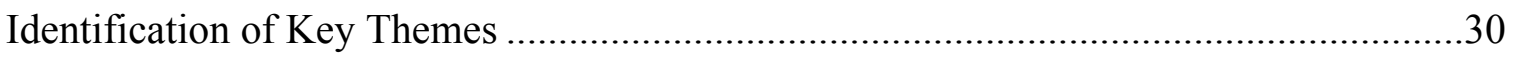

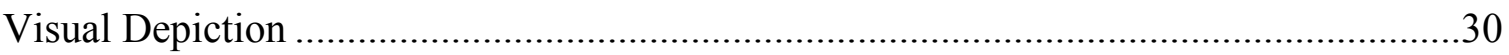

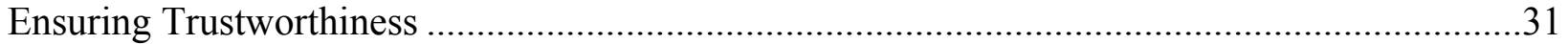

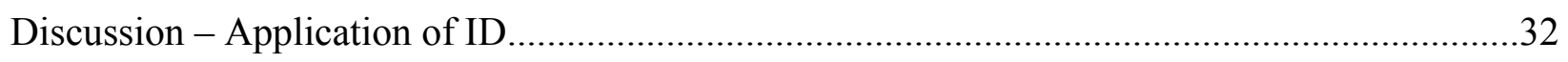

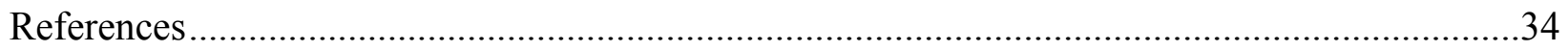

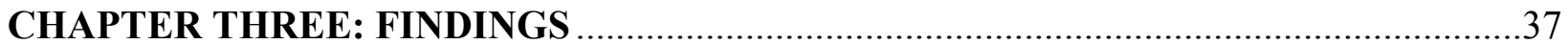

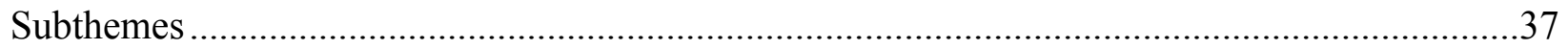

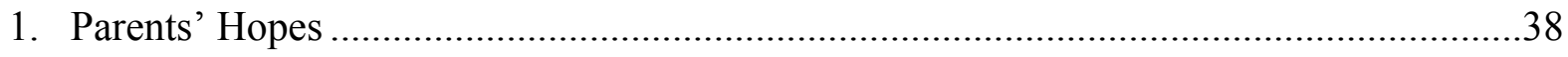

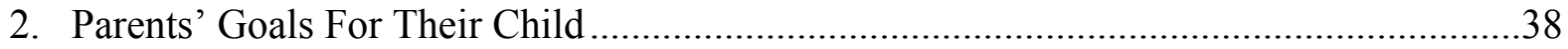

a. Promoting Their Child's Independence ..........................................................

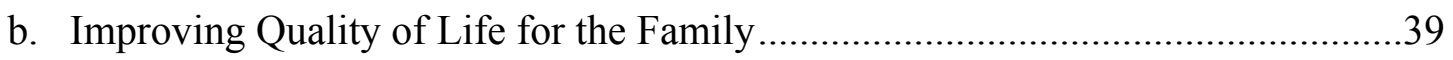

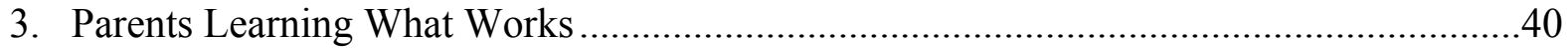

a. Body Structures and Function................................................................. 40

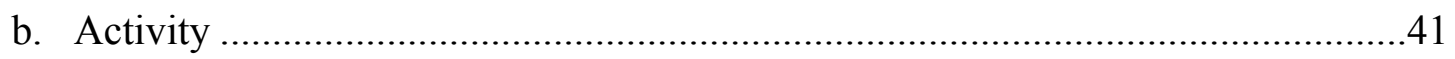

i. Caregiving Activities ......................................................................... 41

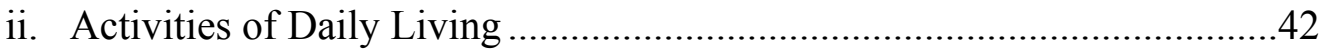

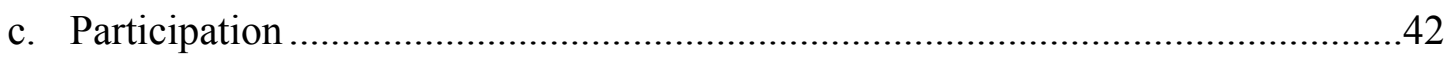

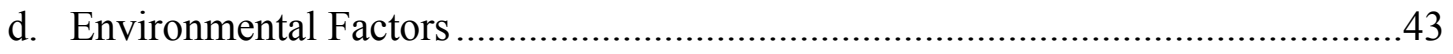

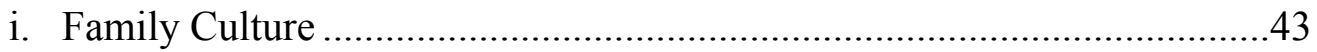

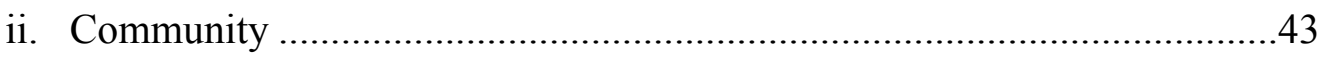

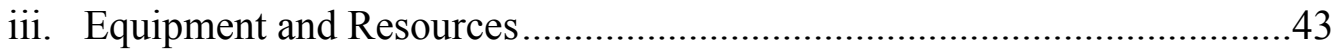

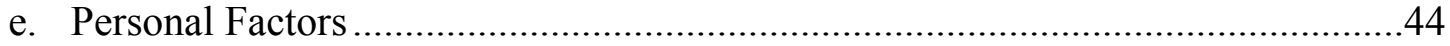

4. Parents' Reflections on the Impact of BoNT-A Treatment ........................................44

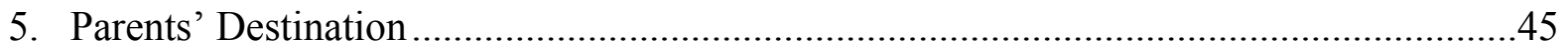

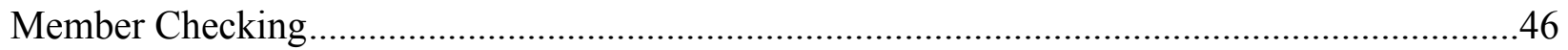

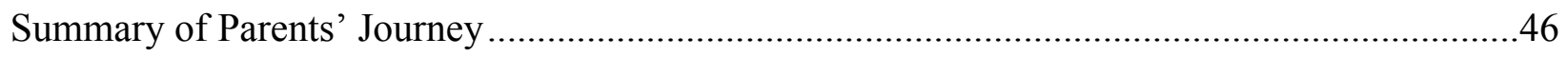




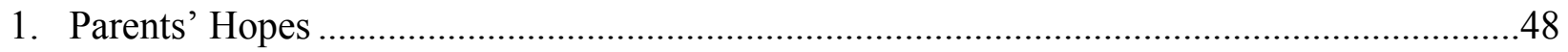

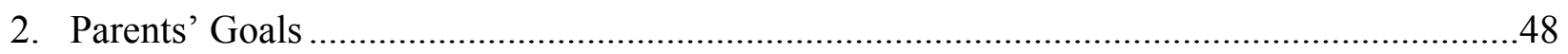

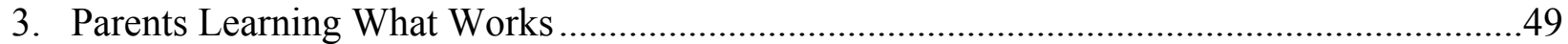

a. Body Structures and Function..................................................................................

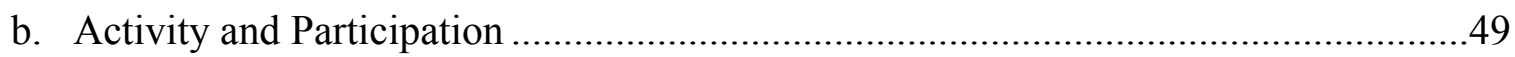

4. Parents' Reflections ....................................................................................................... 50

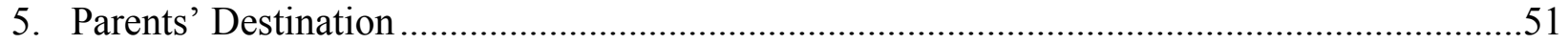

a. Application Healthcare Professionals and Goal-Setting ..............................................51

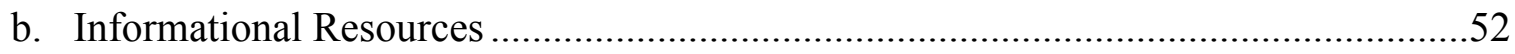

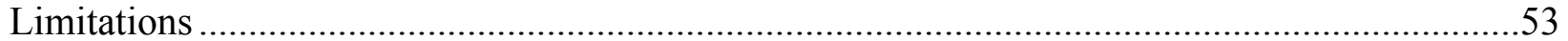

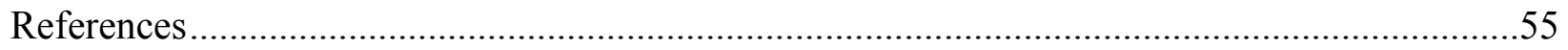

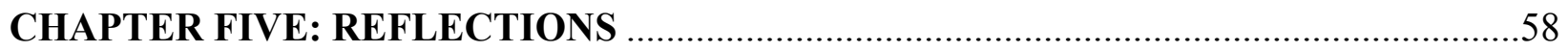

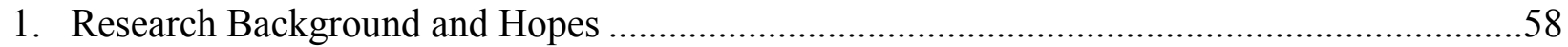

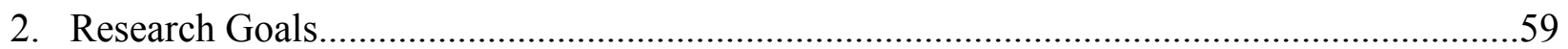

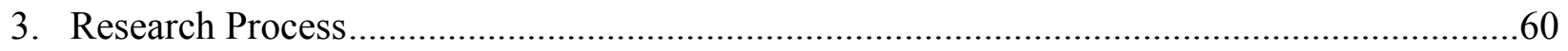

4. Reflections on Strengths and Challenges..........................................................................61

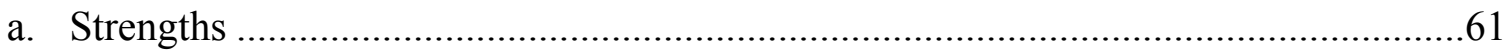

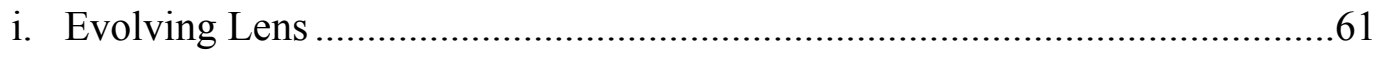

ii. Understanding Parents' Perspectives.............................................................62

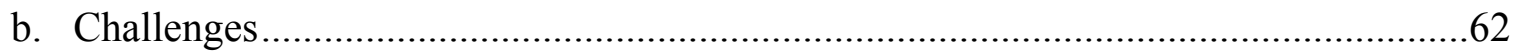

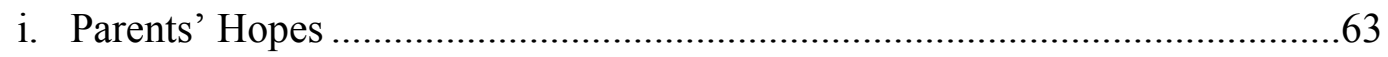

ii. Parents' Goals ………………………………….......................................63

iii. Parents Learning What Works .......................................................................63

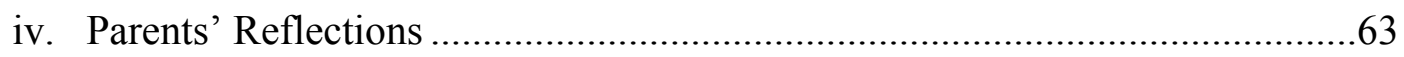

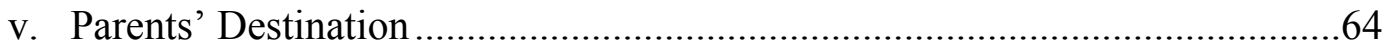

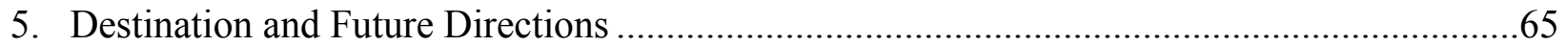

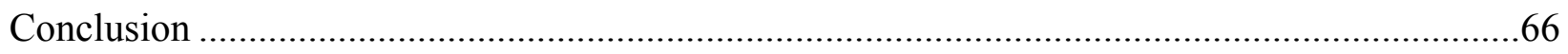

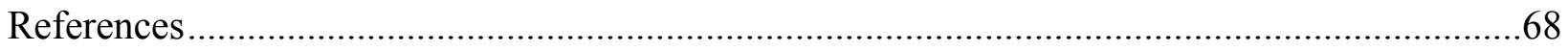




\section{LIST OF FIGURES AND TABLES}

\section{CHAPTER ONE: INTRODUCTION}

Table 1. Description of goal-setting tools

\section{CHAPTER TWO: METHODOLOGY}

Table 1. Description and comparison of three primary qualitative approaches .22

Table 2. Designing a qualitative study with an ID analytic approach .24

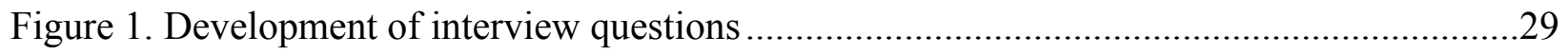

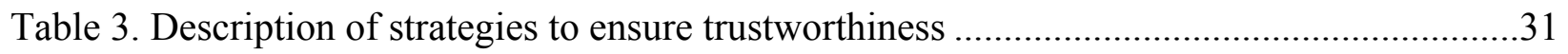

\section{CHAPTER THREE: FINDINGS}

Table 1. Characteristics of children of parents who participated in this study

\section{CHAPTER FIVE: REFLECTION}

Table 1. A description of the four philosophical assumptions associated with a constructivist paradigm. 


\section{LIST OF APPENDICES}

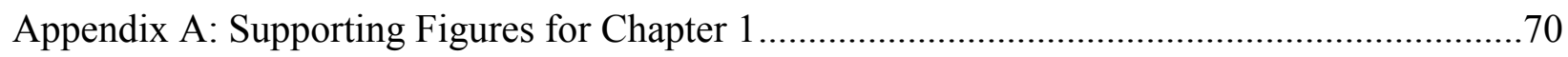

Figure 1. The International Classification of Functioning, Disability and Health..............70

Figure 2. Conceptual relationships between the ICF categories.........................................71

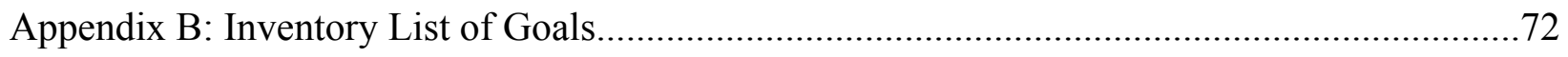

Appendix C: Recruitment Poster ............................................................................................

Appendix D: Information Sheet and Consent Form …………................................................ 74

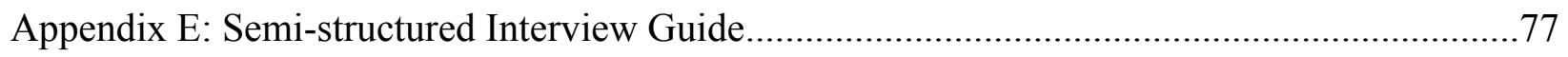

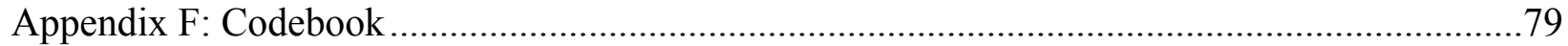

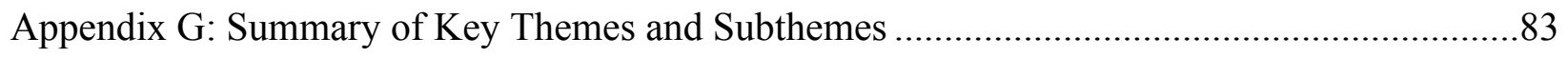

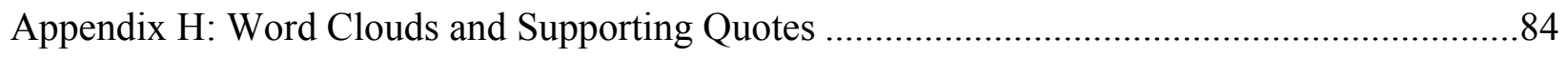

Figure 1. Word cloud of all parent interviews ...............................................................

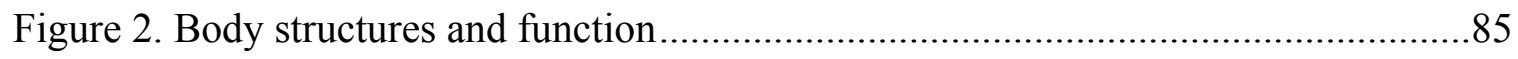

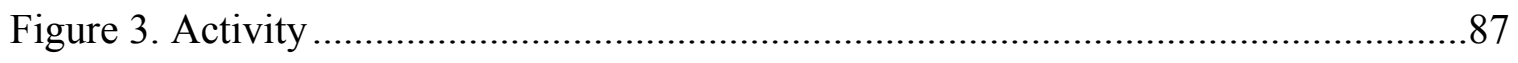

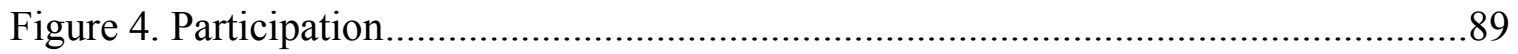

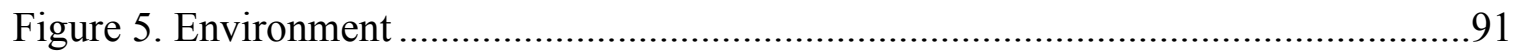

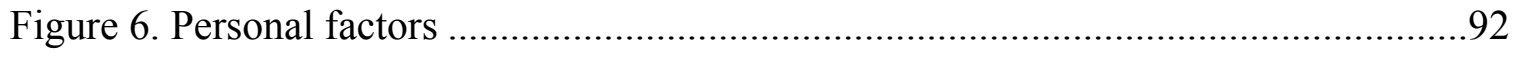

Figure 7. Learning process.........................................................................................94

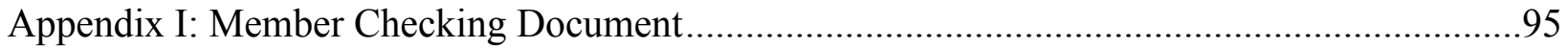

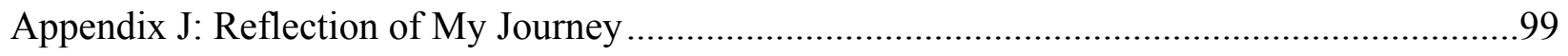

Appendix K: Reflections on the Strengths and Challenges of this Study....................................100 


\section{LIST OF ABBREVIATIONS}

$\begin{array}{ll}\text { ACPR } & \text { Australian Cerebral Palsy Register } \\ \text { ADDM } & \text { Autism and Developmental Disabilities Monitoring } \\ \text { BoNT-A } & \text { Botulinum Toxin Treatment } \\ \text { CP } & \text { Cerebral Palsy } \\ \text { COPM } & \text { Canadian Occupational Performance Measure } \\ \text { CFCS } & \text { Communication Function Classification System } \\ \text { EBP } & \text { Evidence-based Practice } \\ \text { GAS } & \text { Goal Attainment Scale } \\ \text { GMFCS } & \text { Gross Motor Function Classification System } \\ \text { ICF } & \text { International Classification of Functioning, Disability and Health } \\ \text { ID } & \text { Interpretive Description } \\ \text { MACS } & \text { Manual Ability Classification System } \\ \text { PEGS } & \text { Perceived Efficacy and Goal Setting System } \\ \text { SIG } & \text { Special Interest Group } \\ \text { WHO } & \text { World Health Organization }\end{array}$




\section{DECLARATION OF ACADEMIC ACHIEVEMENT}

The student (Linda Nguyen) was the main contributor in all aspects of the study including: development of the research question and objectives, study design, data collection and interviews with participants, interview transcriptions, data analysis, and interpretation of results. This study was approved by the Hamilton Integrated Research Ethics Board.

The co-investigators in this study included:

Dr. Jan Willem Gorter, MD, PhD, FRCP(C), Professor, Department of Pediatrics, and Associate Member in the School of Rehabilitation Science, McMaster University;

Dr. Peter Rosenbaum, MD, FRCP(C), Professor, Department of Pediatrics, Joint Member in the School of Rehabilitation Sciences, and Associate Member of the Department of Health Research Methods, Evidence, and Impact, McMaster University;

Dr. Briano Di Rezze, OT, Ph.D. Assistant Professor, School of Rehabilitation Science, McMaster University;

Dr. Ronit Mesterman, MD, FRCP(C), Associate Professor, Department of Pediatrics, McMaster University.

The co-investigators provided ongoing feedback throughout the research process. They assisted in the refinement of the research questions, assisted with the structuring of the interview guide and proposed methods, and provided an interpretation of the findings. 
M.Sc. Thesis - L Nguyen; McMaster University - Rehabilitation Science

\section{CHAPTER ONE INTRODUCTION}

\section{Cerebral Palsy}

In clinical practice, it is important to provide definitions for disorders, diseases, and disabilities in order to develop appropriate treatment plans. Definitions can be helpful to diagnose individuals based on specific characteristics and classify these individuals into similar groups. In the field of childhood disability, the definition of cerebral palsy (CP) has undergone multiple revisions. The definition proposed by Bax (1964) for CP was most commonly used for almost 50 years, in which $\mathrm{CP}$ is a "disorder of movement and posture due to a lesion of the immature brain" (1). Mutch et al. (1992) further revised this definition to highlight the heterogeneity of CP as "an umbrella term covering a group of non-progressive, but often changing, motor impairment syndromes secondary to lesions or anomalies of the brain arising in the early stages of development" (2).

In 2004, the Castang Foundation of the UK and the United Cerebral Palsy Research and Educational Foundation of the USA identified that the definition of CP required further revision (3). There was a need to recognize that the motor deficits associated with $\mathrm{CP}$ can also be accompanied by other neurological impairments.

The most recent consensus definition of CP was published in 2007:

Cerebral palsy describes a group of permanent disorders of the development of movement and posture, causing activity limitation, that are attributed to non-progressive disturbances that occurred in the developing fetal or infant brain. The motor disorders of $\mathrm{CP}$ are often accompanied by disturbances of sensation, perception, cognition, communication, and behaviour, by epilepsy, and by secondary musculoskeletal problems.

(Rosenbaum, 2007)

This definition illustrates that $\mathrm{CP}$ is a developmental disability, in which children and adolescents have motor impairments, but also may have other secondary challenges including cognition, behaviour, and secondary musculoskeletal problems. It is important to address both the motor impairments and secondary functional capabilities affected by CP (4). Furthermore, $\mathrm{CP}$ is a lifelong, permanent condition. It is important to develop intervention programs that focus on the strengths of children and adolescents with $\mathrm{CP}$, which will allow them to develop skills and functional competencies starting early and continuing into adulthood (4).

\section{Prevalence and Incidence}

A universal definition of $\mathrm{CP}$ is helpful for understanding its epidemiology, which is the distribution of disease in a population. It is important to identify the number of individuals diagnosed with $\mathrm{CP}$ in order to develop and deliver appropriate healthcare services. Prevalence is the number of individuals with a diagnosis of $\mathrm{CP}$, while incidence is the number of new cases of individuals with $\mathrm{CP}$. Considering that there have been varying definitions of $\mathrm{CP}$, there may be varying differences in the incidence and prevalence rates of $\mathrm{CP}$. There have been three systematic reviews, with the most recent systematic review published in 2013, to assess the 
M.Sc. Thesis - L Nguyen; McMaster University - Rehabilitation Science

overall prevalence of $\mathrm{CP}$ and its risk factors (5-7). The overall prevalence of CP is 2 to 3 per 1000 births in developed countries, and has remained consistent since the early 1980s (8-11). However, there is increased prevalence of $\mathrm{CP}$ in populations with risk factors, which can be grouped into the following categories (12):

1. Antenatal (before birth): low birthweight for gestational age, maternal diseases such as respiratory diseases, heart diseases, and seizures, bleeding in the second and third trimesters, and hypertension (12)

Specifically, there is an inverse relationship between the increased risk of CP and gestational age or low birthweight $(12,13)$. Population-based studies from North America, Europe, and Australia identified a range in prevalence for the following gestational ages and birthweight (13):

a) 35.0 to 79.5 per 1000 livebirths for children born at 28 to 31 weeks gestation and $<1500$ grams.

b) 4.9 to 11.1 per 1000 livebirths for children born at 32 to 36 weeks gestation and 1500-2499 grams.

c) 1.1 to 1.7 per 1000 livebirths for children born $\geq 37$ weeks gestation and $\geq 2500$ grams.

2. Intrapartum (during birth): birth asphyxia and abnormal duration of labour (12).

3. Neonatal (immediately after birth): presence of seizures, respiratory distress syndrome, and hypoglycemia (12).

In the United States, population-based surveillance for CP has been conducted by the Autism and Developmental Disabilities Monitoring (ADDM) Network. A meta-analysis reported stability in the overall prevalence of CP for cohorts of children with CP during the early 1980s to 2004 (11). In 2008, the ADDM CP Network identified that CP was more common among boys than girls, and approximately $77.4 \%$ of children with CP had spastic CP (14). It was also identified that approximately $41 \%$ and $6.9 \%$ of children with $\mathrm{CP}$ had epilepsy and autism spectrum disorder, respectively (14). Based on the data from 2008, 58.2\% of children with CP could walk independently, $11.3 \%$ with a mobility device, and 30.6\% had limited or no walking ability (14). Additionally, the Australian Cerebral Palsy Register (ACPR) provided information about the prevalence of CP according to Gross Motor Function Classification System (GMFCS) subtypes in a cohort of 3466 persons with CP born between 1996 and $2005(15,16)$. The distribution of GMFCS levels is as follows: (I) $34 \%$, (II) $25 \%$, (III) $12 \%$, (IV) $13 \%$, and (V) $16 \%$. There is an increased prevalence of impairments, such as hearing, speech, and vision, in children and adolescents who are more affected by $\mathrm{CP}$. The proportion of children and adolescents with two or more associated impairments was $73 \%$ in individuals classified as GMFCS level V compared to $3 \%$ in individuals classified as GMFCS level I (15).

The Canadian CP Registry is currently being developed to provide information about the epidemiology of CP in Canada (17). The registry will reflect the heterogeneity of the disorder, including estimates of the incidence, prevalence, and distribution of CP across different geographical regions of Ontario and other provinces in Canada (17). These epidemiologic data 
M.Sc. Thesis - L Nguyen; McMaster University - Rehabilitation Science

may be helpful to further refine healthcare services and support programs for children with $\mathrm{CP}$ and their families in Canada.

\section{Management of CP}

International Classification of Functioning, Disability and Health

There is no cure for $\mathrm{CP}$, but children with $\mathrm{CP}$ often receive various types of interventions in an effort to improve their functional abilities, engagement in activities and participation, and quality of life (3,18-20). The International Classification of Functioning, Disability and Health (ICF) is a biopsychosocial model that was developed by the World Health Organization (WHO) to identify the factors that can influence an individual's health and well-being (Appendix A, Figure 1) (21). The ICF model involves five domains: (1) body functions and structures, defined as the body's physiological functions and anatomical parts; (2) activities, defined as the individual's ability to complete a task; (3) participation, defined as the individual's involvement in a life situation; (4) environmental factors, defined as the physical, social, and attitudinal environment where an individual lives; and (5) personal factors, defined as the background of an individual that is not part of their health condition $(21,22)$. The ICF framework can be used to guide the provision of healthcare services for children and adolescents with CP by highlighting other factors involved in an individual's life, such as personal and environmental factors in addition to body structures and function $(22,23)$.

The ICF framework emphasizes the many factors that should be taken into consideration when setting goals and developing treatment plans for children and adolescents with CP. The concepts of the ICF align with the current and most widely used definition of CP, in which the child's 'activity limitations' is emphasized (24). Treatment plans should be focused on the family's strengths and limitations in order to deliver services that would meet the needs of the child and family (24). The ICF framework demonstrates how healthcare professionals could identify the relationships among body impairments, activity limitations, and participation restrictions in the child. Contextual factors including the environment and personal factors may have an effect on these relationships $(21,22)$. Therefore, healthcare professionals should take into consideration the relationships between the ICF domains and their contextual factors during the development of treatment plans for children and adolescents with $\mathrm{CP}$.

\section{Classification Systems}

The level of functioning of children with CP can be classified according to the Gross Motor Function Classification System (GMFCS), which consists of five levels of function, from level I (most able) to level V (least able) (25). The GMFCS also includes five age bands to account for developmental differences in children and adolescents (25). The GMFCS consists of a series of "word pictures" that describes the five distinct levels of function based on age strata. Both parents and healthcare professionals may use the GMFCS to classify and describe a child's functional abilities based on these descriptions without prior training (26). Studies have demonstrated high congruence in GMFCS rating between parents and professionals (27). The GMFCS has been shown to be valid, reliable, and stable over time after the age of $2(25,28-31)$.

Furthermore, individuals with CP can be classified based on their manual abilities according to the Manual Ability Classification System (MACS) (32). The MACS consists of five levels of 
manual ability function with level I being the most functional and level V being the least functional. Similar to the GMFCS, the MACS can be applied by both parents and healthcare professionals to describe a child's ability to use their hands and manipulate objects in daily activities (26). The MACS has been found to be reliable for children ages 4 to 18 years old $(32,33)$. The MACS ratings from caregivers and parents have been demonstrated to remain stable over 12 months in children with all subtypes of CP (34).

Similar to the GMFCS and MACS scales, a Communication Function Classification System (CFCS) was created to describe the communication abilities of individuals with CP in the context of activity and participation on an everyday basis (35). The CFCS consists of five levels of involvement, with level I indicating good communication abilities and level V indicating limited communication. The CFCS has been demonstrated to have good test-retest reliability, professional interrater reliability, and moderate parent-professional interrater reliability (35)

These three classification systems complement each other and can be used to describe different aspects and functional abilities of individuals with $\mathrm{CP}$ in daily life. These classification systems can help to describe an individual's ability to move, handle objects, and communicate with others, which are all domains that can be affected by CP (36). Although the GMFCS, MACS, and CFCS, were developed one after another, some studies have identified correlations in classification levels in individuals. In all age groups, the GMFCS levels were highly correlated with MACS levels, but moderately correlated with CFCS levels (36). The MACS levels and CFCS levels were also moderately correlated across all age groups (36). In a case series, it was identified that $25 \%$ of children with low mobility function and classified as GMFCS level IV or $\mathrm{V}$ often used communication devices to communicate with others (36).

Some children may also be classified with the "all IV or V" functional profile, in which their performances were classified as GMFCS IV or V, MACS IV or V, and CFCS IV or V. The "all IV or V" functional profile indicates that an individual's ability to complete daily activities and participate is significantly affected by CP (36). Studies have shown that there is a statistical correlation with children and adolescents with the "all V" profile with low functioning abilities $(36,37)$. They may have to rely on other resources and individuals for assistance (36). The use of these classifications can provide healthcare professionals with a holistic overview of the functioning and performance of children with $\mathrm{CP}$, and tailor rehabilitation services for each child.

\section{Interventions and Treatments}

\section{Botulinum Toxin Treatment}

Children and adolescents with CP may have different clinical manifestations, and interventions should be tailored for each child. Treatments and interventions can help children with CP to function optimally and complete daily activities. A comprehensive overview of the child's abilities using the classification systems of the GMFCS, MACS, and CFCS are helpful to recognize treatments that may be effective for the child. Botulinum toxin type A (BoNT-A) injections is one treatment that is widely used to manage spasticity in children and adolescents with CP (38-41). Spasticity is a type of muscle hypertonicity that is characterized by velocitydependent resistance to muscle stretches $(42,43)$. Approximately $80 \%$ of children with $\mathrm{CP}$ have 
a predominant spastic type, which can affect their mobility and participation in daily activities (9). Spasticity may lead to secondary musculoskeletal problems and is associated with development of contractures, hip dislocations, and scoliosis $(44,45)$. The administration of BoNT-A can temporarily reduce spasticity and muscle hypertonia, which can lead to improvements in range of motion of muscle limbs or can help maintain joint range of motion (46).

BoNT-A is injected directly into the selected muscle and reinjections can be needed every 3-4 months (47-49). The dosage of BoNT-A injections is calculated based on the bodyweight of the patient and the number of targeted muscles, and safety considerations must also be taken into account such as allergies to BoNT-A, neuromuscular diseases, and use of drugs that may interfere with neuromuscular function (38). There have been two international consensus papers stating that the use of BoNT-A treatment may be effective in reducing muscle tone and improving range of muscle movement $(50,51)$. There are very few adverse effects that have been reported associated with BoNT-A treatment, particularly in children GMFCS level I-III $(49,52,53)$. Some commonly reported adverse effects are local redness, pain, bruising, and excessive weakness $(38,54)$. There is an increased risk of serious adverse effects of BoNT-A treatment in children classified as GMFCS level IV or V, such as respiratory complications including upper respiratory tract infection and difficulty breathing, and bladder or bowel incontinence (55). There is an increased risk of adverse effects with higher doses of BoNT-A treatment that is independent of GMFCS level (55). Children and adolescents classified as GMFCS level IV or V may have comorbidities, which increases the likelihood of adverse effects (53). Therefore, healthcare professionals should have a discussion with families about these potential adverse effects and identify the appropriate dose of BoNT-A injections for each child.

\section{Goals and Effects of Botulinum Toxin Treatment}

The primary goals of BoNT-A are often to enhance outcomes at the level of body structures and function, such as reduction of muscle over-activity, reduction in pain, increased range of motion, and improved tolerance of splinting and casting $(47,56)$. Although the primary effect of BoNT-A treatment is to reduce muscle tone and improve range of motion, these direct effects may also lead to changes in the level of activity and participation $(38,47)$. For example, BoNT-A injections may be helpful in reducing muscle tone, which can subsequently lead to improvements in range of motion, and ultimately help the child to engage in certain activities, such as standing in a stander or walking in a walker. BoNT-A injections may also relieve ease of caregiving in activities such as dressing, and facilitate the child's participation in outdoor and community activities, but further studies are required to assess these effects (53). A conceptual diagram of possible relationships between body structures and function, activity, and participation is outlined in Appendix A, Figure 2. Mall et al. (1997) demonstrated in three case studies that BoNT-A was associated with functional improvements, which in turn enhanced the level of activity and participation (57). In one case study, a 13-year boy diagnosed with spastic bilateral CP (quadriplegic distribution) often woke up 2-4 times each night so that his parents could move him into a more comfortable position. After receiving BoNT-A treatment in the arms, his arm was not hyperextended towards his back and the boy and his parents were able to sleep without interruptions. It was also easier and less painful for him to get dressed with the help of his parents (57). Another case study described a 16-year old girl diagnosed with spastic bilateral CP (quadriplegic distribution) and flexion contracture of the left hand. She received BoNT-A 
treatment, which helped decrease muscular hyperactivity and improved her ability to extend her hand. She also received physiotherapy sessions to improve her mobility, which subsequently allowed her to hold onto a handlebar and steer a tricycle (57). These case studies demonstrate that the functional improvements of BoNT-A treatment may also lead to benefits in other areas, such as better sleep and participation activities.

BoNT-A treatment can be used in combination with other therapies to reduce tone and improve mobility, such as stretching, casting, and splinting (58). When BoNT-A treatment is provided in conjunction with physical and occupation therapy, it can also be an effective method to improve ease of caregiving and comfort in children and adolescents with CP (59). For example, the provision of occupational therapy after BoNT-A injections can complement the effects of BoNTA and enhance the child's performance in completing activities (60). The child's abilities to complete activities may be further enhanced with other services, such as motor training, environmental modification, and practice of specific activities (60). After BoNT-A injections in combination with other therapies, the child may present changes in their mobility, gait, and ability to complete daily activities (58). Therefore, it is important to evaluate the outcomes of BoNT-A injections in order to identify and refine goals for future treatment sessions.

\section{Goal-Setting}

\section{Process of Goal-Setting}

Since CP is a lifelong condition, it is important for families of children and adolescents with CP to work together with healthcare professionals to develop an appropriate therapy plan. The main aim of any intervention is to optimize the child's ability to carry out daily activities and participation, while minimizing the impairments of CP (61). Based on the ICF, the intervention should be focused on enhancing capacity (what a person can do in a controlled environment), capability (what a person can do in a daily environment), and performance (what people actually do in a daily environment) $(62,63)$. The goals for the intervention should include the perspectives of the child and family.

In family-centred practice, parents are considered to be the experts of their child who can share their child's strengths and abilities. Families can have a collaborative discussion with healthcare professionals about their needs and goal-setting during BoNT-A treatment. Healthcare professionals and families should have a collaborative discussion about their needs and goalsetting during BoNT-A treatment. According to "best practice" guidelines, goal-setting should be incorporated into clinical assessments $(46,51,64)$. Before a child's first injection with BoNT-A treatment, families are provided with written documents outlining the expectations and possible adverse outcomes of treatment. The child is assessed for BoNT-A treatment by identifying the function of body structures, such as the presence and severity of tone, presence of spasticity, and range of motion. Family goals are also set with healthcare professionals to ensure that there is a common plan for the child.

Goal-setting is an integral component of family-centred services that allows parents to identify goals that are relevant and meaningful to the family $(65,66)$. Goal-setting plays an important role in the administration of BoNT-A treatment because it is the first stage that provides an opportunity for families to share information about their values, beliefs, and desires. Information 
should be exchanged between the parents and healthcare professionals in order to enhance the parent-healthcare professional relationship $(65,67)$. Parents want to share with healthcare professionals their observations about the strengths of their child, the family lifestyle, and the available resources in the home environment $(68,69)$. Families also require information from healthcare professionals in order to understand the benefits of BoNT-A treatment, and information that will help identify the goals that will be appropriate for their child and family. Healthcare professionals should also consider how to inform parents about setting goals that are realistic and appropriate for the family (70). The exchange of information during the goal-setting process allows the parents to feel involved and contribute to the development of the therapy plan in the context of BoNT-A treatment. BoNT-A treatment typically works best when it is provided with additional therapies, and families may want to share how the therapy plan was beneficial for their child, such as eating, dressing, and participation in leisure activities (60). The process of setting goals has the potential to strengthen partnership between healthcare professionals and parents, increase parental satisfaction with healthcare services, and enhance the motivation of parents to engage in therapy activities with their child (71-74). The goal-setting process provides an opportunity for families and healthcare professionals to collaborate and set goals that will be meaningful to the family in the context of BoNT-A treatment.

\section{Goal-Setting Tools}

The identification of goals should also be systematically documented in order to evaluate whether the child accomplished those goals. Treatment outcomes and the accomplishment of goals should be measured using appropriate tools. Goldberg (1991) identified three types of outcomes: 1) technical; 2) functional; and 3) patient satisfaction (75). Technical outcomes are the objective changes (often assessing professionals' goals) that can be measured after a procedure (76). For example, the outcome in improving joint of range of motion can be measured using a goniometer (76). Functional health outcomes address how the technical outcomes affected the patient's life and well-being, which includes the changes at the ICF level of activity and participation (76). For example, a reduction in tone is a technical outcome that may improve activity outcomes of walking and lifting objects $(75,77)$. The third category of outcomes address patient satisfaction, which includes the extent to which the patient was satisfied with the treatment and how the treatment was delivered (75). Support group newsletters that provide testimonials from patients and families may describe the successes and effects of treatments, and subsequently influence other patients' choices in deciding on treatments (75). Therefore, the types of treatment outcomes should be identified in order to apply the appropriate tools to measure attainment of goals and record outcomes.

There are several goal-setting tools that healthcare professionals can use to document goals during BoNT-A treatment, including the Goal Attainment Scale (GAS), Canadian Occupational Performance Measure (COPM), and the Perceived Efficacy and Goal Setting System (PEGS). Both the GAS and COPM have been commonly used to measure outcomes in BoNT-A treatment for children with CP $(78,79)$. Often, the primary goals of these studies have focused on outcomes in the domain of body structures and function, such as reduction in spasticity or improvement in range of motion $(53,78,80)$. It is important for healthcare professionals to facilitate a discussion with parents about setting goals that are also focused on their own activity and participation in addition to body structures and function. Goal-setting tools such as the COPM, GAS or PEGS can be used to document and facilitate a collaborative discussion. 
Table 1. Description of goal-setting tools.

\begin{tabular}{|c|c|c|c|}
\hline & Purpose and Administration & Psychometric Properties & $\begin{array}{l}\text { Use in Rehabilitation Programs for } \\
\text { Young People with Disabilities }\end{array}$ \\
\hline $\begin{array}{l}\text { Goal } \\
\text { Attainment } \\
\text { Scale (GAS) } \\
(81-84)\end{array}$ & $\begin{array}{l}\text { The GAS consists of an } \\
\text { interview where the therapist } \\
\text { works with the family to } \\
\text { identify and prioritize goals } \\
\text { that are important to the } \\
\text { family (81). } \\
\text { The achievement of a goal } \\
\text { after an intervention can be } \\
\text { evaluated on a 5-point scale, } \\
\text { in which } 1 \text { indicates the most } \\
\text { unfavourable outcome and } 5 \\
\text { indicates a favourable } \\
\text { outcome (81). } \\
\text { The therapist describes the } \\
\text { child's baseline performance, } \\
\text { and the level of performance } \\
\text { for each level of rating scale } \\
\text { (85). It is recommended to } \\
\text { provide a written description } \\
\text { of each level to understand the } \\
\text { evaluation process in } \\
\text { measuring outcomes at the } \\
\text { end of the intervention ( } 85 \text { ). } \\
\text { There are different methods } \\
\text { that can be employed to } \\
\text { ensure that the GAS is a valid } \\
\text { and reliable instrument } \\
\text { including: the provision of } \\
\text { training to therapists, use of } \\
\text { collaborative goal-setting; }\end{array}$ & $\begin{array}{l}\text { The GAS can be considered to } \\
\text { have a better sensitivity to } \\
\text { change compared to other } \\
\text { measures at the ICF level of } \\
\text { activity and participation, } \\
\text { because it can measure the } \\
\text { attainment of goals that may not } \\
\text { be included in other measures } \\
\text { such as the Gross Motor } \\
\text { Function Measure (GMFM) or } \\
\text { the Pediatric Evaluation of } \\
\text { Disability Inventory (PEDI) } \\
\text { (86). } \\
\text { Low concurrent validity with } \\
\text { the Peabody Gross Motor and } \\
\text { Fine Motor Scale change score, } \\
\text { r=0.44 and r=0.18 respectively } \\
\text { (86,87). However, this low } \\
\text { concurrent validity may be } \\
\text { explained by the differences in } \\
\text { items measured by the GAS and } \\
\text { the Peabody Gross Motor and } \\
\text { Fine Motor Scale ( } 86,87 \text { ). } \\
\text { Content validity was assessed } \\
\text { using three criteria: } 1) \text { whether } \\
\text { the goal was important for } \\
\text { motor development and } \\
\text { function; } 2 \text { ) whether the goal } \\
\text { was achievable; and } 3 \text { ) whether } \\
\text { the level of goal achievement }\end{array}$ & $\begin{array}{l}\text { The GAS provides an opportunity } \\
\text { for children and their families to } \\
\text { identify goals that are relevant to } \\
\text { their daily life. The goals in the } \\
\text { GAS can be structured using ICF } \\
\text { framework in order to capture the } \\
\text { different domains that affect the } \\
\text { child's life (88). The domains of } \\
\text { the ICF framework can be used to } \\
\text { structure the goals in the GAS. } \\
\text { In previous studies, most goals } \\
\text { have been identified at the ICF } \\
\text { level of activity and participation } \\
\text { in rehabilitation services, such as } \\
\text { speech therapy, physical therapy, } \\
\text { and occupational therapy } \\
\text { (85,86,89). } \\
\text { The GAS is sensitive to change } \\
\text { when administered in studies to } \\
\text { assess the effects of BoNT-A in } \\
\text { children, such as changes in upper } \\
\text { limb movement and function and } \\
\text { adductor spasticity (56,60,86,90- } \\
\text { 93). }\end{array}$ \\
\hline
\end{tabular}




\begin{tabular}{|c|c|c|c|}
\hline & $\begin{array}{l}\text { comprehensive written } \\
\text { description of goals; and use } \\
\text { of independent raters in the } \\
\text { evaluation of outcomes }(85) \text {. }\end{array}$ & $\begin{array}{l}\text { was clinically important and } \\
\text { relevant. Approximately } 77 \% \\
\text { and } 88 \% \text { of the therapists' goals } \\
\text { and ratings met the criteria for } \\
\text { content validity ( } 87) \text {. } \\
\text { The interrater reliability was } \\
\text { measured between the child's } \\
\text { therapists and independent } \\
\text { rater, and was measured using } \\
\text { Cohen's kappa. Interrater } \\
\text { reliability was } 0.82 \text { (95\% } \\
\text { confidence interval } 0.73-0.91) \\
\text { based on GAS scales } \\
\text { constructed by the child's } \\
\text { therapist and } 0.64 \text { (95\% } \\
\text { confidence interval } 0.49-0.79) \\
\text { based on GAS scales } \\
\text { constructed by the independent } \\
\text { rater ( } 82 \text { ). The difference in the } \\
\text { GAS scales constructed by the } \\
\text { children's therapists or } \\
\text { independent raters was not } \\
\text { statistically significant, and the } \\
\text { GAS demonstrates good-to- } \\
\text { excellent interrater reliability. }\end{array}$ & \\
\hline $\begin{array}{l}\text { Canadian } \\
\text { Occupational } \\
\text { Performance } \\
\text { Measure (94) }\end{array}$ & $\begin{array}{l}\text { The COPM involves a semi- } \\
\text { structured interview between a } \\
\text { healthcare professional and } \\
\text { family that is comprised of } \\
\text { three sections: 1) self-care } \\
\text { including personal care, } \\
\text { functional mobility, and } \\
\text { community management; } 2 \text { ) }\end{array}$ & $\begin{array}{l}\text { - In comparison to the GAS, the } \\
\text { COPM was more efficient in } \\
\text { time for training, development } \\
\text { of scales, and administration in } \\
\text { clinical practice (79). } \\
\text { The test-retest reliability was } \\
80 \% \text { among parents with } \\
\text { disabilities (96). }\end{array}$ & $\begin{array}{l}\text { - In children with CP, parent- } \\
\text { identified goals were often phrased } \\
\text { as activities such as personal care, } \\
\text { functional mobility, play, and } \\
\text { socialization or as body functions, } \\
\text { such as arm and hand strength or } \\
\text { balance (74). } \\
\text { - The COPM was administered in a }\end{array}$ \\
\hline
\end{tabular}




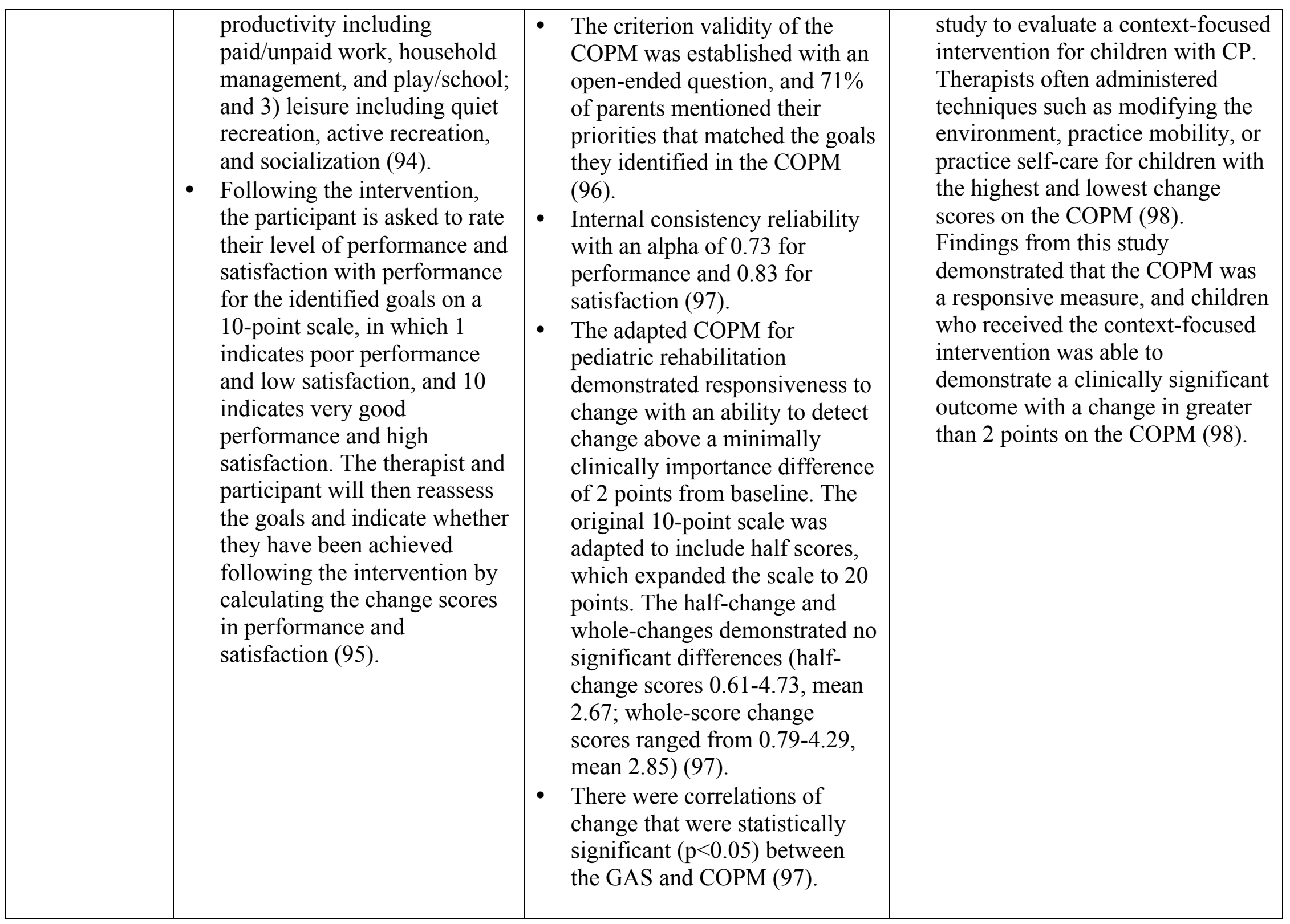




\begin{tabular}{|c|c|c|c|}
\hline $\begin{array}{l}\text { Perceived } \\
\text { Efficacy and } \\
\text { Goal Setting } \\
\text { System } \\
\text { (PEGS) (99) }\end{array}$ & $\begin{array}{l}\text { The PEGS is a goal-setting } \\
\text { tool that incorporates the } \\
\text { perspectives of the child by } \\
\text { using a forced choice } \\
\text { structure, in which the child } \\
\text { will be asked to select their } \\
\text { competency level in each } \\
\text { activity. The child will also be } \\
\text { asked to select the tasks that } \\
\text { they would like to work on } \\
\text { during therapy (99). In } \\
\text { addition to the child-reported } \\
\text { goals, caregivers are provided } \\
\text { with questionnaires on the } \\
\text { tasks that they would like their } \\
\text { child to complete (99). }\end{array}$ & $\begin{array}{l}\text { - In a study of children (ages 6-9) } \\
\text { referred for occupational } \\
\text { therapy in three regions in } \\
\text { Ontario, Canada, 92\% of } \\
\text { children selected between two } \\
\text { and four of the same goals two } \\
\text { weeks later (99). } \\
\text { - Internal consistency of the scale } \\
\text { reported using Cronbach's } \\
\text { alpha reliability coefficient of } \\
\text { 0.795 (99). } \\
\text { Clinical utility of the PEGS was } \\
\text { assessed using a questionnaire, } \\
\text { and therapists reported an } \\
\text { improvement in the quality of } \\
\text { the relationship and } \\
\text { communication with teachers } \\
\text { and parents (99). }\end{array}$ & $\begin{array}{l}\text { The PEGS has been administered } \\
\text { for children with disabilities, } \\
\text { including Attention Deficit } \\
\text { Hyperactivity Disorder and } \\
\text { Developmental Coordination } \\
\text { Disorder. } \\
\text { Children often identified goals on } \\
\text { finishing work on time, tying } \\
\text { shoelaces, or cutting food. } \\
\text { Parents often identified goals on } \\
\text { printing, finishing work on time, } \\
\text { and tying shoelaces. } \\
\text { Teachers identified goals on } \\
\text { printing, use of scissors, and } \\
\text { finishing work on time, while also } \\
\text { adding behavioural goals such as } \\
\text { paying attention and following } \\
\text { classroom schedules. } \\
\text { There was a low level of } \\
\text { agreement between the child's } \\
\text { selection and prioritization of } \\
\text { goals compared to parents and } \\
\text { therapists (99). } \\
\text { Children with developmental } \\
\text { coordination disorder often } \\
\text { identified daily self-care and } \\
\text { leisure activities. In contrast to the } \\
\text { child's priorities, therapists often } \\
\text { had concerns about handwriting } \\
\text { and parents had concerns about } \\
\text { their child's motor performance } \\
\text { and its impact on school activities } \\
\text { (100). }\end{array}$ \\
\hline
\end{tabular}




\section{Goal-Setting in Children and Adolescents with CP}

In clinical practice, the implementation of goal-setting that is truly collaborative continues to be a challenge due to families' perceptions of goal-setting, time constraints, and professional routines $(101,102)$. A retrospective study reviewed the charts of 60 young people diagnosed with $\mathrm{CP}$ and classified in GMFCS level IV or V who had received BoNT-A treatment (103). Goals were usually collaboratively identified between healthcare professionals and family, and they were categorized into the ICF domains as follows (often into more than one category):

a) Body structure and function: improving range of motion (68\%); improving positioning, including seating, the ability to use orthotics $(33 \%)$, general well-being including irritability and sleep (10\%), prior to serial casting to improve outcomes $(8 \%)$, and pain $(7 \%)$.

b) Activity and participation: improve function of lower limbs (82\%), improve function of upper limbs (33\%), and improve transfers (38\%).

c) Self-care: facilitating ease of care, including dressing, toileting, and diapering (38\%).

Although the goals were identified in $80 \%$ of the charts and accomplished in $75-80 \%$ of cases, it was not clear who identified the goals (i.e., healthcare professional, parent, or both). Often, healthcare professionals would indicate that they provided health services that were familycentred, but parents may not feel that they were actively involved in the process of goal-setting with healthcare professionals (101). Parents may have different degrees of involvement in their child's therapy, which may change over time depending on the child's age (70). For example, parents may initially receive a diagnosis of $\mathrm{CP}$ for their younger child and may feel overwhelmed with the types of services that their child will require. They may still need information to understand their child's diagnosis and would need suggestions from healthcare professionals about goals that are appropriate for their child $(70,104,105)$. Over time, parents of older children may suggest goals based on their child's preferences and available resources, such as participation in community activities and fostering friendships for their child (70). It is important for healthcare professionals to clearly identify and document the parents' expectations and goals during BoNT-A treatment, and to ensure that an appropriate therapy plan is developed.

\section{Development of an Inventory List of Goals}

At a national botulinum toxin conference in Montreal in January 2014, a special interest group (SIG) of physicians with experience in BoNT-A treatment in children with CP identified goal setting in the context of BoNT-A treatment as a priority but a challenge for children with CP. At the meeting, the SIG developed a draft list of potential goals that might be relevant to families and children diagnosed with CP across all GMFCS levels (106). This list of goals is still a workin-progress, and a comprehensive list needs to be developed that captures family values (See Appendix B). A previous study conducted by this research team (Linda Nguyen, Dr. Ronit Mesterman, and Dr. Jan Willem Gorter) in 2014 demonstrated that parents often selected goals related to ease of caregiving, such as ease of transfers and dressing. They also mentioned that these goals were achieved when their child demonstrated reduced tone and increased range of motion as a direct effect of BoNT-A treatment (107). The inventory of goals can be used to supplement goal-setting tools such as the COPM and GAS. Healthcare professionals can facilitate a discussion with parents about goals in the domains of activity and participation as well as body structures and function. 
M.Sc. Thesis - L Nguyen; McMaster University - Rehabilitation Science

A family needs inventory has been developed to facilitate the goal-setting discussion for children with disabilities, families, and healthcare professionals in pediatric rehabilitation $(108,109)$. More than $50 \%$ of parents identified that they required information about development, treatment, and services for their child (109). However, an inventory of goals that is specific to children with CP and classified in GMFCS level IV or V may also be helpful to facilitate the goal-setting discussion. In this population, parents have often identified goals in the domain of body function and structure (53). There is a need to better understand the parents' perspectives in whether BoNT-A treatment is helpful for their child in accomplishing goals in specific ICF domains. Parents should be provided with an opportunity to share and identify goals that are realistic and achievable by their child (110). There has only been one qualitative descriptive study conducted in Sweden conducted by Lorin and Forsberg (2016) that explored the effects of BoNT-A treatment from the parents' perspectives (111). The study conducted by Lorin and Forsberg included parents of children with CP, with GMFCS levels from I to IV, and ranging in age from 5 to 13 years old (111). However, these effects were not categorized into the ICF domains (111). Further studies can be conducted to provide an opportunity for parents to share the changes of BoNT-A treatment in their child and better understand the parents' level of satisfaction and expectations with BoNT-A treatment. Parental observations will allow an inventory of goals in the context of BoNT-A treatment to be further developed and refined to capture the values and expectations of the parents.

\section{Study Objectives}

The overall purpose of the study reported in this thesis is to explore the effects of BoNT-A treatment in children and adolescents with CP in GMFCS level IV or V and to categorize these effects according to the ICF framework in the following domains: body structures and function, activity, participation, environment factors, and personal factors. These findings will be used to refine and inform the inventory of goals in the context of BoNT-A treatment.

This study will address the following research questions:

1. In what ways, if any, does BoNT-A treatment make a difference to children and adolescents with CP in GMFCS level IV or V, based on the parents' perspectives?

2. In what ways, if any, does BoNT-A treatment make a difference to parents of children and adolescents with CP, in GMFCS level IV or V? 
M.Sc. Thesis - L Nguyen; McMaster University - Rehabilitation Science

\section{References}

1. Bax MC. Terminology and Classification of Cerebral Palsy. Dev Med Child Neurol. 1964;6:295-7.

2. Mutch L, Alberman E, Hagberg B, Kodama K, Perat MV. Cerebral palsy epidemiology: where are we now and where are we going?. Dev Med Child Neurol. 1992;34(6):547-51.

3. Rosenbaum P, Paneth N, Leviton A, Goldstein M, Bax M, Damiano D, et al. A report: the definition and classification of cerebral palsy April 2006. Dev Med Child Neurol Suppl. 2007;109(suppl 109):8-14.

4. Rosenbaum P, Rosenbloom L. Chapter 1: What is cerebral palsy?. In: Cerebral Palsy: From Diagnosis to Adult Life. London: Mac Keith Press; 2012. p. 3-13.

5. Himpens E, Van den Broeck C, Oostra A, Calders P, Vanhaesebrouck P. Prevalence, type, distribution, and severity of cerebral palsy in relation to gestational age: a meta-analytic review. Dev Med Child Neurol. 2008;50(5):334-40.

6. Hirtz D, Thurman DJ, Gwinn-Hardy K, Mohamed M, Chaudhuri AR, Zalutsky R. How common are the \&quot;common\&quot; neurologic disorders? Neurology. 2007;68(5):326-37.

7. Oskoui M, Coutinho F, Dykeman J, Jetté N, Pringsheim T. An update on the prevalence of cerebral palsy: a systematic review and meta-analysis. Dev Med Child Neurol. 2013;55(6):509-19.

8. Escobar GJ, Littenberg B, Petitti DB. Outcome among surviving very low birthweight infants: a meta-analysis. Arch Dis Child. 1991;66(2):204-11.

9. Odding E, Roebroeck ME, Stam HJ. The epidemiology of cerebral palsy: Incidence, impairments and risk factors. Disabil Rehabil. 2006;28:183-91.

10. Paneth N, Hong T, Korzeniewski S. The Descriptive Epidemiology of Cerebral Palsy. Clin Perinatol. 2006;33:251-67.

11. Van Naarden Braun K, Doernberg N, Schieve L, Christensen D, Goodman A, YearginAllsopp M. Birth Prevalence of Cerebral Palsy: A Population-Based Study. Pediatrics; 2016;137(1):1.

12. McIntyre S, Taitz D, Keogh J, Goldsmith S, Badawi N, Blair E. A systematic review of risk factors for cerebral palsy in children born at term in developed countries. Dev Med Child Neurol. 2013;55(6):499-508.

13. Pakula AT, Van Naarden Braun K, Yeargin-Allsopp M. Cerebral Palsy: Classification and Epidemiology. Phys Med Rehabil Clin N Am. 2009;20(3):425-52.

14. Christensen D, Van Naarden Braun K, Doernberg NS, Maenner MJ, Arneson CL, Durkin MS, et al. Prevalence of cerebral palsy, co-occurring autism spectrum disorders, and motor functioning - Autism and Developmental Disabilities Monitoring Network, USA, 2008. Dev Med Child Neurol. 2014;56(1):59-65.

15. Delacy MJ, Reid SM. Profile of associated impairments at age 5 years in Australia by cerebral palsy subtype and Gross Motor Function Classification System level for birth years 1996 to 2005. Dev Med Child Neurol. 2016;58(S2):50-6.

16. Badawi N, Balde I, Goldsmith S, Karlsson P, McIntyre S, Novak I, et al. Australia and the Australian Cerebral Palsy Register for the birth cohort 1993 to 2006. Dev Med Child Neurol. 2016;58(S2):3-4.

17. Bloorview Research Institute. Cerebral Palsy Discovery Project (CPDP) - The Canadian Cerebral Palsy (GTA Division) Summary [Internet]. Toronto: Holland Bloorview Kids 
M.Sc. Thesis - L Nguyen; McMaster University - Rehabilitation Science

Rehabilitation Hospital;2017 [cited 2017 February 10]. Available from: http://research.hollandbloorview.ca/ResearchProjectDetail?prid=5e7b03ce-0592-44bb96a6-c6e712c172bc

18. Novak I, McIntyre S, Morgan C, Campbell L, Dark L, Morton N, et al. A systematic review of interventions for children with cerebral palsy: state of the evidence. Dev Med Child Neurol. 2013;55(10):885-910.

19. Rogers A, Furler B-L, Brinks S, Darrah J. A systematic review of the effectiveness of aerobic exercise interventions for children with cerebral palsy: an AACPDM evidence report. Dev Med Child Neurol. 2008;50(11):808-14.

20. Shikako-Thomas K, Majnemer A, Law M, Lach L. Determinants of participation in leisure activities in children and youth with cerebral palsy: systematic review. Phys Occup Ther Pediatr. 2008;28(2):155-69.

21. World Health Organization. International Classification of Functioning, Disability and Health (ICF). Geneva, Switzerland: World Health Organization; 2001.

22. Rosenbaum P, Stewart D. The world health organization international classification of functioning, disability, and health: a model to guide clinical thinking, practice and research in the field of cerebral palsy. Semin Pediatr Neurol. 2004;11(1):5-10.

23. Rosenbaum P. Family and quality of life: key elements in intervention in children with cerebral palsy. Dev Med Child Neurol. 2011;53(S4):68-70.

24. Palisano RJ. A collaborative model of service delivery for children with movement disorders: a framework for evidence-based decision making. Phys Ther. 2006;86(9):1295305.

25. Palisano RJ, Rosenbaum P, Bartlett D, Livingston MH. Content validity of the expanded and revised Gross Motor Function Classification System. Dev Med Child Neurol. 2008;50(10):744-50.

26. Gunel MK, Mutlu A, Tarsuslu T, Livanelioglu A. Relationship among the Manual Ability Classification System (MACS), the Gross Motor Function Classification System (GMFCS), and the functional status (WeeFIM) in children with spastic cerebral palsy. Eur J Pediatr. 2009;168(4):477-85.

27. Mutlu A, Kara OK, Gunel MK, Karahan S, Livanelioglu A. Agreement between parents and clinicians for the motor functional classification systems of children with cerebral palsy. Disabil Rehabil. 2011;33(11):927-32.

28. Palisano R, Rosenbaum P, Walter S, Russell D, Wood E, Galuppi B. Development and reliability of a system to classify gross motor function in children with cerebral palsy. Dev Med Child Neuro. 1997;39(4):214-23.

29. Palisano RJ, Cameron D, Rosenbaum PL, Walter SD, Russell D. Stability of the gross motor function classification system. Dev Med Child Neurol. 2006;48(6):424-8.

30. Wood E, Rosenbaum PL. The gross motor function classification system for cerebral palsy: a study of reliability and stability over time. Dev Med Child Neurol. 2000;42(5):292-6.

31. McCormick A, Brien M, Plourde J, Wood E, Rosenbaum P, McLean J. Stability of the Gross Motor Function Classification System in adults with cerebral palsy. Dev Med Child Neurol. 2007;49(4):265-9.

32. Eliasson A-C, Krumlinde-Sundholm L, Rösblad B, Beckung E, Arner M, Ohrvall A-M, et al. The Manual Ability Classification System (MACS) for children with cerebral palsy: scale development and evidence of validity and reliability. Dev Med Child Neurol. 
M.Sc. Thesis - L Nguyen; McMaster University - Rehabilitation Science

2006;48(7):549-54.

33. Morris C, Kurinczuk JJ, Fitzpatrick R, Rosenbaum PL. Reliability of the Manual Ability Classification System for children with cerebral palsy. Dev Med Child Neurol. 2006;48(12):950-953.

34. Öhrvall AM, Krumlinde-Sundholm L, Eliasson AC. The stability of the manual ability classification system over time. Dev Med Child Neurol. 2014;56(2):185-9.

35. Hidecker MJC, Paneth N, Rosenbaum PL, Kent RD, Lillie J, Eulenberg JB, et al. Developing and validating the Communication Function Classification System for individuals with cerebral palsy. Dev Med Child Neurol. 2011;53(8):704-10.

36. Hidecker MJC, Ho NT, Dodge N, Hurvitz EA, Slaughter J, Workinger MS, et al. Interrelationships of functional status in cerebral palsy: Analyzing gross motor function, manual ability, and communication function classification systems in children. Dev Med Child Neurol. 2012;54(8):737-42.

37. Compagnone E, Maniglio J, Camposeo S, Vespino T, Losito L, De Rinaldis M, et al. Functional classifications for cerebral palsy: Correlations between the gross motor function classification system (GMFCS), the manual ability classification system (MACS) and the communication function classification system (CFCS). Res Dev Disabil. 2014;35(11):2651-7.

38. Koman LA, Smith BP, Balkrishnan R. Spasticity Associated with Cerebral Palsy in Children Guidelines for the Use of Botulinum A Toxin. Pediatric Drugs. 2003;5(1):11-23.

39. Koman LA, Mooney III JF, Smith BP, Walker F, Leon JM, BOTOX Study Group. Botulinum Toxin Type A Neuromuscular Blockade in the Treatment of Lower Extremity Spasticity in Cerebral Palsy: A Randomized, Double-Blind, Placebo-Controlled Trial. Journal of Pediatric Orthopaedics. 2000;20(1):108

40. Bakheit AMO, Hospital P, Ireland N, Morton R, Centre RM, Hospital DC. Safety profile and efficacy of Botulinum toxin A (Dysporta) in children with muscle spasticity. Developmental Medicine \& Child Neurology. 2001;43(4):234-8.

41. Thorley M, Donaghey S, Edwards P, Copeland L, Kentish M, McLennan K, et al. Evaluation of the effects of botulinum toxin A injections when used to improve ease of care and comfort in children with cerebral palsy whom are non-ambulant: a double blind randomized controlled trial. BMC Pediatrics; 2012;12(1):120.

42. Pin TW, Elmasry J, Lewis J. Efficacy of botulinum toxin A in children with cerebral palsy in Gross Motor Function Classification System levels IV and V: a systematic review. Dev Med Child Neurol. 2013;55(4):304-13.

43. Dressler D. Effectiveness of botulinum toxin A for upper and lower limb spasticity in children with cerebral palsy: a summary of evidence. Journal of neural transmission. 2009;116(3):319-31.

44. Ramstad K, Jahnsen R, Skjeldal OH, Diseth TH. Characteristics of recurrent musculoskeletal pain in children with cerebral palsy aged 8 to 18 years. Dev Med Child Neurol. 2011;53(11):1013-8.

45. Penner M, Xie WY, Binepal N, Switzer L, Fehlings D. Characteristics of Pain in Children and Youth With Cerebral Palsy. Pediatrics. 2013;132(2).

46. Fehlings D, Novak I, Berweck S, Hoare B, Stott NS, Russo RN. Botulinum toxin assessment, intervention and follow-up for paediatric upper limb hypertonicity: international consensus statement. Eur J Neurol. 2010;17(S2):38-56.

47. Tilton AH. Therapeutic Interventions for Tone Abnormalities in Cerebral Palsy. NeuroRx. 
M.Sc. Thesis - L Nguyen; McMaster University - Rehabilitation Science

2006;3(2):217-24.

48. Fattal-Valevski A, Sagi L, Domenievitz D. Botulinum toxin a injections to the upper limbs in children with cerebral palsy: duration of effect. J Child Neurol. 2011;26(2):166-70.

49. Heinen F, Desloovere K, Schroeder AS, Berweck S, Borggraefe I, van Campenhout A, et al. The updated European Consensus 2009 on the use of Botulinum toxin for children with cerebral palsy. Eur J Paediatr Neurol. 2010;14(1):45-66.

50. Love SC, Novak I, Kentish M, Desloovere K, Heinen F, Molenaers G, O'Flaherty S, Graham HK. Botulinum toxin assessment, intervention and after-care for lower limb spasticity in children with cerebral palsy: international consensus statement. European Journal of Neurology. 2010;17(S2):9-37.

51. Fehlings D, Narayanan U, Andersen J, Beauchamp R, Gorter JW, Kawamura A, Kiefer G, Mason M, McCormick A, Mesterman R, Switzer L. Botulinum toxin-A use in paediatric hypertonia: Canadian practice patterns. Can J Neurol Sci. 2012;39(4):508-15.

52. Tedesco AP, Martins JS, Nicolini-Panisson RD. Focal treatment of spasticity using botulinum toxin A in cerebral palsy cases of GMFCS level V: evaluation of adverse effects. Rev Bras Ortop. 2014;49(4):359-63.

53. Copeland L, Edwards P, Thorley M, Donaghey S, Gascoigne-Pees L, Kentish M, Cert G, Lindsley J, McLennan K, Sakzewski L, Boyd RN. Botulinum toxin A for nonambulatory children with cerebral palsy: a double blind randomized controlled trial. The Journal of Pediatrics. 2014;165(1):140-6.

54. Flett PJ. Rehabilitation of spasticity and related problems in childhood cerebral palsy. Journal of paediatrics and child health. 2003;39(1):6-14.

55. Naidu K, Smith K, Sheedy M, Adair B, Yu X, Graham HK. Systemic adverse events following botulinum toxin A therapy in children with cerebral palsy. Dev Med Child Neurol. 2010;52(2):139-44.

56. Bjornson K, Hays R, Graubert C, Price R, Won F, Mclaughlin JF. Botulinum toxin for spasticity in children with cerebral palsy: a comprehensive evaluation. Pediatrics. 2007;120(1):49-58.

57. Mall V, Heinen F, Linder M, Philipsen A, Korinthenberg R. Treatment of cerebral palsy with botulinum toxin A: functional benefit and reduction of disability. Three case reports. Pediatric Rehabilitation. 1997;1(4):235-7.

58. Molenaers G, van Campenhout A, Fagard K, de Cat J, Desloovere K. The use of botulinum toxin A in children with cerebral palsy, with a focus on the lower limb. J Child Orthop. 2010;4(3):183-95.

59. Chau V, Fehlings D, Miller SP. Further evidence for botulinum toxin a in cerebral palsy. J Pediatr. 2014;165(1):15-7.

60. Wallen M, O’Flaherty SJ, Waugh M-CA. Functional Outcomes of Intramuscular Botulinum Toxin Type A and Occupational Therapy in the Upper Limbs of Children With Cerebral Palsy: A Randomized Controlled Trial. Arch Phys Med Rehabil. 2007;88(1):110 .

61. Mayston M. Chapter 20: Intervention Planning, Implementation, and Evaluation. In: Dan B, Mayston M, Paneth N, Rosenbloom L, editors. Cerebral palsy: science and clinical practice. London: Mac Keith Press; c2014. p.329-360.

62. Holsbeeke L, Ketelaar M, Schoemaker MM, Gorter JW. Capacity, Capability, and Performance: Different Constructs or Three of a Kind? Arch Phys Med Rehabil. 2009;90(5):849-55. 
M.Sc. Thesis - L Nguyen; McMaster University - Rehabilitation Science

63. Rosenbaum P, Rosenbloom L. Chapter 7: The International Classification of Functioning, Disability and Health. In: Cerebral Palsy: From Diagnosis to Adult Life. London: Mac Keith Press; 2012. p. 70-75.

64. Strobl W, Theologis T, Brunner R, Kocer S, Viehweger E, Pascual-Pascual I, Placzek R. Best clinical practice in botulinum toxin treatment for children with cerebral palsy. Toxins. 2015;7(5):1629-48.

65. Bamm EL, Rosenbaum P. Family-centered theory: origins, development, barriers, and supports to implementation in rehabilitation medicine. Arch Phys Med Rehabil. 2008;89(8):1618-24.

66. Law M, Hanna S, King G, Hurley P, King S, Kertoy M, et al. Factors affecting familycentred service delivery for children with disabilities. Child Care Health Dev. 2003;29(5):357-66.

67. Hanna K, Rodger S. Towards family-centred practice in paediatric occupational therapy: A review of the literature on parent -therapist collaboration. Aust Occup Ther J. 2002;(49):14-24.

68. King G, King S, Rosenbaum P, Goffin R. Family-centered caregiving and well-being of parents of children with disabilities: linking process with outcome. J Pediatr Psychol. 1999;24(1):41-53.

69. King S, Teplicky R, King G, Rosenbaum P. Family-Centered Service for Children With Cerebral Palsy and Their Families: A Review of the Literature. Semin Pediatr Neurol. 2004;11(1):78-86.

70. Wiart L, Ray L, Darrah J, Magill-evans J. Parents ' perspectives on occupational therapy and physical therapy goals for children with cerebral palsy. 2010;32(3):248-58.

71. Ahl LE, Johansson E, Granat T, Carlberg EB. Functional therapy for children with cerebral palsy: an ecological approach. Dev Med Child Neurol. 2005;47(9):613-9.

72. Lammi BM, Law M. The effects of family-centred functional therapy on the occupational performance of children with cerebral palsy. Can J Occup Ther. 2003;70(5):285-97.

73. Øien I, Fallang B, Østensjø S. Goal-setting in paediatric rehabilitation: perceptions of parents and professional. Child: care, health and development. 2010;36(4):558-65.

74. Ostensjø S, Oien I, Fallang B. Goal-oriented rehabilitation of preschoolers with cerebral palsy-a multi-case study of combined use of the Canadian Occupational Performance Measure (COPM) and the Goal Attainment Scaling (GAS). Dev Neurorehabil. 2008;11(4):252-9.

75. Goldberg MJ. Measuring outcomes in cerebral palsy. J Pediatr Orthop. 1991;11(5):682-5.

76. Rosenbaum P, Rosenbloom L. Chapter 13: Outcomes. In: Cerebral Palsy: From Diagnosis to Adult Life. London: Mac Keith Press; 2012. p.151-160.

77. Wright V, Rosenbaum P, Goldsmith CH, Law M, Fehlings D. How do changes in body functions and structures, activity, participation relate in children with cerebral palsy?. Dev Med Child Neurol. 2008;50:283-289.

78. Baird MW, Vargus-Adams J. Outcome measures used in studies of botulinum toxin in childhood cerebral palsy: a systematic review. J Child Neurol. 2010;25(6):721-7.

79. Cusick A, McIntyre S, Novak I, Lannin N, Lowe K. A comparison of goal attainment scaling and the Canadian Occupational Performance Measure for paediatric rehabilitation research. Pediatric rehabilitation. 2006;9(2):149-57.

80. Siebes RC, Ketelaar M, Gorter JW, Wijnroks L, De Blécourt AC, Reinders-Messelink HA, Van Schie PE, Vermeer A, Siebes RC, Ketelaar M, Gorter JW. Transparency and 
M.Sc. Thesis - L Nguyen; McMaster University - Rehabilitation Science

tuning of rehabilitation care for children with cerebral palsy: a multiple case study in five children with complex needs. Developmental Neurorehabilitation. 2007 ;10(3):193-204.

81. Kiresuk TJ, Sherman MR. Goal attainment scaling: A general method for evaluating comprehensive community mental health programs. Community Ment Health J.

1968;4(6):443-53.

82. Steenbeek D, Ketelaar M, Lindeman E, Galama K, Gorter JW. Interrater reliability of goal attainment scaling in rehabilitation of children with cerebral palsy. Arch Phys Med Rehabil. 2010;91(3):429-35.

83. Steenbeek D, Gorter JW, Ketelaar M, Galama K, Lindeman E. Responsiveness of Goal Attainment Scaling in comparison to two standardized measures in outcome evaluation of children with cerebral palsy. Clin Rehabil. 2011;25(12):1128-39.

84. Steenbeek D, Ketelaar M, Galama K, Gorter JW. Goal attainment scaling in paediatric rehabilitation: A report on the clinical training of an interdisciplinary team. Child Care Health Dev. 2008;34(4):521-9.

85. King GA, McDougall J, Palisano RJ, Gritzan J, Tucker MA. Goal Attainment Scaling. Phys Occup Ther Pediatr. 2000;19(2):31-52.

86. Steenbeek D, Ketelaar M, Galama K, Gorter JW. Goal attainment scaling in paediatric rehabilitation: A critical review of the literature. Dev Med Child Neurol. 2007;49(7):5506.

87. Palisano RJ. Validity of goal attainment scaling in infants with motor delays. Phys Ther. 1993;73(10):651-658.

88. McDougall J, Wright V. The ICF-CY and Goal Attainment Scaling: benefits of their combined use for pediatric practice. Disabil Rehabil. 2009;31(16):1362-72.

89. Sakzewski L, Boyd R, Ziviani J. Clinimetric properties of participation measures for 5-13 year old children with cerebral palsy: a systematic review. Dev Med Child Neurol. 2007;49:232-40.

90. Mall V, Heinen F, Siebel A, Bertram C, Hafkemeyer U, Wissel J, et al. Treatment of adductor spasticity with BTX-A in children with CP: a randomized, double-blind, placebo-controlled study. Dev Med Child Neurol. 2005;48(1):10-13.

91. Lowe K, Novak I, Cusick A. Low-dose/high-concentration localized botulinum toxin A improves upper limb movement and function in children with hemiplegic cerebral palsy. Dev Med Child Neurol. 2006;48(3):170-175.

92. Steenbeek D, Meester-Delver A, Becher JG, Lankhorst GJ. The effect of botulinum toxin type A treatment of the lower extremity on the level of functional abilities in children with cerebral palsy: evaluation with goal attainment scaling. Clin Rehabil. 2005;19(3):274-82.

93. Paolicelli, P. B., Ferrari, A., Lodesani, M., \& Muzzini S. Use of botulinum toxin type A in walking disorders of children with cerebral palsy. Eur J Phys Rehabil Med. 2001;32(2):83-92.

94. Law MC, Baptiste S, Carswell A, McColl MA, Polatajko H, Pollock N. Canadian occupational performance measure. Ottawa ON: Canadian Association of Occupational Therapists; 1998.

95. Law M, Baptiste S, McColl M, Opzoomer a, Polatajko H, Pollock N. The Canadian occupational performance measure: an outcome measure for occupational therapy. Can $\mathbf{J}$ Occup Ther. 1990;57(2):82-7.

96. Verkerk GJ, Wolf MJM, Louwers AM, Meester-Delver A, Nollet F. The reproducibility and validity of the Canadian Occupational Performance Measure in parents of children 
M.Sc. Thesis - L Nguyen; McMaster University - Rehabilitation Science

with disabilities. Clin Rehabil. 2006;20(11):980-8.

97. Cusick A, Lannin NA, Lowe K. Adapting the Canadian Occupational Performance Measure for use in a paediatric clinical trial. Disability and Rehabilitation. 2007;29(10):761-6.

98. Pollock N, Sharma N, Christenson C, Law M, Gorter JW, Darrah J. Change in parentidentified goals in young children with cerebral palsy receiving a context-focused intervention: associations with child, goal and intervention factors. Phys Occup Ther Pediatr. 2014;34(1):62-74.

99. Missiuna C, Pollock N, Law M, Walter S, Cavey N. Examination of the Perceived Efficacy and Goal Setting System (PEGS) with children with disabilities, their parents, and teachers. Am J Occup Ther. 2006;60(2):204-14.

100. Dunford C, Missiuna C, Street E, Sibert J. Children's perceptions of the impact of developmental coordination disorder on activities of daily living. Br J Occup Ther. 2005;68(5):207-14.

101. Brewer K, Pollock N, Wright FV. Addressing the challenges of collaborative goal setting with children and their families. Phys Occup Ther Pediatr. 2014;34(2):138-52.

102. Egilson ST. Parent perspectives of therapy services for their children with physical disabilities. Scandinavian Journal of Caring Sciences. 2011;25(2):277-84.

103. Mesterman R, Gorter JW, Harvey A, Lockhart J, McEwen-Hill J, Margallo K, et al. Botulinum toxin type $\mathrm{A}$ in children and adolescents with severe cerebral palsy: a retrospective chart review. J Child Neurol. 2014;29(2):210-3.

104. Osofsky JD, Thompson MD. Adaptive and maladaptive parenting: perspectives on risk and protective factors. In: Shonkoff JP, Meisels SJ, editors. Handbook of Eearly Childhood Intervention. Cambridge, UK: Cambridge University Press; 2000. p. 54-75.

105. Piggot J, Hocking C, Paterson J. Parental adjustment to having a child with cerebral palsy and participation in home therapy programs. Physical \& Occupational Therapy in Pediatrics. 2003;23(4):5-29.

106. Note Summary - CBTC Special Interest Group. Pediatric Spasticity with Dr. Jan Willem Gorter. Oral Communication. 2014 Jan 31.

107. Nguyen L, Mesterman R, Gorter JW. Development of an inventory of goals using the International Classification of Functioning, Disability and Health in a population of nonambulatory children and adolescents with cerebral palsy treated with botulinum toxin A. Unpublished thesis type [manuscript in submission]. McMaster University; 2015.

108. Siebes RC, Ketelaar M, Gorter JW, Alsem M, Jongmans MJ. Needs of families with children with have a physical disability: a literature review. Critical Reviews in Physical and Rehabilitation Medicine. 2012;24:85-108.

109. Alsem MW, Siebes RC, Gorter JW, Jongmans MJ, Nijhuis BGJ, Ketelaar M. Assessment of family needs in children with physical disabilities: development of a family needs inventory. Child Care Health Dev. 2014;40(4):498-506.

110. Rosenbaum P, Rosenbloom L. Chapter 10: Principles of Interventions. In: Cerebral Palsy: From Diagnosis to Adult Life. London: Mac Keith Press; 2012. p. 102-114.

111. Lorin K, Forsberg A. Treatment with botulinum toxin in children with cerebral palsy: a qualitative study of parents' experiences. Child Care Health Dev. 2016;42(4):494-503. 
M.Sc. Thesis - L Nguyen; McMaster University - Rehabilitation Science

\section{CHAPTER 2 METHODOLOGY}

\section{Importance of Qualitative Research in Pediatric Therapy}

In the provision of healthcare services, it is important that parents and families are able to voice their opinions. Evidence-based practice (EBP) is comprised of patient values and preferences, best research evidence, and clinical expertise $(1,2)$. Qualitative research studies provide an opportunity for families to describe their experiences of healthcare services and interventions. Families are able to explain whether and how these interventions were meaningful to their child and family. By understanding the perspectives of families, healthcare professionals are able to understand the delivery and effectiveness of the intervention in context (3).

The goal of interventions is to improve the quality of life for both the child and family (3), and qualitative studies can provide rich, in-depth information about the stories of families of children with $\mathrm{CP}$, including their values, beliefs, and needs in healthcare interventions (3). Many qualitative research studies have been conducted in pediatric therapy $(4,5)$. Gibson et al. conducted a qualitative study to better understand how walking was a priority for families, in which parents described that they considered walking to be a "normal" milestone for their child based on societal values (4). Parents may place priorities on certain goals based on their own values and beliefs. Landsman described parents' evolving beliefs and perceptions about their child's disability (5). As their child grew older, parents began to share shift their perspective of their child's disability from being a "negative" aspect towards a more positive influence on the family.

Qualitative studies also allow healthcare professionals to better understand the components of healthcare interventions that are meaningful to the family (6). For example, healthcare professionals may be able to identify the activity and participation preferences of children and adolescents with CP. Families of children and adolescents with CP are more likely to engage in therapy if they recognize its potential benefits. Through qualitative studies, healthcare professionals are also able to recognize the outcomes and goals that families would like their child to achieve during therapy (6). The results of these qualitative studies can then be translated into clinical practice regarding how healthcare professionals engage and collaborate with families.

\section{Rationale for this Qualitative Study}

According to "best practice" recommendations, goal-setting with families is an integral component during BoNT-A treatment for children and adolescents with CP (7-9). An assessment of current practices of fifty physicians in Canada administering BoNT-A treatment for children and adolescents with $\mathrm{CP}$ was conducted in 2011, which identified that goal-setting tools were infrequently used with $28 \%$ of physicians using the GAS and less than $10 \%$ of physicians using the COPM (8). Parents should also be provided with written information about the potential effects of BoNT-A treatment, but only $71 \%$ of Canadian physicians distributed written information for parents at the time of injection.

When parents are raising their child with $\mathrm{CP}$, they often require information on the different treatment options (10-12). They also require information on how they can become involved with 
setting goals for their child (13). In 2014, I was an undergraduate student in the Bachelor of Health Sciences (Honours) Program in the Child Health Specialization at McMaster University. I conducted my undergraduate thesis project under the supervision of Dr. Ronit Mesterman and Dr. Jan Willem Gorter to explore the types of goals that parents set during BoNT-A treatment. For my undergraduate thesis project, I worked with Dr. Mesterman and Dr. Gorter to design and conduct an observational study (14). We asked parents about the type of goals that they would like their child to achieve after BoNT-A treatment using the draft inventory of goals (14). The list of goals is a work-in-progress and requires ongoing refinements. Parents may identify goals, but it is also important for goals to be realistic and achievable for the child (15). Parents may require information to better understand the effects of BoNT-A treatment and whether it may be appropriate for their child $(16,17)$. This current qualitative study will provide an opportunity for parents to describe effects of BoNT-A on their child from previous administrations of BoNT-A. Based on these observations, parents will be asked to describe whether they considered these effects as potential goals in future BoNT-A treatments for their child. The results of this study will provide information to further refine the inventory list of goals and provide empirical evidence of parents' experiences of BoNT-A treatment. This information can be shared with other families of children and adolescents with $\mathrm{CP}$ and healthcare professionals to inform the goal-setting process.

\section{Types of Qualitative Approaches}

Studies can be designed with various qualitative approaches depending on the research question and specific study outcomes. The three primary qualitative approaches that have been used in research include: phenomenology, grounded theory, and ethnography (18).

Table 1. Description and comparison of three primary qualitative approaches (18).

\begin{tabular}{|l|l|l|l|}
\hline & Phenomenology & Grounded Theory & Ethnography \\
\hline Origins & Philosophy & Sociology & Anthropology \\
\hline Study Aims & $\begin{array}{l}\text { To describe the } \\
\text { elements of a lived } \\
\text { phenomenon of } \\
\text { individuals }\end{array}$ & $\begin{array}{l}\text { To develop a theory } \\
\text { from individuals' } \\
\text { viewpoints in the field } \\
\text { of sociology }\end{array}$ & $\begin{array}{l}\text { To describe and } \\
\text { interpret the shared } \\
\text { patterns of a culture or } \\
\text { group }\end{array}$ \\
\hline Study Methods & $\begin{array}{l}\text { E.g., interviews, } \\
\text { poems, observations, } \\
\text { and documents }\end{array}$ & $\begin{array}{l}\text { E.g., iterative data } \\
\text { collection, multiple } \\
\text { forms of coding } \\
\text { during analysis, and } \\
\text { memos by the } \\
\text { researcher }\end{array}$ & $\begin{array}{l}\text { E.g., observations, } \\
\text { surveys, interviews, } \\
\text { content analysis }\end{array}$ \\
\hline Study Outcomes & $\begin{array}{l}\text { Report the experience } \\
\text { of individuals, } \\
\text { including the meaning } \\
\text { of participants } \\
\text { statements and themes }\end{array}$ & $\begin{array}{l}\text { Develop or advance a } \\
\text { theory, and describe } \\
\text { the relationships } \\
\text { between categories in } \\
\text { the model, which } \\
\text { summarizes the theory }\end{array}$ & $\begin{array}{l}\text { Describe the patterns } \\
\text { and themes of a } \\
\text { culture, and key } \\
\text { concepts within the } \\
\text { cultural or group }\end{array}$ \\
\hline
\end{tabular}


Each qualitative approach includes a methodological framework and strategies that must be employed to ensure rigour in the study. Clinical research aims to investigate outcomes that can be applied in practice by healthcare professionals. It is important to link the study objectives with the appropriate qualitative approach and methodological framework. However, there may be strategies from each methodological framework that might not be relevant to the study objectives. In the past, clinical researchers might identify a qualitative approach and employ methodological strategies that did not align with the qualitative approach. The lack of alignment between the qualitative approach and methodological framework is considered as "method slurring" or "sloppy research" $(19,20)$.

\section{Interpretive Description}

Interpretive Description (ID) was developed from the field of nursing in order to understand clinical phenomena (21). This qualitative study was designed with an ID methodology, which is an exploratory and grounded approach to explain patterns and themes of a phenomenon with a clinical perspective (22). The phenomenon will be described by individuals participating in the study, and may be shaped by their interactions and experiences with others. Each individual will have a different perception of their experience (23). It provides an approach for researchers with a clinical background to better understand patients' experiences, identify common patterns, and subsequently apply these results to clinical practice (24). The understanding of these patterns will allow clinicians to interact more effectively with patients and improve the quality of healthcare services that are delivered.

For this study, a rehabilitation science perspective will be used to understand the clinical phenomena, in which the research team is comprised of a developmental pediatrician, a pediatric physiatrist, a pediatric neurologist, an occupational therapist, and a graduate student. The graduate student's clinical lens stems from a background in child health and development through my academic coursework and research experience. The graduate student graduated from the Bachelor of Health Sciences (Honours) Program, and continued to pursue a Masters in Rehabilitation Science. While conducting this study, the clinical lens came from the graduate student's learnings and experience in clinical research through undergraduate and graduate studies.

Research is often conducted in the field of rehabilitation sciences to collect empirical evidence, propose hypotheses, and test hypotheses using valid and reliable methods (25). These research findings can be used to enhance knowledge that can be directly applied in clinical settings and provide better healthcare services for patients and families $(25,26)$. In this study, ID was used to understand parents' experiences of BoNT-A treatment for their child. Our 2014 study provided us with quantitative results of parent-identified goals using an inventory list of goals in the context of BoNT-A treatment (14). The majority of parents selected goals related to body structures and function. They often required prompting in order to consider goals related to participation. It was concluded that there was a need to understand the reasons for why certain parent-identified goals were important for the child and family. Therefore, it was necessary to conduct a qualitative study and better understand parents' reasoning for selecting certain goals, and whether they have observed their child achieving these goals based on previous BoNT-A treatment sessions. 
This study recruited participants at a single clinic in order to begin exploring parents' experiences of BoNT-A treatment using ID. Based on an assessment of Canadian practices for BoNT-A treatment for children and adolescents with CP, there is a need for standardized goal setting (8). The inventory list of goals is a work in progress, and requires additional revisions based on parent input. Parents may have additional goals that are not listed in the inventory. Parents who are participating in this study may also provide further information about the context and settings for when BoNT-A is an appropriate treatment option for their child with CP. The results of this study could help inform healthcare professionals and parents about the effects of BoNT-A treatment as experienced by other parents, and contribute to the ongoing refinement of the inventory. The study results and the inventory list of goals could be shared with other clinics administering BoNT-A treatment to be used as tools to facilitate the goal-setting process.

Table 2. Designing a qualitative study with an ID analytic approach $(22,24,27)$.

\begin{tabular}{|c|c|c|}
\hline Design Element & Description & Study \\
\hline $\begin{array}{l}\text { Analytic } \\
\text { framework }\end{array}$ & $\begin{array}{l}\text { Individuals will construct their } \\
\text { own experiences located within } \\
\text { a certain context. } \\
\text { There are multiple constructed } \\
\text { realities. }\end{array}$ & $\begin{array}{l}\text { An inventory list of goals was } \\
\text { previously administered to parents } \\
\text { of non-ambulatory children with } \\
\text { CP. Items from the inventory were } \\
\text { asked as close-ended questions. } \\
\text { This study used the ICF framework } \\
\text { to categorize the effects of BoNT-A } \\
\text { described by parents. }\end{array}$ \\
\hline Data collection & $\begin{array}{l}\text { - Sampling approaches including } \\
\text { convenience, purposive, and } \\
\text { theoretical sampling. } \\
\text { - Sampling should ensure } \\
\text { maximal variation in emerging } \\
\text { patterns and themes. }\end{array}$ & $\begin{array}{l}\text { Convenience sampling was } \\
\text { conducted to recruit parents of } \\
\text { children and adolescents with CP } \\
\text { and classified as GMFCS level IV } \\
\text { or V, who have already received } \\
\text { BoNT-A treatment within the past } \\
\text { year }\end{array}$ \\
\hline Data analysis & $\begin{array}{l}\text { - Follows an inductive analytic } \\
\text { process, in which codes and } \\
\text { themes emerge from the data. } \\
\text { - Exploration of questions } \\
\text { including: } \\
\text { o "Why is this here?" } \\
\text { "Why not something } \\
\text { else?" } \\
\text { - "What does it mean?" } \\
\text { Interpretation process to } \\
\text { conceptualize ideas and identify } \\
\text { patterns of a phenomenon. }\end{array}$ & $\begin{array}{l}\text { The coding process was iterative, } \\
\text { since data collection and data } \\
\text { analysis were conducted } \\
\text { simultaneously. } \\
\text { An abductive coding process was } \\
\text { used, in which codes are derived } \\
\text { from a theoretical framework and } \\
\text { additional codes are incorporated } \\
\text { based on the data. } \\
\text { The ICF framework was used to } \\
\text { develop initial codes and categorize } \\
\text { the effects of BoNT described by } \\
\text { parents. } \\
\text { Additional codes were incorporated } \\
\text { into the coding framework based on } \\
\text { new ideas, thoughts, and } \\
\text { experiences described by parents. }\end{array}$ \\
\hline
\end{tabular}




\begin{tabular}{|c|c|c|}
\hline $\begin{array}{l}\text { Study outcomes } \\
\text { and envisioning } \\
\text { the research } \\
\text { product }\end{array}$ & $\begin{array}{l}\text { Patterns and themes are } \\
\text { conveyed as a story or } \\
\text { professional narrative. } \\
\text { - Findings are disseminated as a } \\
\text { research product based on the } \\
\text { needs of the audience. }\end{array}$ & $\begin{array}{l}\text { - Parents' description of the effects } \\
\text { of BoNT-A on their child will be } \\
\text { incorporated into the inventory list } \\
\text { of goals. } \\
\text { - An informative resource may be } \\
\text { created to provide information that } \\
\text { is relevant and meaningful to } \\
\text { parents exploring BoNT-A as a } \\
\text { potential treatment option for their } \\
\text { child. }\end{array}$ \\
\hline
\end{tabular}

\section{Data Collection Methods}

Semi-structured interviews were conducted with participants in order to better understand their experiences of BoNT-A for their child. Interviews were selected as a method to collect data because they provide an opportunity for parents to share their experiences (27). In clinical practice, parents may only be able to share certain information with healthcare professionals due to time constraints and a busy clinic (28). The interviews were conducted by a graduate student researcher (LN), which may encourage parents to share their experiences openly, compared to a healthcare professional who they may have interacted with in the clinical setting.

\section{Study Setting}

Participants were recruited from the Spasticity Management Clinic at McMaster Children's Hospital (Hamilton, ON), a multidisciplinary clinic comprised of two physicians, one nurse, two physiotherapists, one occupational therapist, and a child life specialist. Approximately 60 patients diagnosed with CP and classified in GMFCS level IV or V have previously received BoNT-A injections. At this clinic, the occupational therapist or physiotherapist conducts the initial assessment with the child and family, and the physician would further review the assessment with the family. During this assessment, verbal and written information is provided to parents about the effects of BoNT-A treatment. The child is also assessed for hypertonia severity and passive range of motion. The GMFCS, MACS, and CFCS are also used to describe the child's overall abilities in gross motor function, manual ability, and communication ability, respectively. The muscles that are targeted for BoNT-A injections is based on a discussion with the family and healthcare professionals, in terms of which muscles would be appropriate. For example, an improved range of motion in certain muscles might be helpful for the child to complete daily activities or engage in participation. There is also a specific question during the assessment about what the family's goals are for their child. The healthcare professional team would have a discussion with families about their goals and outline the steps that could help the child to achieve these goals. Adjunctive therapies, such as serial casting, may also be recommended. The follow-up appointment would take place approximately two months after the BoNT-A injections to assess the child's progress and abilities.

Although there are international consensus guidelines, which describe that a similar process should be conducted with families during BoNT-A treatment, there are variations in clinical practice from physicians across Canada (8). Formal measures to assess spasticity and goalsetting tools are not consistently used (8). The process of goal-setting may vary between clinics 
depending on the healthcare professional team working with families. The lack of use of these formal measure and tools may indicate that there are not enough team members, such as therapists. Child life specialists or trained nurses might also be helpful to provide distraction techniques as a form of pain management during BoNT-A treatment, but other clinics may not have enough resources or personnel (8). Therefore, this study was conducted at the Spasticity Management Clinic with a healthcare professional team and goal-setting resources that other clinics might not have. This study can provide additional goal-setting tools, such as the inventory list of goals, as an approach to standardize the goal-setting process for all clinics administering BoNT-A treatment for children and adolescents with CP.

\section{Participant Recruitment}

To be eligible to participate in this study, individuals needed to be primary caregivers (i.e. mother or father) of a child or adolescents with CP, classified in GMFCS level IV or V, who had received BoNT-A injections. Both the mother and father were invited to participate in the interview. All eligible participants were approached by a physiotherapist, occupational therapist, or physician during their clinical appointment in the Spasticity Management Clinic. Recruitment posters were displayed in the Spasticity Management Clinic (Appendix C). Social media strategies were also used to generate awareness about the participant recruitment, including the CanChild website, CanChild Facebook page, and Twitter.

\section{Sample Size}

Participants were consecutively recruited from August 2016 to November 2016. Data saturation was achieved when no new findings were observed in the interviews. In ID methodology, the required number of interviews may vary depending on the study. In previous qualitative studies using an ID methodology, approximately 10-12 participants were interviewed (29-31). This study focused on the experiences of parents of children with CP classified in GMFCS level IV or $\mathrm{V}$, and a small sample size of parents was sufficient to capture their experiences while their child was receiving BoNT-A treatment at the clinic. A previous qualitative study using content analysis in this population also recruited 15 participants (32). The graduate student researcher (LN) wrote observational field notes after each interview to identify codes and themes, to ensure that saturation was reached. Research team meetings were held throughout the study to identify that there were no new findings after a certain number of interviews.

\section{Ethics}

This study received ethics approval by the Hamilton Integrated Research Ethics Board (REB Project \#14-804). An informed consent form and information sheet was provided to eligible participants (Appendix D). The information sheet included information about the purpose of the study, their involvement in the study, the potential benefits and risks for their involvement, the maintenance of confidentiality and protection of their privacy, and the option of not participating in the study. Participants were asked to sign the consent form prior to participating in the interviews.

\section{Individual Interviews}

An interview guide was developed by the research team to encourage parents to describe their experiences of BoNT-A treatment. When parents are introduced to BoNT-A treatment for their child, they often receive information from healthcare professionals about the functional changes 
at the ICF level of body structures and function. It is also important to encourage parents to discuss the changes of BoNT-A in other relevant areas, such as activity and participation. To address multiple aspects of the child's life, the interview guide was comprised of questions based on the ICF categories, including body structures and function, activity, and participation.

The interview guide was comprised of both open-ended questions to provide an opportunity for parents to elaborate on their responses, and close-ended questions to encourage parents to discuss the specific changes that they observed from BoNT-A treatment (Appendix E). The interview guide consisted of the following topics to explore all aspects of parents' experience with BoNTA: (1) Initial expectations of BoNT-A treatment; (2) Observed effects of BoNT-A treatment in the child, including positive and negative changes; (3) Changes in the family's life; (4) Identification of future goals; and (5) Recommendations for future BoNT-A treatment for their child, and for other families (See Figure 1).

The interview began with an open-ended question of "Please tell me about your child?" This question provided an opportunity for parents to set the agenda, and discuss the strengths and challenges that they have had with their child in healthcare treatments (33). It also allowed the interviewer $(\mathrm{LN})$ to develop rapport with parents, and better understand the parents' relationship with their child. Some probes to follow-up with this question included the child's diagnosis, current problems, and whether the child was receiving healthcare treatments and rehabilitation therapies.

The second question of the interview was: "Has your child received BoNT-A treatment before?". This question directed parents to discuss BoNT-A treatment for their child, which was the key focus of the interview. Follow-up questions addressed parents' experiences of BoNT-A, the effects that they observed in their child, and the changes that occurred on the family's lifestyle based on these effects. Parents were asked about the specific effects of BoNT-A using questions, based on a past inventory list of goals from a previous study conducted in 2014 (14). Closeended questions were used to prompt parents to think about all possible effects of BoNT-A treatment based on the domains of the ICF framework (34). Often, parents may consider effects at the ICF level of body structures and function, because BoNT-A treatment is typically considered to have direct effects on reducing tone and improving range of motion in the muscles (35-38). However, there are other possible effects that parents may not have considered before, including effects at the ICF levels of activity and participation (39). Specific probes included whether it was easier or more difficult for parents to complete certain activities, such as bathing, dressing, or transfers in position for their child.

Although BoNT-A treatment is administered for the child, the changes in the child may also affect changes in the family's lifestyle. All parents want to do what is best for their child, and when there are positive changes in their child, these also affect the well-being of the family as a whole (40-42). It was important to ask questions about the possible changes in the family's life after their child received BoNT-A treatment. Parents participating in this study were probed with specific questions, including whether there were any changes in sleeping schedule or quality of sleep, participation in family activities, and well-being of the family after their child received BoNT-A treatment. 
M.Sc. Thesis - L Nguyen; McMaster University - Rehabilitation Science

Based on the effects of BoNT-A that parents have observed, they were asked whether these effects are future goals that they would like to continue to see in their child. This question helped to better understand the process of how parents identify goals with healthcare professionals. Parents often require information on the potential effects of BoNT-A for their child (43). It is also important for healthcare professionals to have a discussion with parents and identify goals that are realistic for the child to achieve (13). Goal-setting tools, such as the GAS and COPM, provide opportunities for healthcare professionals to have a collaborative discussion in identifying goals $(44,45)$. When parents reflect back on previous BoNT-A treatment sessions and the effects that they have observed, they may consider whether and how these effects are future goals for their child (17). Therefore, this question was asked to better understand how parents identify goals based on their previous observations and experiences with BoNT-A treatment.

Parents may also consider whether they would continue with BoNT-A for their child based on their experiences. Children and adolescents with $\mathrm{CP}$ often receive multiple treatments and rehabilitation therapies (46), of which BoNT-A treatment is one. Based on observations and discussions with healthcare professionals, parents would need to re-evaluate and consider whether they should continue with future treatment sessions of BoNT-A for their child. Often, the goals of treatment sessions are decided from observations of the child in completing activities, the child's interest in participation, feedback, and shared knowledge between parents and healthcare professionals $(13,17)$. It was important to ask parents whether they would continue with BoNT-A for their child, and whether they would recommend BoNT-A for other families. The recommendations that parents provide about BoNT-A would be helpful in considering revisions for the inventory of goals and the dissemination of study findings to families of children and adolescents with $\mathrm{CP}$. 


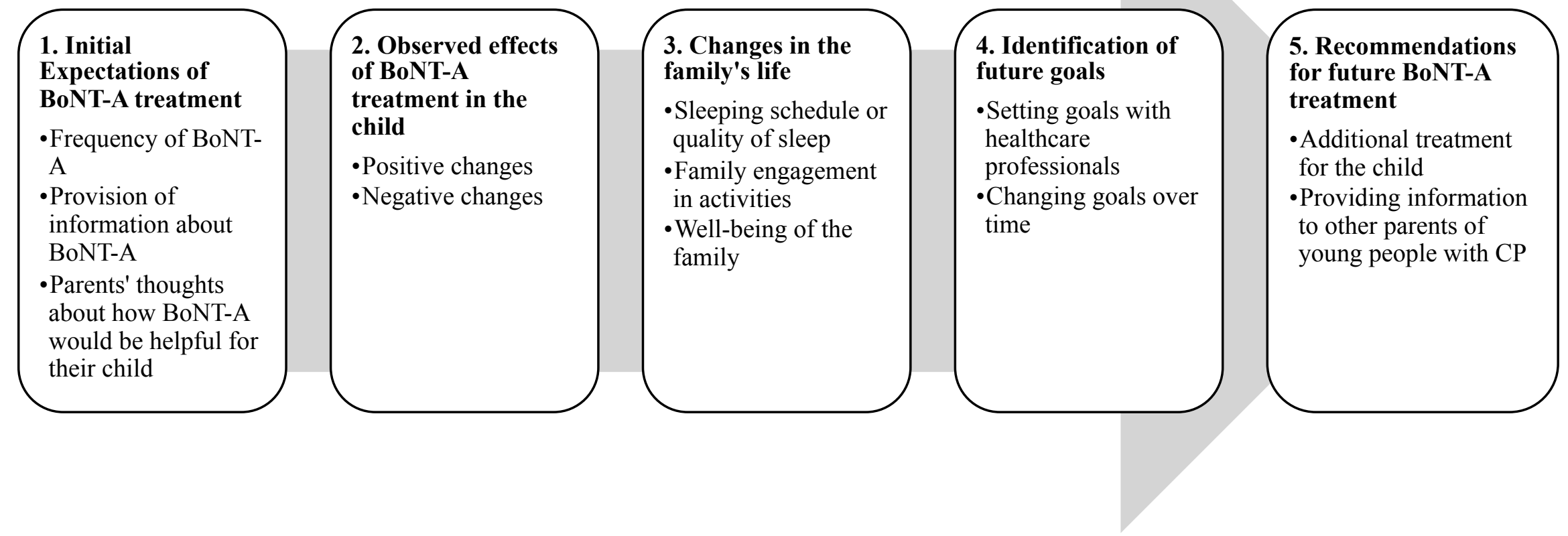

Figure 1. Development of interview questions. The interview questions explored a variety of topics to provide an opportunity for parents to describe in-depth the effects of BoNT-A treatment in both the child and family, and whether these effects were potential goals in future treatment sessions. Based on these experiences, parents may also have information and recommendations that they would like to share with other parents of young people with CP similar to their own family. 
M.Sc. Thesis - L Nguyen; McMaster University - Rehabilitation Science

\section{Data Management}

Individual interviews were audiotaped and transcribed using a word processing program. The transcripts were then imported into a software program that was designed to organize and analyze qualitative data (NVivo Version 10.2.2). All participant identifiers were removed from transcripts.

\section{Data Analysis}

This study employed several analytic strategies that have been recommended previously to understand, describe, and interpret the data, as well as ensure rigour in the study $(47,48)$.

\section{Data Immersion and Reflexivity}

Reflexivity provides an opportunity for researchers to become aware of their influence during interactions with participants and the decisions that they make in the research (49). Reflexive memos were written by the graduate student researcher (LN) after each interview. It was important for the graduate student researcher as an interviewer to develop rapport with parents in order to encourage them to share information. This topic was addressed in the reflexive memos in which the graduate student researcher identified specific questions to ask and with which to develop rapport with parents, including "Is your child happy?" and "Does your child enjoy going to school?". These questions encouraged parents to share their child's favourite hobbies and activities, and how certain healthcare interventions such as BoNT-A could facilitate these activities. Other topics were addressed in the reflexive memos, including new ideas that were raised by parents. Reflexive memos allowed the interviewer to reflect on personal knowledge prior to entering the study, interactions with participants, and initial insights about the findings (27). These reflexive memos also ensured that saturation was achieved when no new findings or topics are discussed by parents.

\section{Identification of Key Themes}

The coding of the interviews followed an abductive reasoning process, in which an observation that may explain a phenomenon was further explored, and other observations may be discovered to explain the phenomenon (50). Using an abductive reasoning process, an initial framework was used to develop the codes for the initial coding framework. As more data are collected from the interview transcripts, additional codes will be included into the coding framework. All research team members conducted topic coding by coding the initial transcript independently according to the domains of the ICF framework (51). In addition to the ICF domains, new codes were added to the coding framework in order to identify how the different effects of BoNT-A treatment relate to each other. The coding framework and codebook is provided in Appendix F. Peer debriefing among research team members was conducted during the coding process to help ensure rigour (47).

\section{Visual Depiction}

The effects of BoNT-A shared by parents were categorized into the domains of the ICF framework. Specific information that was discussed by parents at each ICF level was organized into a visual word cloud. Word frequency was also used to identify key words that were raised by all parents. Specific words that appeared more frequently in interviews were followed up in order to understand whether they were significant concepts (52). The frequency of words that parents mentioned was helpful to identify important concepts and themes to capture their story. 
M.Sc. Thesis - L Nguyen; McMaster University - Rehabilitation Science

\section{Ensuring Trustworthiness}

Multiple strategies were used to ensure trustworthiness in the data, including credibility, transferability, dependability, and confirmability (47).

Table 3. Description of strategies to ensure trustworthiness.

\begin{tabular}{|c|c|c|}
\hline Strategy & Description & Study \\
\hline Credibility & $\begin{array}{l}\text { Analogous to internal } \\
\text { validity, in which the } \\
\text { findings are accurate to } \\
\text { the 'truth'. }\end{array}$ & $\begin{array}{l}\text { Reflexive memos were written after each interview, } \\
\text { in which key ideas or thoughts were recorded. Key } \\
\text { ideas that were mentioned in several interviews were } \\
\text { identified as codes. New ideas or codes were } \\
\text { incorporated into the coding framework. Member } \\
\text { checking was conducted by providing a summary } \\
\text { document of key findings and themes to participants } \\
\text { to gain feedback. }\end{array}$ \\
\hline Transferability & $\begin{array}{l}\text { The findings can be } \\
\text { transferred and applied } \\
\text { in other settings. }\end{array}$ & $\begin{array}{l}\text { Descriptions about the participants and settings were } \\
\text { provided in detail. }\end{array}$ \\
\hline Dependability & $\begin{array}{l}\text { There is consistency in } \\
\text { the data and findings } \\
\text { with a clear explanation } \\
\text { of the research process, } \\
\text { including methods of } \\
\text { data collection, } \\
\text { analyses, and } \\
\text { interpretations. }\end{array}$ & $\begin{array}{l}\text { A clear audit trail was provided of the strategies } \\
\text { used for data analysis. }\end{array}$ \\
\hline Confirmability & $\begin{array}{l}\text { The findings are } \\
\text { collected from } \\
\text { participants' } \\
\text { perspectives with } \\
\text { limited bias and } \\
\text { influence from the } \\
\text { researcher. }\end{array}$ & $\begin{array}{l}\text { Peer debriefing was conducted in order to take into } \\
\text { account the perspectives from different individuals } \\
\text { in interpreting the data. Peer debriefing included } \\
\text { informal discussions and research team meetings. } \\
\text { Individuals involved in peer debriefing included the } \\
\text { research team comprised of a developmental } \\
\text { pediatrician, a pediatric physiatrist, a pediatric } \\
\text { neurologist, and occupational therapist. Other } \\
\text { individuals included a qualitative researcher with an } \\
\text { occupational therapist professional background, } \\
\text { parents, and current graduate students in the School } \\
\text { of Rehabilitation Science at McMaster University. } \\
\text { These peer debriefings were conducted through data } \\
\text { analysis to understand their perspectives in viewing } \\
\text { the data. }\end{array}$ \\
\hline
\end{tabular}


M.Sc. Thesis - L Nguyen; McMaster University - Rehabilitation Science

\section{Discussion: Application of ID}

The aim of this chapter was to discuss the design of this qualitative study, including its application of ID as an analytic methodology. This study provided an opportunity for parents to share their previous experiences with BoNT-A treatment for their child. At McMaster Children's Hospital, goal-setting is already an aspect that is incorporated into clinical appointments. Parents may already have identified goals with healthcare professionals. It is important to understand and document parents' reasoning for selecting goals, and the process for how they identified their goals with healthcare professionals. The ICF framework can be helpful in identifying how BoNT-A treatment can affect different areas of both the child's and family's life (34).

Furthermore, this study described the use of ID as an analytic methodology for qualitative studies. Previous qualitative studies in the field of pediatric rehabilitation have focused on other qualitative approaches, such as phenomenology or grounded theory (3). As noted at the start of this chapter, phenomenology aims to describe the lived experiences of individuals, and grounded theory aims to develop a theory with constructs that can be used to explain a phenomenon (53). This qualitative study is building on our previous work in which the focus was on item generation for the development of an inventory list of goals in the context of BoNT-A treatment. This qualitative study uses ID to ask about parents' experiences and understanding of BoNT-A treatment. ID is an approach that acknowledges the clinical background that researchers are entering into the study (22). ID recognizes that the phenomenon of interest was identified in a clinical context, and acknowledges that clinical knowledge can form the foundational knowledge for designing and conducting the study. Since this approach was developed in the field of nursing, healthcare professionals are rarely satisfied with a description of the patient experience and are interested in taking action to change their clinical practice (22). It is important for healthcare professionals to provide care for families that encompasses many aspects of the child's life based on the domains of the ICF framework. The domains of the ICF framework were helpful to structure and develop the initial set of codes, which encompasses a holistic approach of an individual's life including body structures and function as well as participation. Themes were generated from a rehabilitation science perspective with the aim to share these findings with other families and healthcare professionals, and develop resources for goal setting in clinical practice. This study aimed to incorporate parents' descriptions of the effects of BoNTA into the refinement of the inventory list of goals. The research product of this study is to modify and refine the inventory list of goals that could be used as a tool to facilitate the goalsetting process in the context of BoNT-A treatment.

Lorin and Forsberg (2016) conducted a qualitative study to describe the effects of BoNT-A treatment from the parents' perspectives (32). Similar to Lorin and Forsberg, this study provides an opportunity for parents to share their experiences. The use of ID allows the qualitative results to be synthesized and formulated into a narrative story that can convey parents' experiences. It is important to highlight the complexity of parents' experiences in caring for their child, and that BoNT-A treatment can affect multiple aspects of the child's life. This study also engaged with all participants through the process of member checking, although only one parent responded, who was able to confirm that preliminary analysis and identification of themes captured her experiences. The inventory of list of goals will be refined as the research product of this study. The authors will also consider developing an informative resource for parents to learn and understand other possible effects of BoNT-A treatment. 
M.Sc. Thesis - L Nguyen; McMaster University - Rehabilitation Science

In family-centred services, healthcare professionals are forming partnerships with families in order to deliver treatments, programs and services that will meet the needs of the families. Goalsetting is an essential component in family-centred service in order to incorporate the values and beliefs of the family into the treatment plan $(15,54)$. Parents' satisfaction with healthcare services is often based on the extent to which the services are family-centred (54). Parents require clear information and recommendations about their child's disability and treatments. During treatments, parents' viewpoints should also be considered in order to understand their needs, expectations, and goals. However, parents may have difficulties in identifying and setting goals with healthcare professional (28). Education is a core component of family-centred services, and parents require information from healthcare professionals about their child's health condition and treatment options (Gallo et al., 2016). Parents may require knowledge and information to set goals that are appropriate for their child. They also want to set goals that are meaningful to the child and family (17).

An inventory of goals may be a helpful tool to facilitate the goal-setting process with families. An inventory of family needs was previously developed for families of children with physical disabilities. This inventory can be helpful to encourage parents to share the needs of the child and family during the goal-setting discussion about treatments (55). The study findings will be used to refine an inventory of goals that is specific for non-ambulatory children with $\mathrm{CP}$ and receiving BoNT-A treatment. The inventory will also be an informative resource for parents to consider the different potential effects that BoNT-A treatment may have for the child and family.

In conclusion, ID is an emerging qualitative approach. Qualitative studies are important to provide the context of parents' experiences in pediatric rehabilitation and healthcare treatments. It is important to describe the strategies that will be employed to ensure rigour and trustworthiness of the data. 
M.Sc. Thesis - L Nguyen; McMaster University - Rehabilitation Science

\section{References}

1. Sackett DL, Rosenberg WMC, Gray JAM, Haynes RB, Richardson WS. Evidence based medicine: what it is and what it isn't. BMJ. 1996;312:71-2.

2. Sackett DL. Evidence-based medicine. Semin Perinatol. 1997;21(1):3-5.

3. Wiart L. How can qualitative research contribute to the expanding knowledge base in pediatric physical therapy? Phys Ther Rev. 2012;425-9.

4. Gibson BE, Teachman G, Wright V, Fehlings D, Young NL, McKeever P. Children's and parents' beliefs regarding the value of walking: rehabilitation implications for children with cerebral palsy. Child Care Health Dev. 2012;38(1):61-9.

5. Landsman G. Mothers and Models of Disability. J Med Humanit. 2005;26(2-3):121-39.

6. Schreiber J, Benger J, Salls J, Marchetti G, Reed L. Parent Perspectives on Rehabilitation Services for Their Children with Disabilities: A Mixed Methods Approach. Phys Occup Ther Pediatr. 2011;31(3):225-38.

7. Fehlings D, Novak I, Berweck S, Hoare B, Stott NS, Russo RN. Botulinum toxin assessment, intervention and follow-up for paediatric upper limb hypertonicity: international consensus statement. Eur J Neurol. 2010;17(S2):38-56.

8. Fehlings D, Narayanan U, Andersen J, Beauchamp R, Gorter JW, Kawamura a, et al. Botulinum toxin-A use in paediatric hypertonia: Canadian practice patterns. Can J Neurol Sci. 2012;39(4):508-15.

9. Strobl W, Theologis T, Brunner R, Kocer S. Best clinical practice in botulinum toxin treatment for children with cerebral palsy. Toxins. 2015;7(5):1629-1648.

10. Siebes RC, Ketelaar M, Gorter JW, Alsem M, Jongmans MJ. Needs of Families with Children Who Have a Physical Disability: A Literature Review. 2012;24(1-2):85-108.

11. Palisano RJ, Almarsi N, Chiarello LA, Orlin MN, Bagley A, Maggs J. Family needs of parents of children and youth with cerebral palsy. Child Care Health Dev. 2010;36(1):8592.

12. Pain H. Coping with a child with disabilities from the parents' perspective: The function of information. Child Care Health Dev. 1999;25(4):299-312.

13. Wiart L, Ray L, Darrah J, Magill-evans J. Parents ' perspectives on occupational therapy and physical therapy goals for children with cerebral palsy. 2010;32(3):248-58.

14. Nguyen L, Mesterman R, Gorter JW. Development of an inventory of goals using the International Classification of Functioning, Disability and Health in a population of nonambulatory children and adolescents with cerebral palsy treated with botulinum toxin A. Unpublished thesis type [manuscript in submission]. McMaster University; 2015.

15. King S, Teplicky R, King G, Rosenbaum P. Family-Centered Service for Children With Cerebral Palsy and Their Families: A Review of the Literature. 2004;11(1):78-86.

16. Rosenbaum P. Cerebral palsy: what parents and doctors want to know. BMJ: British Medical Journal. 2003;326:970-4.

17. Øien I, Fallang B, Østensjø S. Goal-setting in paediatric rehabilitation: perceptions of parents and professional. Child Care Health Dev. 2010;36(4):558-65.18. Creswell JPC. Chapter 4. Qualitative Inquiry \& Research Design - Choosing Among Five Approaches. 2017. 65-110 p.

19. Morse, JM. Qualitative nursing research: A free-for-all? In: Morse JM, ed. Qualitative nursing research: A contemporary dialogue. Rockville, MD: Aspen; 1989. p. 3-10.

20. Baker C, Judith W, Phyllis S. Method slurring : the grounded theory / phenomenology 
M.Sc. Thesis - L Nguyen; McMaster University - Rehabilitation Science

example. J Adv Nurs. 1992;17:1355-60.

21. Thorne S, Kirkham SR, MacDonald-Emes J. Interpretive description: A noncategorical qualitative alternative for developing nursing knowledge. Res Nurs Health. 1997;20(2):169-77.

22. Thorne S, Kirkham SR, O'Flynn-Magee K. The analytic challenge in interpretive description. Int J Qual Methods. 2004;3(1):1-11.

23. Scotland J. Exploring the Philosophical Underpinnings of Research: Relating Ontology and Epistemology to the Methodology and Methods of the Scientific, Interpretive, and Critical Research Paradigms. English Lang Teach. 2012;5(9):9.

24. Thorne S, Stephens J, Truant T. Building qualitative study design using nursing's disciplinary epistemology. J Adv Nurs [Internet]. 2016 Feb [cited 2017 Mar 14];72(2):451-60. Available from: http://doi.wiley.com/10.1111/jan.12822

25. Tate DG. The State of Rehabilitation Research: Art or Science? Arch Phys Med Rehabil. 2006;87(2):160-6.

26. Carter R \& Lubinsky J. Chapter 1: Rehabilitation Research. In: Rehabilitation Research: Principles and Applications. Missouri, USA: Elsevier Health Sciences; 2015. p. 1-11.

27. Thorne SE. Chapter 1: Qualitative Research in the Applied Disciplines. In: Interpretive Description: Qualitative Research For Applied Practice. 2nd ed. New York: Routledge; 2016. p. 25-38.

28. Brewer K, Pollock N, Wright FV. Addressing the challenges of collaborative goal setting with children and their families. Physical \& occupational therapy in pediatrics. 2014 May 1;34(2):138-52.

29. Abdul-Razzak A, You J, Sherifali D, Simon J, Brazil K. "Conditional candour" and "knowing me": an interpretive description study on patient preferences for physician behaviours during end-of-life communication. BMJ. 2014;4(10):e005653.

30. Darlow B, Dean S, Perry M, Mathieson F, Baxter GD, Dowell A. Acute low back pain management in general practice: uncertainty and conflicting certainties. Fam Pract. 2014;31(6):723-32.

31. Robinson CA, York K, Rothenberg A, Bissell LJL. Parenting a Child with Asperger's Syndrome: A Balancing Act. J Child Fam Stud. 2015;24(8):2310-21.

32. Lorin K, Forsberg A. Treatment with botulinum toxin in children with cerebral palsy: a qualitative study of parents' experiences. Child Care Health Dev. 2016;42(4):494-503.

33. Rosenbaum P. Communicating with Families: A Challenge We Can and Must Address! Phys Occup Ther Pediatr. Taylor \& Francis; 2011;31(2):133-4.

34. World Health Organization. International Classification of Functioning, Disability and Health (ICF). Geneva, Switzerland: World Health Organization; 2001.

35. Koman LA, Smith BP, Balkrishnan R. Spasticity Associated with Cerebral Palsy in Children Guidelines for the Use of Botulinum A Toxin. Pediatric Drugs. 2003;5(1):11-23.

36. Koman LA, Smith BP, Balkrishnan R. Spasticity Associated with Cerebral Palsy in Children Guidelines for the Use of Botulinum A Toxin. 2003;5(1):11-23.

37. Bakheit AMO, Hospital P, Ireland N, Morton R, Centre RM, Hospital DC. Safety profile and efficacy of Botulinum toxin A (Dysporta) in children with muscle spasticity. Developmental Medicine \& Child Neurology. 2001;43(4):234-8.

38. Thorley M, Donaghey S, Edwards P, Copeland L, Kentish M, McLennan K, et al. Evaluation of the effects of botulinum toxin A injections when used to improve ease of care and comfort in children with cerebral palsy whom are non-ambulant: a double blind 
M.Sc. Thesis - L Nguyen; McMaster University - Rehabilitation Science

randomized controlled trial. BMC Pediatrics; 2012;12(1):120.

39. Mall V, Heinen F, Linder M, Philipsen A, Korinthenberg R. Treatment of cerebral palsy with botulinum toxin A: functional benefit and reduction of disability. Three case reports. Pediatric Rehabilitation. 1997;1(4):235-7.

40. Raina P, O'Donnell M, Rosenbaum P, Brehaut J, Walter SD, Russell D, Swinton M, Zhu $\mathrm{B}$, Wood E. The health and well-being of caregivers of children with cerebral palsy. Pediatrics. 2005 Jun 1;115(6):e626-36.

41. Davis K, Gavidia-Payne S. The impact of child, family, and professional support characteristics on the quality of life in families of young children with disabilities. $\mathbf{J}$ Intellect Dev Disabil. 2009;34(2):153-62.

42. Reichman NE, Corman H, Noonan K. Impact of Child Disability on the Family. Matern Child Health J. 2008;12(6):679-83.

43. King S, Teplicky R, King G, Rosenbaum P. Family-Centered Service for Children With Cerebral Palsy and Their Families: A Review of the Literature. Semin Pediatr Neurol. 2004;11(1):78-86.

44. Sherman RE. Goal Attainment Scaling : A General Method for Evaluating Comprehensive Community Mental Health Programs. 1968;4(6):443-53.

45. Law M, Baptiste S, McColl M, Opzoomer a, Polatajko H, Pollock N. The Canadian occupational performance measure: an outcome measure for occupational therapy. Can $\mathrm{J}$ Occup Ther. 1990;57(2):82-7.

46. Novak I, McIntyre S, Morgan C, Campbell L, Dark L, Morton N, et al. A systematic review of interventions for children with cerebral palsy: state of the evidence. Dev Med Child Neurol. 2013;55(10):885-910.

47. Morse JM. Critical Analysis of Strategies for Determining Rigor in Qualitative Inquiry. Qual Health Res. 2015;25(9):1212-22.

48. Richards L. Chapter 4: Up from the Data. In: Handling Qualitative Data: A Practical Guide. London, England: Sage Publications Inc.; 2015. p. 85-102.

49. Richards L. Chapter 2: Making qualitative data. In: Handling Qualitative Data: A Practical Guide. London, England: Sage Publications Inc.; 2015. p. 35-60.

50. Folger R, Stein C. Abduction 101: Reasoning processes to aid discovery. Hum Resour Manag Rev. 2017;27(2):306-15.

51. Bazeley P. Chapter 6: Naming, organising, and refining codes. In: Qualitative Data Analysis: Practical Strategies. London, England; 2013. p. 157-87.

52. Bazeley P. Chapter 4: Read, reflect and connect: initial explorations of data. In: Qualitative Data Analysis: Practical Strategies. London, England: Sage Publications Inc.; 2013. p. 101-24.

53. Creswell JPC. Chapter 4: Five Qualitative Approaches to Inquiry. In: Qualitative Inquiry \& Research Design: Choosing Among Five Approaches. 4th ed. London, England: Sage Publications Inc.; 2018. p. 65-110.

54. Law M, Hanna S, King G, Hurley P, King S, Kertoy M, et al. Factors affecting familycentred service delivery for children with disabilities. Child Care Health Dev. 2003;29(5):357-66.

55. Alsem MW, Siebes RC, Gorter JW, Jongmans MJ, Nijhuis BGJ, Ketelaar M. Assessment of family needs in children with physical disabilities: development of a family needs inventory. Child Care Health Dev. 2014;40(4):498-506. 
M.Sc. Thesis - L Nguyen; McMaster University - Rehabilitation Science

\section{CHAPTER 3 FINDINGS}

This chapter presents the findings of parent interviews in this interpretive description study. Each parent described their experience with BoNT-A treatment, including the direct effects of BoNTA treatment on their child and how these effects impacted both the child and family. Eleven mothers and four fathers participated in this study, and self-identified as the primary caregiver. All parents reported that their child received BoNT-A treatment at least twice before the interview, and twelve parents indicated that their child received BoNT-A treatment on a regular basis of approximately every 3-6 months. Table 1 displays the characteristics of children of parents who participated in this study. Children were described by their gross motor, manual, and communication abilities using the GMFCS, MACS, and CFCS, respectively. The healthcare professional team informally assessed the children's cognitive abilities, such as the child's level of understanding and responsiveness to questions during discussions in clinical appointments.

Table 1. Characteristics of Children.

\begin{tabular}{|l|l|}
\hline Characteristics & Subjects, N=15 (\%) \\
\hline Age (in years) & $10.2 \pm 3.9$ \\
mean \pm SD & $5-17$ \\
Age range & \\
Gender & $7(47)$ \\
Male & $8(53)$ \\
Female & \\
GMFCS & $10(67)$ \\
level IV & $5(33)$ \\
level V & \\
MACS & $0(0)$ \\
level I & $2(10)$ \\
level II & $4(30)$ \\
level III & $5(30)$ \\
level IV & $4(30)$ \\
level V & \\
& \\
CFCS & $3(20)$ \\
level I & $3(20)$ \\
level II & $1(10)$ \\
level III & $3(20)$ \\
level IV & $5(30)$ \\
level V & $10(67)$ \\
Significant Cognitive Impairments & \\
\hline
\end{tabular}

GMFCS, Gross motor Function Classification System; MACS, Manual Ability Classification System, CFCS, Communication Function Classification System. SD, Standard Deviation.

*Note: There were 4 participants classified with the 'all V' profile of level V for GMFCS, MACS, and CFCS. 
M.Sc. Thesis - L Nguyen; McMaster University - Rehabilitation Science

Study findings are presented as an interpretation of the stories shared by parents during the interviews with supporting quotes. The interpretation of parents' stories is consistent with an ID methodology to describe parents' experiences of BoNT-A treatment and subsequently, interpret these findings into key themes. An overall theme was identified as "Finding the right path to do what is best for my child" to provide an overview of parents' journey, and their processes of learning and goal setting with healthcare professionals. There are five subthemes: Parents' hopes; 2) Parents' goals for their child; 3) Parents learning what works; 4) Parents' reflections; and 5) Parents' destination. The diagram in Appendix G describes the stages (subthemes) of parents' journey.

\section{Parents' Hopes}

All parents in this study described their hope that their child will be as happy as possible. The interpretation of parents' hope was their expectations, desires, and wishes for their child. As their child continued to develop, parents hoped that their child would be able to walk and communicate one day. Some parents believed that the ability to walk and interact with others would contribute to their child's overall happiness. Parents recognized that there are challenges due to CP that can affect their child's ability to engage in meaningful activities that make them happy. They described how their child's happiness influenced their own well-being and happiness: "Like obviously, physically she has a lot of complications. You know, we're doing the best that we can. She's happy, so we're happy" (Mother of an 8-year-old girl, GMFCS level $I V)$. Parents wanted to minimize as many challenges as they could for their child, such as access with healthcare services or resources. Despite the challenges and complications families of children and adolescents with CP might face, parents are doing the best that they can to keep their child happy. "Especially if it's for daily life, for caregiving, for dressing, and even for them, in school, for learning. Just to do something, just to see a goal" (Mother of a 6-year-old girl, GMFCS level V). Parents' hopes motivated them to do something and try the best that they can to raise their child.

All parents began the interview by describing their child's personality and overall happiness. It was apparent that every child has a unique personality with different characteristics. Parents described how there were many different aspects to the child's personality, such as their love, motivation, and humour. A mother described her son as “... a great kid. He's very easygoing. People person, loves to be outside, has a lot of friends, very social. And he happens to have cerebral palsy as well" (Mother of an 11-year-old boy, GMFCS level IV). Parents also recognized that their child wanted to engage in hobbies and interests similar to other children, such as socializing with friends and watching TV. Children and adolescents were happy when they were able to engage in different activities depending on their age. Both young and older children were happy when they were able to socialize with their peers at school and in the community.

\section{Parents' Goals For Their Child}

While raising their child, parents wanted to maintain their child's level of happiness by focusing on two goals: 1) promoting their child's independence; and 2) improving the quality of life for their child, and subsequently their family as a whole. 
M.Sc. Thesis - L Nguyen; McMaster University - Rehabilitation Science

\section{Promoting Their Child's Independence}

All parents indicated that they wanted to promote their child's independence to a certain degree, depending on their child's abilities. Parents of young children described that they were learning about their child's abilities and challenges.

However, children and adolescents who were significantly affected by CP had to rely on their parents to assist them with completing daily activities, such as bathing and dressing. When their child got older, parents wanted their child to complete activities more independently or with little supervision.

"We have a lot of goals. We have an appointment with an OT to get her to set up at home, trying to get her to get snacks for herself if we're not able [to]... And she's almost 18 , we're trying to figure out things, to access things, and to do things for herself." (Mother of a 17-year-old girl, GMFCS level IV).

All parents described the actions and activities associated with independence, but the term "independence" may have different meanings for parents. Some parents described independence as being able to make a snack without assistance, or sit on the couch with little supervision, while other parents described independence as being able to go to the doctor alone. For example, a mother described that she continually encouraged her daughter to be independent and worked with a physiotherapist to have discussions about independence:

"She's very independent, it's something [we have] kind of been pushing since she was really little, like 'You need to try to do it yourself'. She had a chat with her physiotherapist who came to the house yesterday and they just had a one-on-one chat. And he said that he was saying, to be an independent adult, you have to put the work in. And being able to get up and be moving is going to be a good step in that direction. We really do try and focus on her being able to be as independent as possible." (Mother of an 11-year-old daughter, GMFCS level IV).

Therefore, parents' understanding of their child's independence may vary over time as parents needed time to understand and help their child develop the skills necessary to be independent.

\section{Improving Quality of Life for the Family}

All parents wanted their child to be happy to ensure that both the child and family have a good quality of life. Parents wanted their child to bond and form relationships with family members. Community activities provided an opportunity for family members to bond and interact with each other. It was important for parents to continue to maintain their current lifestyle and participation in the community: "He definitely goes out in the community all the time. He goes to school. He goes to the park and playing with his friends." (Mother of an 11-year-old boy, GMFCS level IV). Parents also identified that it can be difficult for their child to participate in the community, but tried not to let their child's physical difficulties affect their family's engagement in community activities. 
M.Sc. Thesis - L Nguyen; McMaster University - Rehabilitation Science

Quality of life also includes sleeping behaviour for both the child and family. A mother explained how her child's sleeping behavour impacted the overall functioning and well-being of the family:

"It makes it so much better that she's able to get a whole night's sleep. We would only sleep for like two hours at a time. She would scream, she would cry. It was like having a newborn for every day for four years... I didn't even know what was going on. Because my sole concern was feeding, changing, and taking care of my baby." (Mother of a 6year-old girl, GMFCS level IV)

Parents wanted to access healthcare services that could help them attain their goals and make it easier for their child and family to have a good quality of life.

\section{Parents Learning What Works}

When a child was initially diagnosed with CP, parents were learning about the different appropriate treatments and therapies to help manage CP. Parents were often introduced to BoNTA treatment by healthcare professionals, such as their doctors, physical therapists, or occupational therapists. BoNT-A is one treatment option to help children and adolescents with CP manage spasticity. Parents learned about the physical and direct effects of BoNT-A treatment from healthcare professionals: "I was told that it would relax the muscles that were tight. Basically it paralyzes the muscles for a period of time. And I think that was pretty much a good description of it for me" (Mother of a 6-year-old girl, GMFCS level V). Healthcare professionals also elaborated about additional benefits from relaxing the muscles by letting parents "be able to do more exercises and it helps with diapering and changing clothes, and basically gives her a chance to relax" (Mother of an 11-year-old girl, GMFCS level IV). Healthcare professionals often provided information about how BoNT-A treatment helped to relax the muscles, which in turn may have an effect on activities of daily living, such as dressing and personal hygiene.

Parents also found it helpful to hear about other parents' experiences of BoNT-A treatment for their child: "... once it was suggested, I think I asked a couple of friends of mine. And then when you hear a mom tell you that has a kid very similar to her [their child] that it was great, I would trust that" (Mother of a 6-year-old girl, GMFCS level V). Parents wanted information about BoNT-A treatment from both healthcare professionals and parents in order to learn about the benefits and challenges in pursuing this treatment option.

When parents decided to pursue BoNT-A treatment for their child, they needed time to learn about the effects of BoNT-A treatment. Parents might observe different effects of BoNT-A depending on the location of BoNT-A injections at each treatment session, and parents continued to learn about these effects as their child was developing. The ICF framework was used to categorize and describe these effects into five categories; Word clouds were generated for each ICF domain to highlight the key terms that were frequently mentioned by parents (Appendix H).

\section{Body Structures and Function}

All parents identified effects on body structures and functions. Parents described that certain muscle groups were targeted for BoNT-A injections due to their tightness, and the injections were helpful in reducing tone and increasing range of motion in these muscle areas. BoNT-A 
M.Sc. Thesis - L Nguyen; McMaster University - Rehabilitation Science

injections were often administered in the legs, but some children and adolescents also received injections in the arms. When BoNT-A injections were administered for the legs, parents identified that there was reduced tightness in the legs, which allowed their child to be able to walk more easily. A mother described how her son "had a lot of scissoring while he was walking, and that's much better now [after BoNT-A injections]. So I do think it helped with that, for sure" (Mother of a 10-year-old boy, GMFCS level IV). Parents also indicated that BoNT-A treatment had no effect on certain muscle areas. Every child reacted differently to BoNT-A treatment. When a child first received BoNT-A treatment, healthcare professionals and parents were trying injections on different muscle areas to understand whether BoNT-A would make a difference in muscle function. At follow-up appointments, parents had a discussion with healthcare professionals to make decisions about which muscle areas would be appropriate to target with subsequent BoNT-A treatment.

As children grew older, they communicated with their parents and healthcare professionals about the direct effects of BoNT-A treatment on their body.

"Now she can verbalize. Like 'Mom, I can't do this. I can't extend my leg, I can't put my leg down, I can't sit.' Like now it's different. When they're a baby, you're pushing them to see what they can do. But now, she has a good idea and she can communicate that onto me." (Mother of an 8-year-old girl, GMFCS level IV).

Therefore, parents were expecting BoNT-A treatment to have direct effects on body structures and function. Parents observed how BoNT-A treatment had an effect on their child's physical abilities, and recognized certain body limitations on which BoNT-A treatment did not have an effect. It was also important for children and adolescents to share their perspectives, because they could share their experiences and feelings about the direct effects of BoNT-A treatment on their body.

\section{Activity}

All parents described how the effects of BoNT-A treatment on body structures and function also led to effects on activity. Parents described two main types of activity: 1) activities related to caregiving; and 2) activities of daily living accomplished by the child.

Caregiving Activities. All parents identified that it was easier for them to care for their child after BoNT-A treatment, in which caregiving activities encompassed dressing, maintenance of personal hygiene, and transfers in position for their child. A mother explained "everything is just so much more easy for me" and further elaborated on the effect of BoNT-A treatment on "... just dressing. Just getting her arms, and with winter, into jackets and stuff like that. It's like night and day difference" (Mother of a 6-year-old girl, GMFCS level V).

However, parents of young children with $\mathrm{CP}$ required prompting to think about whether BoNT-A treatment made a difference on caregiving activities. Six parents responded to dichotomous questions about whether BoNT-A treatment had an effect on caregiving activities. Five of these parents had a child less than 8 years old, and one parent had a child who was 17 years old with cognitive impairments. After these prompting questions, parents thought about other possible effects that BoNT-A treatment could have on their children. Then, parents often 
M.Sc. Thesis - L Nguyen; McMaster University - Rehabilitation Science

responded with a 'yes' regarding changes observed, in which there was a positive difference after their child received BoNT-A treatment.

Activities of Daily Living. When young children initially received BoNT-A treatment, parents wanted to improve their child's movement abilities, such as sitting, standing, and walking. Parents provided opportunities for their child to develop and improve movement abilities with and without assistive equipment. A mother identified that it was meaningful to observe her child complete another developmental milestone similar to typically developing children.

"She's been receiving [BoNT-A treatment] for over five years. I would say that in the beginning it was for the tone... as she got older, it started allowing her to do things that she wasn't able to do. I would say long length sitting. So that was awesome to see... Botox allowed her to just sit. She can actually sit because that's actually a huge milestone in a baby's life. I think she was around maybe four before she could start doing that." (Mother of an 8-year-old girl, GMFCS level IV).

Two parents described that it was important for their child to be able to sit independently. In addition to the mother's observation of a developmental milestone, a father also indicated that it was meaningful for how BoNT-A treatment allowed his son to sit on the couch independently. He did not have to carry his son all the time, and it was more comfortable for his son to sit on the couch and interact with the family. Therefore, there were certain mobility activities that parents wanted their child to be able to achieve, such as sitting, standing, and walking, after BoNT-A treatment.

\section{Participation}

Parents of young children needed to initiate and encourage their child to participate in activities. After BoNT-A treatment, it was easier for children to complete activities, which led to increased participation at school and in the community. Parents often encouraged their child to participate in sports, such as swimming, horseback riding, dance, yoga, or other social activities in the community. When children grew older, they also voiced their perspectives on certain activities that they wanted to participate in based on their interests. The mother of a 17-year-old daughter described how they decided to try BoNT-A treatment after hip surgery because her daughter wanted to be able to ride a horse again.

"It was all around the hip surgery, that was kind of our downfall. She was in a lot of pain during the surgery and afterwards for a long time, like many years. And we couldn't get her back on her feet. But now, even the horseback riding, we can't do that anymore because she's just not able to sit on the horse. So now, we've got to get her back to whatever is possible again. Oh, she loves horses. It was a big thing for her." (Mother of a 17-year-old girl, GMFCS level IV).

BoNT-A treatment helped their child to engage in these activities in a more enjoyable manner by making the completion of these activities easier. When parents recognized that BoNT-A had an effect on their child's abilities to participate in certain activities, they began to schedule treatment sessions around the time that their child would be participating in these activities. 
M.Sc. Thesis - L Nguyen; McMaster University - Rehabilitation Science

Some parents also required prompting to consider how their child might participate in free play, such as during recess at school or at the park with friends. Children and adolescents might not participate in organized activities, but they might participate in informal activities, such as playing soccer at the park or socializing with friends.

\section{Environmental Factors}

Parents described how environmental factors played an important role in their experiences of BoNT-A treatment. In the context of this study, the child's environment is comprised of: 1) family culture; 2) community; and 3) equipment and resources.

Family Culture. Every family and child is unique with different experiences of BoNT-A treatment. Families have their own personal factors that might influence their expectations of BoNT-A treatment. All parents wanted their child to be comfortable, which subsequently allowed their child to be happy. Some parents indicated that BoNT-A was helpful for their child by alleviating pain and releasing muscle tension. However, some young children were nonverbal and may not have developed a communication system to interact with their parents yet. Parents could only judge whether their child was in discomfort or pain based on facial expressions. Getting to know their child, and being able to recognize the signs for when their child was in discomfort or in pain were the main personal factors that influenced whether parents continued with future BoNT-A treatment sessions.

Community. Parents observed how BoNT-A treatment produced positive changes in their child, which subsequently affected the family's lifestyle and engagement in the community. One father described the positive effects of BoNT-A treatment on his son, which allowed his family to participate more frequently in social outings.

"So we go out to a lot of places, like we never did before. For example, I think he got Botox six months the first time. He went to Florida a month after that. He sat down on an airplane seat very comfortably and with no problems, no issues or anything like that. [He] sits more comfortably in a wheelchair than he was before, and the car seat too." (Father of a 9-year-old boy, GMFCS level V)

Although most parents indicated that there were no changes in the family's lifestyle after BoNTA treatment, these parents were already participating in the community. BoNT-A treatment made it easier for two families to attend social outings by allowing their child to be more comfortable. Therefore, the child's level of participation was dependent on the family's preferences for participating in the community. Families continued to maintain their level of community involvement with their child, but BoNT-A treatment made it easier for families to participate.

Equipment and Resources. Some parents identified that the environment needed to be modified in order to accommodate for the needs of their child. BoNT-A treatment was helpful for improving their child's mobility, but other equipment further facilitated their child's mobility. A father described that his family liked to go bike riding: "We've got our bike. We've also [got] a larger bike that we use for [him] that's modified for children with special mobility issues. He enjoys riding his bike" (Father of a 4-year-old boy, GMFCS level IV). Parents described how 
M.Sc. Thesis - L Nguyen; McMaster University - Rehabilitation Science

their child participated in modified recreational activities, such as gym class or dance lessons. Therefore, BoNT-A treatment was helpful for improving the child's ability to complete activities, but changes to the environment were also needed to further facilitate children's engagement in activities.

\section{Personal Factors}

Personal factors are comprised of other information about the child's background, such as gender, race, age, and personality. All parents described that their child was happy, and how they wanted to do the best that they can to ensure their child's happiness in the future. However, parents did not specifically comment on the child's personal factors in the context of their experiences of BoNT-A treatment. Parents only commented on their own experiences of BoNTA treatment for their child, which would be considered as the family's personal factors. For example, parents described the factors of the family environment and effects on the family's lifestyle. Therefore, the personal factors about the family were described as a component of the family culture in the "environment" category of the ICF framework.

\section{Parents' Reflections on the Impact of BoNT-A Treatment}

Children and adolescents with CP received multiple BoNT-A injections throughout the year, and parents reflected on how the effects of BoNT-A treatment had an impact on both the child and family after each treatment session. Parents identified how BoNT-A treatment affected different aspects of their child, including body structures and function, activity, and participation. Parents' reflection of the impact of BoNT-A treatment involved how they applied their learning to decision-making, including their level of satisfaction and hopes at future treatment sessions.

Overall, parents felt satisfied that they continued to see positive effects after multiple BoNT-A treatment sessions. The effects of BoNT-A treatment may vary between sessions depending on the muscles that were targeted.

"I am satisfied. Sometimes the Botox does more one time around than it does in the next. And so, there are times where it works 'okay' and other times 'wow, that really made a difference.' So each time is different. So sometimes it's good and sometimes it's better than others. But it's so worth it." (Mother of an 8-year-old girl, GMFCS level IV).

After their child received multiple BoNT-A treatment sessions, parents hoped for the maintenance of the same effects and were not expecting to observe any new effects. As the child grew older, parents became accustomed to seeing the same direct effects and booked regular BoNT-A treatment sessions. Parents identified that the direct effects of BoNT-A treatment were necessary for the child to complete daily activities. Thus, regular clinical appointments for BoNT-A treatment became incorporated into the child's life.

Despite the positive effects of BoNT-A treatment that parents continually observed, parents identified that there were negative aspects in the administration of BoNT-A injections. There was no spectrum in the level of pain experienced by the child; parents identified that their child experienced anything from extreme pain to no pain at all from the needle injections. It was a trade-off for parents, in which they needed to identify whether the positive effects outweighed the negative effects. Parents had to consider whether it was worth having their child experience 
M.Sc. Thesis - L Nguyen; McMaster University - Rehabilitation Science

the pain involved with BoNT-A needle injections in order for their child to receive the positive BoNT-A effects.

"It is very traumatizing and painful initially, especially little kids when you can't explain to them what's happening. But it's over in an instant, and it's so worth it in the end. She's not really old enough to understand it's one trade-off for another." (Mother of a 6-yearold girl, GMFCS level V).

Another mother decided to have her daughter receive BoNT-A treatment through sedation instead. She heard from other parents' experiences about the pain that children might experience from BoNT-A injections, and she was not willing to have her child experience procedural pain. However, the mother described that her child needed BoNT-A treatment to improve the quality of life for both her child and family.

"[Before BoNT-A treatment]...I was so tired and so sleep deprived. I don't even remember so much of [her] smaller life because there's just crying. And she never slept. When she got Botox, I had no idea that it was going to help. If I had known that it was going to help her relax and sleep at night, and that she's gonna be able to feel better, I would have done that a long long time ago." (Mother of a 6-year-old girl, GMFCS level $I V)$.

Parents described their own unique process for identifying and making the best choice in whether to pursue BoNT-A treatment. They considered their own level of satisfaction with the observed effects of BoNT-A treatment as well as their child's emotions when deciding to pursue further BoNT-A treatment. Parents had to balance between the positive and negative effects of BoNT-A treatment, and to consider whether the trade-off for the positive effects was worth more for their child and family.

\section{Parents' Destination}

Parents have a destination that they would like their child to reach, which related to parents' overall hopes throughout the journey. These hopes can be achieved by working on the long-term goals of their child being independent and having a good quality of life. In order to reach the "long-term goals" or "destination", parents identified that long-term goals could be broken down into short-term goals. BoNT-A treatment was one treatment that may be helpful for children and adolescents with CP to accomplish short-term goals, and subsequently long-term goals over their developmental trajectory.

"Where we were in different times in our lives, it does make a difference. It seems like your general goals allows you to fulfill more long-term goals. Her being in her stander, her having relaxed muscles allows for better formation of her hip joints. I don't know what her long-term [goal] is going to be, but hopefully to have a comfortable outcome, not having to need surgery." (Mother of an 8-year-old girl, GMFCS level IV)

Parents shared their observations of their child's development and effects of BoNT-A treatment with healthcare professionals in order to identify appropriate goals. Parents' short-term goals for their child were related to the direct effects of BoNT-A treatment. For example, BoNT-A had a 
M.Sc. Thesis - L Nguyen; McMaster University - Rehabilitation Science

direct effect on the child's ability to increase range of motion and reduce tone, which may allow the child to stand and walk with assistive devices. The short-term goal of improving range of motion in the muscles was also related to the long-term goal of independence, as described by one mother.

"Our main goal for her hand is to be able to put her hand out so that she could get changed. So that when she's a teenager and she wants to go shopping... and get her changed. If you wanna go shopping as an adult, you need to be able to get [yourself] changed instead of being all fisted up against her chest, she needs to be able to actually extend her hand." (Mother of an 11-year-old girl, GMFCS level IV).

During the journey of raising their child with $\mathrm{CP}$, parents reflected on their learning experience. It was important for parents to connect with other parents, share their own journey, and learn from other parents' experiences. In the interviews, parents were asked about what kinds of information they would share with other parents. Most parents indicated that every child is unique, and that BoNT-A treatment should be considered as an option to explore to see if it is effective for their child: "You have to know your options and know one thing doesn't mean yes or no. And that you can always try something” (Mother of a 6-year-old girl, GMFCS level IV). Parents also indicated that they would inform parents about the painful aspect of BoNT-A needle injections. Despite these painful and negative aspects in the administration of BoNT-A treatment, the positive effects of BoNT-A treatment were beneficial for their child. Parents needed information and perspectives about BoNT-A treatment from different individuals, including healthcare professionals and parents. By connecting with multiple individuals, parents were informed in their decision about whether to continue pursuing BoNT-A treatment as the best option for their child.

\section{Member Checking}

Parents were asked to provide feedback about whether they agreed with the interpretation of the study findings and the use of the metaphor to describe their journey in the context of BoNT-A treatment. A summary of the study findings was sent to parents by mail and email (Appendix I). Parents were contacted up to three times by email and telephone. The response rate was limited with one response from one mother. The mother responded that she read the summary document and agreed with all of the findings: "When I was reading from the quotes, I'm thinking 'okay, did I say that one?' because even if I didn't say that one, I know that my thoughts and feelings were reflected in those quotes." (Mother of an 8-year-old girl, GMFCS level IV). The metaphor is a strategy that can be used to summarize the key message of parents' stories.

\section{Summary of Parents' Journey}

\section{Finding The Right Path To Do What Is Best For My Child}

As parents described, every child and family is unique. All parents hope that their child will be happy, and parents wanted to do the best that they could in raising their child. Parents had overall goals of promoting their child's independence and ensuring a good quality of life for both their child and family. BoNT-A treatment was one option that could help parents and their child to achieve these goals. However, parents were undergoing their own process of learning to better understand the specific effects of BoNT-A treatment for their child. It is important to describe how the effects of BoNT-A treatment might have an impact on all aspects of the child's life, as 
M.Sc. Thesis - L Nguyen; McMaster University - Rehabilitation Science

described by the ICF framework. After multiple treatment sessions, parents reflected on the direct effects of BoNT-A treatment for their child, and whether these effects also had an impact on the family's lifestyle. In some instances, parents indicated that the direct effects of BoNT-A treatment on their child facilitated changes in the family's behaviour, such as increasing the frequency of social outings and family engagement in the community. In other cases, parents identified expectations that they had for BoNT-A treatment. However, parents recognized that their child might not have the ability to achieve these goals or expectations based on their developmental stage. After each BoNT-A treatment session, parents needed to make decisions about whether to pursue further treatment by making trade-offs, and balancing the negative and positive effects of BoNT-A treatment.

Along parents' journeys and learning experiences of BoNT-A treatment, older children and adolescents also began to contribute their input into the decision-making process with their parents and healthcare professionals. Eventually, parents have a destination that they would like to reach, which relates to their long-term goals of their child's independence and good quality of life. In the current stage, parents wanted their child to achieve short-term goals with the help of BoNT-A treatment, which would allow their child eventually to attain long-term goals. The journey of finding the right path to do what is best for my child is an ongoing journey, and parents wanted to share their experiences of BoNT-A treatment with other parents. It was important for parents to hear not only from the perspectives of healthcare professionals, but also from other parents who are living the experience of raising a child with $\mathrm{CP}$. 
M.Sc. Thesis - L Nguyen; McMaster University - Rehabilitation Science

\section{CHAPTER 4 DISCUSSION}

This qualitative study aimed to identify the effects of BoNT-A treatment for children and adolescents with CP, GMFCS level IV or V, from parents' perspectives, and how these effects helped parents to identify goals for future BoNT-A treatment sessions. Parents not only identified the effects and goals of BoNT-A treatment, but an interpretation of parents' stories is the journey that parents experienced in "finding the right path to do what is best for my child". This chapter describes how the study findings relate to the current literature, and the information has been organized by the five sub-themes: 1) Parents' hopes; 2) Parents' goals for their child; 3) Parents learning what works; 4) Parents' reflections; and 5) Parents' destination.

\section{Parents' Hopes}

During their journey, parents identified that their hope was to make their child as happy as possible. Parents of young children often experience various emotions when they receive their child's diagnosis of CP. They may experience feelings of guilt, sorrow, and grief for the loss of their envisioned child $(1,2)$. Although parents are coping with these intense emotions, they also want to do their best in raising their child. Parents' hope for their child's happiness has been previously identified in the literature in which all parents want their child to live a happy and fulfilling life $(1,3,4)$. Morrow et al. (2007) conducted a study to assess parents' perceptions of quality of life in non-ambulatory children and adolescents with CP (3). In Morrow et al.'s study, parents described the love that they had for their child: "We're parents... we're going to look at it from 'This is my child, this is my world and we're going to do absolutely everything we possibly can to make their life as pleasurable and as comfortable as we possibly can', as every parent does. "Happiness can be described as the progression towards achieving personal goals, feeling of fulfillment, and enjoyment in daily activities (5). It is important to recognize that children and adolescents are happy when they are having fun and doing activities that are meaningful to them. Parents recognize that they play a role in making sure that their child is happy.

\section{Parents' Goals For Their Child}

In order to provide the best care for their child, parents have broad goals that they would like to achieve. They mainly want to promote independence for their child, and ensure a good quality of life for their child and family. Parents want these goals to be achieved by their child, but at the same time, they are also beginning to understand their child's condition of $\mathrm{CP}$ and identifying appropriate treatments with healthcare professionals. Often, parents of young children with disabilities require time to understand the different healthcare services and treatment for their child (6).

Parents also identified that improved quality of sleep was an effect of BoNT-A treatment that they had not expected to observe, but contributed to the family's quality of life. Two parents identified that BoNT-A treatment was helpful for their child to have a good quality of sleep. Parents believed that BoNT-A treatment reduced muscle tone, which allowed their child to sleep in a comfortable position without interruptions. Parents described that when BoNT-A treatment began to wear off, their child began to experience pain from muscle contractures, which disrupted their sleep, and subsequently their own quality of sleep. The theme of sleep benefits of 
BoNT-A treatment was also seen in a case study, in which a 13-year-old boy had hyperactive muscles that caused his arm to bend towards the back (7). He woke up 2-4 times each night, and his parents had to move him into a more comfortable position for sleep. After BoNT-A treatment, his arm was not bent towards the back and both he and his parents were able to sleep without interruptions. Children with CP often experience pain associated with muscle contractures and spasms, which can affect their quality of sleep and overall quality of life (8). In a prospective cohort study, parents rated that their child's pain was significantly reduced and $62 \%$ of parents reported that their child did not feel pain one month after BoNT-A injections (9). All parents want their child to be happy and comfortable. BoNT-A treatment can be administered to reduce pain, which could have an impact on the child's comfort level and quality of sleep.

\section{Parents Learning What Works}

\section{Body Structures and Function}

In this study, parents were often introduced to BoNT-A treatment by healthcare professionals to help manage spasticity for their child. It is also important to consider how BoNT-A treatment can have an impact on many aspects of the child's life according to the framework of the ICF (10). Children and adolescents with CP often receive multiple BoNT-A treatment sessions, and parents observed the effects of BoNT-A on their child after each session. All parents described that BoNT-A treatment had direct effects on body structures and function, such as improved range of motion in the muscles and reduced muscle tone. Parents also described that BoNT-A treatment had an impact on ease of caregiving, such as dressing, personal hygiene, and ease of transfers in position. A recent qualitative study published by Lorin and Forsberg (2016) also had similar findings based on parents' perceptions of the effects of BoNT-A treatment (11). Often, the main goals of BoNT-A treatment are focused on body structure and function, and activity $(12,13)$. In a retrospective study that reviewed 60 patient charts of children and adolescents ranging in age from 1 year 8 months to 16 years 7 months (median age of 9 years) with $\mathrm{CP}$ classified in GMFCS level IV or V, the majority of charts listed goals on improving range of motion (68\%), improve function of lower limbs (82\%), and improve care in dressing (38\%) (13). Therefore, parents identified that they hope BoNT-A treatment can help to improve body functions and structure as well as their child's ability to complete activities.

\section{Activity and Participation}

Parents also described the hope that they could take action to help their child to become happy. BoNT-A treatment was one option that gave parents hope because it could help promote their child's participation level. Parents indicated their child would still participate in hobbies and interests, regardless of whether they received BoNT-A treatment. However, BoNT-A treatment made it easier for the child to participate in a more comfortable and enjoyable manner. Parents in Lorin and Forsberg's (2016) study also described that the relaxation of muscles from BoNT-A treatment allowed their child to be in a more satisfied and a happier mood (11). Children and adolescents ultimately want to have fun by participating in activities.

Furthermore, there is a broad diversity in activities, including formal and informal activities in which children and adolescents with disabilities can engage (14). In this study, most parents identified that their child was participating in formal activities, such as sports or dance lessons. When prompted, parents also identified that their child loved to participate in social activities, such as community events or socializing with friends. According to the literature, children and 
adolescents with or without disabilities often participate in informal activities compared to formal activities (14-16). Some parents in this study identified that their child was not participating in formal activities such as sports lessons, but their child enjoyed recreational activities such as playing sports at the local park. Adolescents with CP in another qualitative study identified that they enjoyed participating in different activities, such as going to school, volunteering, part-time work, sports, or group activities (17). Participation activities were important to children and adolescents because they provided an opportunity for them to socialize with their peers. Therefore, children and adolescents may be participating in informal activities that are important in fostering social relationships with peers and families. Parents may require prompts and reminders to recognize how their child is participating in different types of activities.

Children and adolescents with CP may have difficulties participating in certain activities due to a combination of both physical abilities and environmental factors (18). They may be hindered at participation and socializing with their friends due to accessibility and cost of transportation (1719). Five parents in this study identified that they made environmental modifications to ensure that their child could participate in activities both at home and in the community. BoNT-A treatment was helpful by making it easier for their child to participate, but parents also required modifications to facilitate their child's participation. These modifications included the provision of equipment supports such as bicycles and power lifts, as well as adjustments to activities such as modified gym class. One of the main barriers identified in the literature is the accessibility of participation programs, and community-based programs may not be designed for children and adolescents with disabilities (20). Therefore, opportunities and resources should also be provided for children and adolescents with CP to ensure their optimal participation.

The level of participation of children and adolescents is dependent on the family's own preferences in participation. Some families were already actively involved in the community, and did not allow their child's physical abilities to affect their family's community engagement. The child's level of participation in the community was influenced by the preferences and lifestyle of the family. Similarly, Heah et al. (2007) identified that parents' preferences and values often influence their child's initial participation in activities, but ongoing engagement in these activities depended on the child's interests (20). Parents in this study identified that in order to maintain their levels of community participation it was easier for their family to be involved in the community when their child received BoNT-A treatment. For example, many families identified that it was easier to dress their child, which may facilitate opportunities for the family to be outdoors. BoNT-A treatment can be helpful in improving range of motion in the muscles (body structures and function) and ease of dressing (activity), which may result in enhanced engagement and participation for the child and family.

\section{Parents' Reflections}

Parents from this study were learning how BoNT-A treatment affects their child on an ongoing basis. Different muscles may be injected with BoNT-A based on a discussion between healthcare professionals, parents, and occasionally with the child. During these discussions in the BoNT-A clinic parents would also reflect and share their thoughts with healthcare professionals about the positive and negative effects of BoNT-A treatment. Parents identified that the positive effects of BoNT-A treatment were how it affected all aspects of the child's life based on the ICF 
framework, including body functions and structure, activity, and participation. Parents also identified that BoNT-A had positive effects on the family, such as ease of caregiving, community participation, and improved quality of sleep. Parents identified that a negative aspect of BoNT-A treatment was the needle injections. Some children and adolescents experienced severe pain and trauma from the injections, which affected their experiences in the clinical setting and interactions with healthcare professionals and parents. Lorin and Forsberg (2016) also reported that children and adolescents experienced anxiety visiting the clinic due to their fear of pain from the needle injections (11). Parents took into consideration whether it was beneficial to continue with BoNT-A injections due to their child's experience of pain. Parents had to make trade-offs, and often identified that the positive effects outweighed the negative effects of BoNT-A treatment.

\section{Parents' Destination}

Throughout parents' journey, they had the hope that they would reach a destination where their child would be happy. It is important for healthcare professionals to consider how parents identified short-term and long-term goals in order to reach a destination.

\section{Application to Healthcare Professionals and Goal-Setting}

In family-centred services, it is important that parents play a role in identifying goals during treatment with healthcare professionals. A key premise of family-centred services is that "parents know their children best and want the best for their children" (21). This study provides further evidence that parents are on a journey in finding the right path to do what is best for my child. Parents want to do the best that they can in raising their child, but it takes time for them to understand the different types of healthcare services and treatments that are appropriate for their child with CP.

Healthcare professionals should assess the family's perception of goal-setting and level of involvement. It is a journey of learning for parents on how to raise their child, and the different treatments and healthcare services for their child. Family-centred care should identify the context, process, and outcomes of interventions for families of children with disabilities (22). The context of children's lives is their family as well as their community environment (23). Family functioning and wellbeing will influence the child's health and wellbeing (23). This study provides further support for understanding the context of the child's life and family, by demonstrating the different stages of parents' journey in raising their child. It is an ongoing journey for parents to envision their child's future, learn how BoNT-A treatment affects their child, identify treatment goals that are important to the child and family, and reflect on whether BoNT-A treatment was beneficial

Collaborative goal-setting is a key component in family-centred services. Goal-setting is a process that involves a partnership between families and healthcare professionals $(22,24)$. Healthcare professionals should take the time to develop rapport and get to know the family, which could encourage parents to identify and share family goals $(23,25)$. The inclusion of parents in the goal-setting process enhances their feelings of competency, establishes rapport with healthcare professionals, and promotes family motivation in therapy (26-28). Since CP is a lifelong condition, families are working with healthcare professionals throughout the child's life and their role in the goal-setting process may change over time. The process of goal-setting 
begins with an interview with parents, in which parents share their story, including their child's interest and needs, family priorities, and the current performance of their child (25). This study identified that parents had a journey in raising their child. They wanted their child to be as happy as possible. Parents also had a destination that they want their child to reach, where they wanted their child to be independent to as great a degree as possible. They also recognized that their child's ability to complete short-term goals would be helpful in achieving the long-term goal of increasing independence for the child. A qualitative study conducted by Wiart et al. (2009) explored parents' experiences of goal setting for children and adolescents with CP (29). Parents in Wiart et al's study identified that they wanted their child to have a happy life (29). Parents' journey and hope for their child's happiness can be generalized across all children and adolescents with CP with different GMFCS levels. However, parents' specific goals towards achieving their broad goals of happiness and independence may vary depending on the child's abilities. It is also important for healthcare professionals to consider the family's priorities and environment in addition to the child's abilities when setting goals (30).

Goal-setting tools, such as the COPM, GAS, and PEGS are helpful to identify and monitor the progress in achievement of these goals over a period of time (31-33). The performance and satisfaction with the achievement of goals can be measured using the COPM (31). Goals written using the COPM are focused on different aspects of the child's life in the domains of self-care, productivity, and leisure (31). GAS is another goal-setting tool that can be used to measure the attainment of goals (32). Goals identified with the GAS should be written according to the SMART criteria, in which they should be specific, measurable, attainable, relevant, and timespecific $(34,35)$. The parent PEGS questionnaire can also be used to identify and prioritize goals during treatment intervention. Goal-setting tools are helpful in encouraging parents to identify goals with healthcare professionals, observe treatment effects, and reflect on whether treatment was beneficial for their child.

During the goal-setting process, parents should be provided with the opportunity to decide their level of involvement (21). Parents' level of readiness to set different types of goals may differ depending on the age of the child (1). Parents of young children with CP require information from healthcare professionals about their child's condition, rehabilitation therapies, and treatment services $(21,36)$. Findings from this study can be helpful for healthcare professionals in providing additional information about parents' experiences of BoNT-A treatment. A summary of parents' journey was described, including parents' learning experiences of the effects of BoNT-A treatment. These effects were potential goals that parents had with future BoNT-A treatment sessions, and were classified according to the ICF framework (10). Parents described that they would share these effects and future goals as recommendations for other parents who are considering BoNT-A treatment for their child.

\section{Informational Resources}

In a previous study conducted in 2014, the inventory list of goals was developed and refined with input from parents of children and adolescents with CP and healthcare professionals (Appendix B) (37). The inventory was structured according to the ICF categories of body structures and function, activity, and participation. The inventory can be helpful for parents to consider different types of goals for BoNT-A treatment that they could discuss with healthcare professionals. 
This study produced another resource in the form of a summary of parents' journeys. Parents may want to hear about other parents' experiences of BoNT-A treatment. A systematic review of qualitative and quantitative studies evaluated parent-to-parent support in families of children and adolescents with chronic conditions, including cerebral palsy (38). Parents identified that they wanted to learn from the experiences of other parents, which provided reassurance and confidence for parents who were still learning about how to raise their young child. Parents who were mentors wanted to share about their own journey, and provide a positive outlook of the child's future for other parents (38). One approach to support parents is the use of informational resources, such as pamphlets, that share parents' perspectives (39). These informational resources that share parents' stories can help other parents by providing hope for the child's future, empower parents to take action, and connect parents to other resources (39).

Healthcare professionals can provide these two informational resources in the context of BoNTA treatment for parents: 1) the inventory list of goals that was previously developed (See Appendix B); and 2) summary of parents' journeys from this study. Both of these resources can help parents to understand the types of goals that could be worked with their child, and the goals that other parents had during BoNT-A treatment. In addition to the use of these informational resources, healthcare professionals can use goal-setting tools to identify and track the child's progress towards achieving these goals. Therefore, collaborative goal-setting between families and healthcare professionals can be further facilitated by the use of informational resources and goal-setting tools that have been informed by parents' perspectives.

\section{Limitations}

A limitation of this study is that only parents, but not young people, were interviewed, which allowed their perspectives to be summarized. It is also important to consider how children and adolescents can also have a role in the goal-setting process. Parents can provide information about of the child's life from their perspective, but the children and adolescents themselves should also have a voice in sharing information. This study focused on the parents' journeys, but children and adolescents may have their own journeys during BoNT-A treatment. Children and adolescents who participated in this study ranged from 5 to 17 years old, and $67 \%$ of them were identified by healthcare professionals in the clinic to have cognitive impairments. Augmentative and alternative communication methods should be considered to engage children and adolescents about their experiences of BoNT-A treatment and the identification of goals $(40,41)$. Children and adolescents with CP may have different goals from their parents; children and adolescents often focus on goals on leisure and schoolwork, while parents focus on activities of daily living such as getting dressed or toileting (42-44). Children and adolescents with CP have also been found to achieve their self-identified goals to the same extent as parent-identified goals (42). Future work is required to better understand the perspectives of children and adolescents with $\mathrm{CP}$ during BoNT-A treatment.

In addition, healthcare professionals should be provided with the opportunity to share their perspectives about the informational resources. Healthcare professionals, including physicians, occupational therapists, and physiotherapists play a role in facilitating the goal-setting discussion with parents $(21,24)$. They may also have feedback and comments about the informational resources from this study, and how these can be used as tools during the goal-setting discussion. 
M.Sc. Thesis - L Nguyen; McMaster University - Rehabilitation Science

The findings of this study will be shared with the healthcare professionals who work in the Spasticity Management Clinic in order to seek their perspectives and ideas for how best to move these processes forward.

Another limitation is that participants were recruited only from the Spasticity Management Clinic at McMaster Children's Hospital, and the results may not be generalizable outside of this context for other clinics administering BoNT-A treatment where service provision processes might be different. This qualitative study aimed to assess in-depth parents' experiences and observed effects of BoNT-A treatment attending this unique clinic. Parents attending other spasticity management may have different experiences of BoNT-A treatment and goal-setting process with healthcare professionals. Future studies can be conducted to assess whether parents attending different clinics had similar experiences of BoNT-A treatment to parents from this study. 
M.Sc. Thesis - L Nguyen; McMaster University - Rehabilitation Science

\section{References}

1. Piggot J, Paterson J, Hocking C. Participation in Home Therapy Programs for Children with Cerebral Palsy: A Compelling Challenge. Qual Health Res. 2002;12(8):1112-29.

2. Schuengel C. Parents' reactions to the diagnosis of cerebral palsy: associations between resolution, age and severity of disability. Child Care Health Dev. 2009;35(5).

3. Morrow AM, Quine S, Loughlin EVO, Craig JC. Different priorities: a comparison of parents' and health professionals' perceptions of quality of life in quadriplegic cerebral palsy. Arch Dis Child. 2008;93(2):119-25.

4. Shevell A. Doing the "Talk": Disclosure of a Diagnosis of Cerebral Palsy. J Child Neurol 2013;28(2).

5. King GA, Cathers T, Polgar JM, MacKinnon E, Havens L. Success in Life for Older Adolescents with Cerebral Palsy. Qual Health Res. 2000;10(6):734-49.

6. Piggot J, Paterson J. Parental Adjustment to Having a Child with Cerebral Palsy and Participation in Home Therapy Programs. Phys Occup Ther Pediatr 2003; 23(4):5-29.

7. Mall V, Heinen F, Linder M, Philipsen A, Korinthenberg R. Treatment of cerebral palsy with botulinum toxin A: Functional benefit and reduction of disability. Three case reports. Pediatr Rehabil.1997;1(4):235-7.

8. McKearnan KA, Kieckhefer GM, Engel JM, Jensen MP, Labyak S. Pain in children with cerebral palsy: a review. J Neurosci Nurs. 2004;36(5):252-60.

9. Rivard PF, Nugent AC, Symons FJ. Parent-proxy Ratings of Pain Before and After Botulinum Toxin Type A Treatment for Children With Spasticity and Cerebral Palsy. Clin J Pain. 2009;25(5):413-7.

10. World Health Organization. International Classification of Functioning, Disability and Health (ICF). Geneva, Switzerland: World Health Organization; 2001.

11. Lorin K, Forsberg A. Treatment with botulinum toxin in children with cerebral palsy: a qualitative study of parents' experiences. Child Care Health Dev 2016;42(4):494-503.

12. Wright FV, Rosenbaum PL, Goldsmith CH, Law M, Fehlings DL. How do changes in body functions and structures, activity, and participation relate in children with cerebral palsy? Dev Med Child Neurol. 2008;50(4):283-9.

13. Mesterman R, Gorter JW, Harvey A, Lockhart J, McEwen-Hill J, Margallo K, et al. Botulinum Toxin Type A in Children and Adolescents With Severe Cerebral Palsy: A Retrospective Chart Review. J Child Neurol. 2014;29(2):210-3.

14. Law M, King G, King S, Kertoy M, Hurley P, Rosenbaum P, et al. Patterns of participation in recreational and leisure activities among children with complex physical disabilities. Dev Med Child Neurol. 2006;48(5):337-42.

15. Imms C. Children with cerebral palsy participate: A review of the literature. Disabil Rehabil. 2008;30(24):1867-84.

16. Shikako-Thomas K, Majnemer A, Law M, Lach L. Determinants of participation in leisure activities in children and youth with cerebral palsy: systematic review. Phys Occup Ther Pediatr. 2008;28(2):155-69.

17. Stewart DA, Lawless JJ, Shimmell LJ, Palisano RJ, Freeman M, Rosenbaum PL, et al. Social Participation of Adolescents with Cerebral Palsy: Trade-offs and Choices. Phys Occup Ther Pediatr. 2012;32(2):167-79.

18. Hewitt-Taylor J. Parents' views of their children who have complex health needs. Paediatr Nurs. 2008;20(8):20-4. 
M.Sc. Thesis - L Nguyen; McMaster University - Rehabilitation Science

19. Lauruschkus K. Parents' experiences of participation in physical activities for children with cerebral palsy-protecting and pushing towards independence. 2017;39(8):1-8.

20. Heah T, Case T, McGuire B, Law M. Successful Participation: The Lived Experience among Children with Disabilities. Can J Occup Ther. 2007;74(1):38-47.

21. Rosenbaum P, King S, Law M, King G, Evans J. Family-Centred Service. Phys Occup Ther Pediatr.1998;18(1):1-20.

22. Arango P. Family-Centered Care. Academic Pediatrics. 2011;11:97-99.

23. Rosenbaum P. Family and quality of life: key elements in intervention in children with cerebral palsy. Dev Med Child Neurol. 2011;53(S4):68-70.

24. Kruijsen-Terpstra AJ, Ketelaar M, Boeije H, Jongmans MJ, Gorter JW, Verheijden J, Lindeman E, Verschuren O. Parents' experiences with physical and occupational therapy for their young child with cerebral palsy: a mixed studies review. Child Care Health Dev. 2014;40(6):787-96.

25. An M, Palisano RJ. Family-professional collaboration in pediatric rehabilitation: a practice model. Disabil Rehabil. 2014;36(5):434-40.

26. Øien I, Fallang B, Østensjø S. Goal-setting in paediatric rehabilitation: perceptions of parents and professional. Child Care Health Dev. 2010;36(4):558-65.

27. Bamm EL, Rosenbaum P. Family-centered theory: origins, development, barriers, and supports to implementation in rehabilitation medicine. Arch Phys Med Rehabil. 2008;89(8):1618-24.

28. Law M, Hanna S, King G, Hurley P, King S, Kertoy M, et al. Factors affecting familycentred service delivery for children with disabilities. Child Care Health Dev. 2003;29(5):357-66.

29. Wiart L, Ray L, Darrah J, Magill-evans J. Parents ' perspectives on occupational therapy and physical therapy goals for children with cerebral palsy. 2010;32(3):248-58.

30. Löwing K, Bexelius A, Brogren Carlberg E. Activity focused and goal directed therapy for children with cerebral palsy--do goals make a difference? Disabil Rehabil. 2009;31(22):1808-16.

31. Law M, Baptiste S, McColl M, Opzoomer a, Polatajko H, Pollock N. The Canadian occupational performance measure: an outcome measure for occupational therapy. Can $\mathrm{J}$ Occup Ther. 1990;57(2):82-7.

32. Kiresuk TJ, Sherman RE. Goal attainment scaling: A general method for evaluating comprehensive community mental health programs. Community Ment Health J. 1968;4(6):443-53.

33. Missiuna C, Pollock N, Law M, Walter S, Cavey N. Examination of the Perceived Efficacy and Goal Setting System (PEGS) With Children With Disabilities, Their Parents, and Teachers. Am J Occup Ther. American Occupational Therapy Association; 2006;60(2):204-14.

34. Krasny-Pacini A, Pauly F, Hiebel J, Godon S, Isner-Horobeti M-E, Chevignard M. Feasibility of a shorter Goal Attainment Scaling method for a pediatric spasticity clinic The 3-milestones GAS. Ann Phys Rehabil Med. 2017.

35. Bovend'Eerdt TJ, Botell RE, Wade DT. Writing SMART rehabilitation goals and achieving goal attainment scaling: a practical guide. Clin Rehabil. 2009;23(4):352-61.

36. Siebes RC, Ketelaar M, Gorter JW, Alsem M, Jongmans MJ. Needs of Families with Children Who Have a Physical Disability: A Literature Review. 2012;24:85-108. 
M.Sc. Thesis - L Nguyen; McMaster University - Rehabilitation Science

37. Nguyen L, Mesterman R, Gorter JW. Development of an inventory of goals using the International Classification of Functioning, Disability and Health in a population of nonambulatory children and adolescents with cerebral palsy treated with botulinum toxin A. Unpublished thesis type [manuscript in submission]. McMaster University; 2015.

38. Shilling V, Morris C, Thompson-Coon J, Ukoumunne O, Rogers M, Logan S. Peer support for parents of children with chronic disabling conditions: a systematic review of quantitative and qualitative studies. Dev Med Child Neurol. 2013;55(7):602-9.

39. Morison JE, Bromfield LM, Cameron HJ. A Therapeutic Model for Supporting Families of Children with a Chronic Illness or Disability. Child Adolesc Ment Health. 2003;8(3):125-30.

40. Clarke M, Price K, Griffiths T. Augmentative and alternative communication for children with cerebral palsy. Paediatr Child Health. 2016;26(9):373-7.

41. Cockerill H, Elbourne D, Allen E, Scrutton D, Will E, McNee A, et al. Speech, communication and use of augmentative communication in young people with cerebral palsy: The SH\&PE population study. Child Care Health Dev. 2014;40(2):149-57.

42. Vroland-Nordstrand K, Eliasson A-C, Jacobsson H, Johansson U, Krumlinde-Sundholm L. Can children identify and achieve goals for intervention? A randomized trial comparing two goal-setting approaches. Dev Med Child Neurol. 2015.

43. Costa UM, Brauchle G, Kennedy-Behr A. Collaborative goal setting with and for children as part of therapeutic intervention. Disabil Rehabil. 2016:1-12.

44. Brandão MB, Oliveira RHS, Mancini MC, Brandão MB, Oliveira RHS, Mancini MC. Functional priorities reported by parents of children with cerebral palsy: contribution to the pediatric rehabilitation process. Brazilian J Phys Ther. 2014;18(6):563-71. 
M.Sc. Thesis - L Nguyen; McMaster University - Rehabilitation Science

\section{CHAPTER 5 REFLECTION}

This chapter offers reflections on my journey as a qualitative researcher to better understand the perspectives of parents of children with $\mathrm{CP}$ and their experiences with BoNT-A treatment for their child. Similar to the parents' journey in learning about BoNT-A treatment, I experienced my own journey in learning about the role of qualitative research in healthcare. My journey can be structured as involving five stages parallel to the five stages of parents' journey: 1) research background and hopes; 2) research goals; 3 ) research process; 4) reflections on strengths and challenges; and 5) destination and future directions (Appendix J). My reflection and experiences may help healthcare professionals understand the importance of engaging in qualitative research with families.

\section{Research Background and Hopes}

This study aimed to understand parents' perspectives during BoNT-A treatment for their child. I wanted to better understand and capture the main message that parents wanted to share about their experiences of BoNT-A treatment. During a clinical appointment, parents may not be provided with the opportunity to share their whole story with healthcare professionals due to a busy clinic and time restrictions. I recognize that parents have their own story to share about their process of identifying goals and making decisions for BoNT-A treatment. A qualitative study design would be appropriate to better understand parents' perspectives and experiences in the context of BoNT-A treatment. Qualitative studies allow researchers to understand the motivations, beliefs, and values of individuals, such as patients and families. Denzin and Lincoln (2005) describe qualitative research as the "attempt to make sense of, or interpret, phenomena in terms of the meanings people bring to them" (1).

In my previous work as an undergraduate student in the Bachelor of Health Sciences (Honours) Program, I conducted my honours thesis project with Dr. Ronit Mesterman (pediatric neurologist) and Dr. Jan Willem Gorter (pediatric physiatrist) in 2014 (2). We conducted a crosssectional observational study to develop an inventory list of goals in the context of BoNT-A treatment. We asked parents of children and adolescents with CP, classified in GMFCS level IV or V, to select goals that they would like their child to accomplish after BoNT-A treatment. Parents often selected goals related to the ICF categories of body structure and function, such as reduced tone and increased range of motion, as well as activity related to ease of caregiving (2). For this study, I wanted to understand parents' reasons for the importance of these goals and parents' process in identifying goals with healthcare professionals. Therefore, a qualitative study design would allow me to interview parents and ask them to share their experiences of goalsetting in the context of BoNT-A treatment.

There have been many qualitative studies conducted in the field of pediatric rehabilitation. It is important to understand the perspectives of children and adolescents with disabilities, as well as their families, in order to recognize how they view their disability (3). By understanding their perspectives, healthcare professionals can tailor therapy services and treatment to meet the needs of families. Qualitative studies provide an opportunity for families to have ongoing discussions with healthcare professionals and researchers about their preferences, values, and needs (3). My 
M.Sc. Thesis - L Nguyen; McMaster University - Rehabilitation Science

research interest was on understanding how families' needs and goals may change over time, and how these goals are meaningful in the context of healthcare treatment, such as BoNT-A treatment.

Three primary qualitative approaches have been commonly used in research, which include:

1. Phenomenology, to describe the lived experience of individuals in the field of philosophy;

2. Grounded theory, to develop a theory from individuals' viewpoints in the field of sociology;

3. Ethnography, to describe and interpret the shared patterns of a culture or group in the field of anthropology (4)

Each of these qualitative approaches has a methodological framework. In the field of healthcare, researchers have different study objectives that might not align with a specific approach. Despite this challenge, researchers might still identify that their study followed one of the three qualitative approaches to ensure rigor. Their study would then proceed with different methodologies despite claiming to have followed a specific qualitative approach. This lack of congruence between a qualitative approach and methodology has been referred to as "method slurring" or "sloppy research" $(5,6)$.

Interpretive description (ID) was developed in the field of nursing to address the challenge of conducting clinical research with objectives that did not align with the primary qualitative approaches (i.e. phenomenology, grounded theory, ethnography) (7). ID provides an opportunity for researchers to investigate a clinical phenomenon (7). In this study, I investigated the phenomenon of how parents experienced BoNT-A treatment for their child with CP. During data analysis, parents' experiences were described based on the content of the information that they shared with us. Parents' experiences were then interpreted to convey a message, and this information can be useful in clinical practice. ID also provides flexibility in the use of different analytic methods, which can be borrowed from other 'standard' qualitative approaches including phenomenology, ethnography, and grounded theory (8). Since there is no single methodological guideline for ID, researchers can use analytic approaches that will best capture parents' experiences of BoNT-A treatment.

My hope, which could be considered as the study hypothesis, is to describe parents' experiences of BoNT-A treatment, and in so doing, be able to identify how these experiences shaped parents' goals for future treatment sessions.

\section{Research Goals}

The objectives or "goals" of our research study were to identify parent-reported effects of BoNTA treatment in children and adolescents with CP in GMFCS level IV or V and to categorize these effects according to the ICF framework in the following domains: body structures and function, activity, participation, environment factors, and personal factors. These findings will be used to refine and inform the inventory of goals in the context of BoNT- treatment. 
Our study aimed to address the following research questions:

1. In what ways, if any, does BoNT-A treatment make a difference to children and adolescents with CP in GMFCS level IV or V, based on the parents' perspectives?

2. In what ways, if any, does BoNT-A treatment make a difference to parents of children and adolescents with CP, in GMFCS level IV or V?

I defined these study objectives before conducting interviews with parents, but I also recognized that there might be other information that parents can share during the interviews. While conducting the interviews, I also wanted to remember how I could best capture parents' stories. I began the study with the research objective to identify the effects of BoNT-A treatment that parents observed in their child and family. However, parents shared additional information beyond the effects of BoNT-A treatment. Parents described their journey in learning and "finding the right path to do what is best for my child". In their journey, I recognized how parents needed to learn about the effects of BoNT-A treatment, and whether these effects were appropriate and necessary for their child. I also understood that parents' overall journey was also comprised of their hopes, goals, learning, reflections, and destination. I wanted to listen and convey parents' messages about their journey. During the research process, I experienced my own journey in learning about qualitative research and ID methodology in the context of this study in parallel to parents' journey.

\section{Research Process}

During the research process, I learned and reflected on the qualitative methodological strategies that I would use to ensure rigour in the study. While designing the study, I wanted to ensure that I could convey parents' stories that were supported by parents' quotes. I identified the paradigmatic and philosophical assumptions that would guide the research process. ID is aligned with a constructivist paradigm, in which there are multiple realities based on an individual's perspective. An understanding of the phenomenon is co-constructed by the researcher and individual, and each individual will have a different perception (9). Therefore, the researcher and individual cannot be considered as independent entities because they will influence each other during data collection. During the interviews, I recognized that I would develop a relationship with parents, and this relationship would influence the information that would emerge from the interviews.

Table 1. A description of the four philosophical assumptions associated with a constructivist paradigm. Adapted from Creswell \& Poth (2017) (10).

\begin{tabular}{|l|l|l|}
\hline Assumption & Description & Characteristics \\
\hline Ontology & The nature of reality & There are multiple views of reality \\
\hline Epistemology & $\begin{array}{l}\text { The identification and } \\
\text { justification of knowledge }\end{array}$ & $\begin{array}{l}\text { Knowledge and information are } \\
\text { gathered from participants. }\end{array}$ \\
\hline Axiology & The role of values & $\begin{array}{l}\text { The researcher recognizes their } \\
\text { biases, and acknowledges their role } \\
\text { in the study. }\end{array}$ \\
\hline Methodology & $\begin{array}{l}\text { The process of conducting } \\
\text { research }\end{array}$ & $\begin{array}{l}\text { Research findings are obtained using } \\
\text { an inductive process, grounded in the } \\
\text { study context, and emerged from } \\
\text { data sources (i.e. participants). }\end{array}$ \\
\hline
\end{tabular}


In addition, I used clinical expertise as an appropriate starting point to begin the research process and design the study, so as to provide background information to the research study $(8,11,12)$. In this study, clinical knowledge was helpful in orienting the research study design by outlining the goals and outcomes. I consulted research team members and healthcare professionals to ask about their perspectives throughout the research process. This process is known as peer debriefing, and meetings were held to discuss the study design, analysis of transcripts, and interpretation of findings. Although I was interviewing parents, I also wanted to understand different perspectives, including those of clinicians and healthcare professionals, about the analysis of my findings. I also encouraged parents to participate in the study on an ongoing basis by sharing a summary of preliminary results (Appendix I). They were asked to provide feedback and comments for these preliminary results and whether they agreed with the interpretation of our findings.

\section{Reflections on Strengths and Challenges}

There were strengths and challenges experienced throughout the process of conducting this study, as illustrated in Appendix K.

\section{Strengths}

The overall strength of the study was the use of reflexive memos to identify how my role as a qualitative researcher affected my interactions with parents during interviews as well as the development of my ability to understand parents' perspectives. These reflexive memos also allowed me to document how my lens in viewing and analyzing the data changed over time throughout the study.

\section{Evolving Lens}

Reflexivity provides an opportunity for researchers to become aware of their physical, social, and cultural position in their researcher role, their influence on the research, and the decisions that they make in the research (13). Other qualitative approaches, such as phenomenology, would use "bracketing" in which researchers would set aside any preconceptions, experiences, or knowledge that they had prior to conducting the study (14). In contrast, ID acknowledges the researcher's role and prior knowledge when entering into the study. I conducted a previous study in 2014 to develop an inventory list of goals in the context of BoNT-A treatment. This study was building on my previous to work to understand parents' perspectives and experiences for the reasons on selecting goals and the effects they observed in their child after BoNT-A treatment. The use of an ID methodology allowed me to recognize my research position and background knowledge before designing the study (15).

I acknowledged my role as a researcher by using reflexive memos throughout the research process. These memos allowed me to document my thoughts and perspectives, and how they might change over time. There are different styles for writing reflexive memos, but researchers have been encouraged to ask themselves three key questions in their memos: 1) what is interesting; 2) why is it interesting; and 3) why am I interested in that? These questions helped me to focus on why a key piece of information was meaningful in the data $(13,16)$. In my reflexive memos, I identified my academic background as a student in the Masters in Rehabilitation Science. Although I did not have a clinical background as a healthcare professional, I recognized that it was important to develop rapport with parents. I introduced 
myself as a student researcher to parents, and I wanted to listen to and understand parents' stories and experience of BoNT-A treatment for their child for this study. I began the interview with a question of: "Tell me about your child", which sets the stage for parents to describe their child (17). I also reflected and wrote about how I wanted to encourage parents to share how BoNT-A impacted the child beyond their physical health outcomes, such as whether the child was engaged in activities and participation. In my subsequent interviews, I noticed a pattern of how all parents indicated that their child was happy. My lens began to change and I asked parents about their child's happiness and school activities. These questions encouraged parents to share details about their child's favourite hobbies and enjoyment of activities at school, and whether and how BoNT-A treatment could facilitate their child's engagement in these activities.

\section{Understanding Parents' Perspectives}

Through reflexive memos, I understood that every parent's story is unique and their perspective about the impact of BoNT-A treatment will vary. Specifically, all parents said that they would recommend BoNT-A treatment for families of children with CP similar to their own child, but every child is unique. Parents identified that each child will respond and behave individually with BoNT-A treatment. Another strength in the use of ID for this study is the acknowledgement of the variations and patterns in parents' stories (18). ID allowed me to recognize that there are two components for analyzing parents' stories: 1) a pure description of parents' experiences, such as the direct effects of BoNT-A treatment and differences in the child and family; and 2) an interpretive lens to understand the depth and details of parents' stories (18).

The interpretation piece of parents' stories was important for me because I wanted to convey this study's findings into a format that will be meaningful for healthcare professionals and families in a clinical setting. Metaphors can be a powerful analytic strategy to describe an important idea and convey an overall message that resonates with the audience (19). Every parent's journey is unique and they will have to create their own "path". This path is comprised of different stages because parents are learning how to raise their child. Based on parents' descriptions and recommendations of BoNT-A treatment, I wanted to convey the key message of this study. This was when I created the metaphor of: "Finding the right path to do what is best for my child." All parents identified that they were doing the best that they can to raise their child and family. There were several individuals who were contacted for feedback about the interpretation of this metaphor including healthcare professionals and parents. I hope that this metaphor will be helpful to translate the main message of the study findings in clinical practice to both families and healthcare professionals.

\section{Challenges}

We experienced challenges in the use of ID during data analysis, because it is a relatively new methodology and there are no specific guidelines for analyzing and interpreting the findings. ID provides a framework to use and document strategies that originated from other qualitative approaches (20). There was an overarching theme of parents needing to "find the right path to do what is best for my child", and parents' journey is comprised of five stages. While following an analytic process to identify each stage of parents' journey, I experienced specific challenges at each stage. These challenges stemmed from the use of an ID methodology to both describe and interpret parents' stories. I used a "zoom in" lens to describe each parents" experiences and a "zoom out" lenses to describe all parents' experiences. 
M.Sc. Thesis - L Nguyen; McMaster University - Rehabilitation Science

\section{Parents' Hopes}

I initially "zoomed out" of parents' interviews to understand what all parents were describing about their experience of BoNT-A treatment. Word frequency and word clouds were generated from all parent interviews, which allowed me to understand parents' main message about their experience of their child's BoNT-A treatment. I recognized that all parents wanted to make their child as happy as possible based on the frequency that the term "happy" was mentioned by parents and the appearance of "happy" in word clouds. The challenge of using a "zoom out" approach to describe all parents' experiences is in defining the term "happy" that would resonate with all parents. I realized that the factors that contribute to a child's happiness will be different for every child, but consistently parents hoped that they could make their child happy.

\section{Parents' Goals}

The challenge of using a "zoom in" lenses was the variations in each parents' description of their goals. Parents described their broad goals of: 1) independence for their child; and 2) good quality of life for both the child and family. However, parents described these goals using different terms and did not explicitly state that they wanted their child to be "independent" or "have a good quality of life". For example, parents were identifying goals related to their child's independence when they said that they wanted their child to be able to complete tasks by themselves with little assistance. Some parents considered the possibility of their child living alone in the future. Parents also identified goals related to how BoNT-A treatment could help their child to have a good quality of life, such as their child's ability to participate in activities including sports and horseback riding. I wrote reflexive memos after each interview to summarize the main messages. These reflexive memos were helpful to recognize the general elements of how parents defined the terms of independence and good quality of life.

\section{Parents Learning What Works}

The challenge of using a "zoom in" approach to describe each parent's experiences of BoNT-A treatment was the application of a coding framework during data analysis. An abductive coding process was applied, in which interviews were initially coded using the domains of the ICF framework. However, it was also important to recognize how BoNT-A treatment had an impact on both the child and family, and that families were experiencing their own process to learn about the effects of BoNT-A treatment. The ICF framework was helpful as a starting point to begin analyzing parent interviews, but the element of parents' process to learn about BoNT-A treatment was missing from the ICF framework. Parents' processes of learning were included as an additional code in the coding framework, defined as parents' reflection of their experience in understanding the challenges of BoNT-A treatment for their child. The challenge was the refinement of the coding framework, because I recognized that the domains of the ICF framework would not encompass all aspects of parents' journey. I read each parent's interview individually, but I also had to consider the overall findings from all interviews in order to incorporate the aspect of parents' process of learning as an additional code in the coding framework. Therefore, the abductive coding process was needed to understand parents' journey and how parents' goals might change over time based on their experience of BoNT-A treatment.

\section{Parents' Reflections}

After BoNT-A treatment for their child, parents needed time to reflect on the direct effects of BoNT-A treatment on the child. The challenge of a "zoom out" lens was the need to consider 
how the overall message of parents' experiences of BoNT-A treatment could be conveyed. I consider how a metaphor could resonate with different individuals, including families and healthcare professionals. A metaphor was a helpful analytic strategy to describe parents' journey of "finding the right path to do what is best for my child." This metaphor was shared with multiple individuals, including healthcare professionals (i.e. physicians, occupational therapists) during research team meetings.

In addition to the different lenses that I employed to analyze the study findings, a challenge with all qualitative approaches is the engagement of participants during member checking. I conducted member checking to seek feedback from parents about whether they agreed with the interpretation of our findings and the use of the metaphor. I used different methods to contact parents, including mail, emails, and telephone. A summary of preliminary findings, including the metaphor, was sent to parents by mail and email (Appendix I). One mother responded that she read the summary document and agreed with all of the findings. She described that she was not able to identify which quote from the summary document was from her interview, because she connected with all of the quotes to her own story. After consulting with multiple individuals, such as healthcare professionals and a parent, I recognized that the metaphor is a helpful tool to summarize the key message of the study, in which all parents will have their own unique experience of BoNT-A treatment for their child.

My challenge with member checking also allowed me to recognize that it could be difficult to engage in research with parents of children and adolescents with disabilities. It is important to provide opportunities for families to contribute to the research process, and share their perspectives in the interpretation and application of study findings. Parents should also be asked about their level of involvement, which may change throughout the course of the study. Further research is required to understand the appropriate methods to best engage patients and families in research (21). There are different methods to facilitate the process of family engagement, including asking families for feedback, data analysis, and interpretation of findings $(22,23)$. An opportunity can be provided for parents to analyze data together with researchers, because they can share their perspective of being a parent with the lived experience of raising a child with CP (24). When parents contribute their perspectives during data analysis, the data can also be applicable and relevant to other parents with similar experiences. Parents want to be able to connect with each other, and have identified that they would trust the perspectives of other parents. Other methods for engaging with parents throughout the research process include planning meetings, contributing to workshops and presentations, and posting on social media (e.g. Twitter, Facebook) (22). Our challenge with member checking was a learning opportunity to recognize the different methods of promoting family engagement in future research.

\section{Parents' Destination}

The challenge of using a "zoom out" lens was identifying the destination that was common to all parents and where they wanted to reach at the end of their journey. Throughout the process of writing reflexive memos, I identified that parents had a destination that they wanted their child to reach. Parents identified that they had short-term and long-term goals based on the effects of BoNT-A treatment that they observed. Although parents may have different goals depending on the child and family, parents recognized that the achievement of short-term goals would help 
their child to work towards long-term goals and eventually allow their child to reach a "destination".

The overall personal challenge was using reflexive memos to identify the different stages of parents' journey. At different stages of parents' journey, I referred to reflexive memos to identify certain elements, such as the coding process, formulation of a metaphor, and identification of parents' destination. I needed to recognize that I was looking for specific information in my reflexive memos at different stages of my data analysis. For example, parents identified the effects of BoNT-A treatment, and some of these effects became future goals that they wanted their child to achieve in future BoNT-A treatment sessions. I needed to be able to recognize how parents identified goals based on the effects that they observed in previous treatment sessions. Furthermore, I read each reflexive memo separately to understand parents' individual story. I then compared the similarities and differences between reflexive memos to identify the common elements of all parents' stories. Reflexive memos were thus helpful to identify my reasoning and thought process at each stage of data analysis.

\section{Destination and Future Directions}

I reached the end of a chapter of my personal journey with the outcome of this study, which was to capture parents' perspectives of BoNT-A treatment. I also want to consider the future directions of how the results of this study could be applied to families of children and adolescents with CP in GMFCS level IV or V. A knowledge translation strategy can be used to share the findings from this study with other parents, and this in turn can help to improve parents' knowledge and satisfaction with healthcare services for BoNT-A treatment.

In this study, parents described that they wanted to connect with other parents about their experiences of BoNT-A treatment, because they would trust the perspectives of other parents and children with $\mathrm{CP}$. When parents are initially learning about their child's diagnosis of $\mathrm{CP}$ and healthcare treatments, they often appreciate being able to contact other parents who can provide a different kind of support from healthcare professionals (25). The summary of parents' journey and inventory list of goals are informational resources that were both developed using the ICF framework with input from parents. The summary of parents' journey allows parents to recognize and acknowledge that their goals fit into the broader context of their family's life. When parents are able to connect and hear from other parents, they may also recognize that other families of children with CP have similar experiences and challenges (26). An inventory list of goals can be provided as a companion tool with the summary of parents' journey. The inventory can help encourage parents to consider different types of goals that are focused not only on body functions and structure, but also on activity and participation. When parents are identifying therapy goals, they want to consider their child's happiness and overall quality of life for both the child and family (26). The inventory list can provide suggestions of therapy goals that parents can raise with healthcare professionals. The inventory only provides items as potential "goals", but these items can help to facilitate discussions between parents and healthcare professionals about plans to help the child accomplish these goals.

Different methods can be used to provide these information tools for parents, such as through websites or mobile applications. A video that can be shared using an online website link can be used as a starting point to raise awareness to parents about these informational resources (27). 
Parents want to do the best that they can to raise their child, and they often ask for more information about treatments and services for their child (28). The video can be created with parents and involve several components: 1) Parents' experiences of BoNT-A treatment; and 2) Instructions on using informational resources, such as the summary of this study's findings and the inventory list of goals. The video may need to have different versions that are tailored for different audiences, including families and healthcare professionals. Informational resources from this study can be shared with families and healthcare professionals from different geographical locations.

In a future study, the effect of these informational resources on the goal-setting process can be evaluated from the perspectives of both parents and healthcare professionals. Parents can be provided with these informational resources prior to attending their clinical appointment for BoNT-A treatment, and they can identify goals with healthcare professionals. Parents' satisfaction with healthcare services and the goal-setting process can be evaluated by asking parents in an interview. Goal-setting tools, such as the COPM, GAS, or PEGS, could also be administered to evaluate whether the child was able to accomplish goals that parents identified with the inventory list of goals (29-31). Healthcare professionals can also share their perspectives about the use of these informational resources and their effects on the goal-setting process with parents. This future study can help to inform the context of providing goal-setting tools in certain clinical settings, and whether these informational resources can be adapted to other clinics administering BoNT-A treatment.

\section{Conclusion}

Children and adolescents with CP classified in GMFCS level IV or V often have spasticity. They may receive a variety of interventions and treatment, and BoNT-A treatment is often used to manage spasticity in this population. BoNT-A treatment can be administered to help reduce muscle tone and improve range of motion in the muscles. The WHO's ICF framework can be used to help guide the types of goals that are identified between healthcare professionals and parents. It is also important to identify how BoNT-A affects not only body structures and function, but also activity, participation and parents' experiences of their child. This study provides additional knowledge about parents' perspectives about their experience of BoNT-A treatment for their child. During the goal-setting process, parents should also be informed about setting goals that are realistic, appropriate, and meaningful to the child and family.

In this study, parents described the effects of BoNT-A treatment on both the child and family. These observed effects informed parents about goals that they had for future BoNT-A treatment sessions. Although the aim of this study was to identify the effects of BoNT-A treatment from parents' perspectives, interpretive description provided an opportunity to interpret this information into the broader context of parents' journey in "finding the right path to do what is best for my child" during BoNT-A treatment. Every family's story is unique, and parents' experiences about BoNT-A treatment may change over time depending on the context of the child and family.

In 2014, I conducted a study to develop an inventory list of goals in the context of BoNT-A treatment (2). The findings of this current study led to the development of a summary of parents' journey in learning about BoNT-A treatment. Both the inventory and summary are informational 
M.Sc. Thesis - L Nguyen; McMaster University - Rehabilitation Science

resources that can be used as tools to facilitate the goal-setting discussion between families and healthcare professionals. These informational resources can be shared through social media for all parents, regardless of their geographical location, because they may want support and information about BoNT-A treatment for their child. Future studies can be conducted to evaluate the effects of these informational resources on the goal-setting process, by asking parents and healthcare professionals about their satisfaction and use of these resources.

This study was also an opportunity for me to learn about and understand parents' perspectives and recognize how their stories can help to inform goal setting in clinical practice. I recognize that it is important to engage with families in research and provide opportunities for them to be involved throughout the study, such as the study design and interpretation of findings. Parents can share valuable stories and information in research about pediatric rehabilitation because they have the lived experience of raising a child with a disability. 
M.Sc. Thesis - L Nguyen; McMaster University - Rehabilitation Science

\section{References}

1. Denzin NK, Lincoln YS. Chapter 1 Introduction: The Discipline and Practice of Qualitative Research. In: Denzin NK, Lincoln YS, eds. The SAGE Handbook of qualitative research. 4th ed. Thousand Oaks, California: SAGE Publications, Inc; 1994. p. $1-20$.

2. Nguyen L, Mesterman R, Gorter JW. Development of an inventory of goals using the International Classification of Functioning, Disability and Health in a population of nonambulatory children and adolescents with cerebral palsy treated with botulinum toxin A. Unpublished thesis type [manuscript in submission]. McMaster University; 2015.

3. Wiart L. How can qualitative research contribute to the expanding knowledge base in pediatric physical therapy? Phys Ther Rev. 2012;425-9.

4. Creswell JW, Poth CN. Chapter 4: Five Qualitative Approaches to Inquiry. In: Qualitative Inquiry \& Research Design - Choosing Among Five Approaches. Thousand Oaks, California: SAGE Publications, Inc; 2017. p. 65-110.

5. Morse, JM. Qualitative nursing research: A free-for-all? In: Morse JM, ed. Qualitative nursing research: A contemporary dialogue. Rockville, MD: Aspen; 1989. p. 3-10.

6. Baker C, Judith W, Phyllis S. Method slurring : the grounded theory / phenomenology example. J Adv Nurs. 1992;17:1355-60.

7. Thorne S, Kirkham SR, MacDonald-Emes J. Interpretive description: A noncategorical qualitative alternative for developing nursing knowledge. Res Nurs Health. 1997;20(2):169-77.

8. Thorne S, Kirkham SR, O'Flynn-Magee K. The analytic challenge in interpretive description. Int J Qual Methods. 2004;3(1):1-11.

9. Scotland J. Exploring the Philosophical Underpinnings of Research: Relating Ontology and Epistemology to the Methodology and Methods of the Scientific, Interpretive, and Critical Research Paradigms. English Lang Teach. 2012;5(9):9.

10. Creswell JW, Poth CN. Chapter 2: Philosophical Assumptions and Interpretive Frameworks. In: Qualitative Inquiry \& Research Design - Choosing Among Five Approaches. Thousand Oaks, California: SAGE Publications, Inc; 2017. p. 15-40.

11. Hunt MR. Strengths and Challenges in the Use of Interpretive Description: Reflections Arising From a Study of the Moral Experience of Health Professionals in Humanitarian Work. Qual Health Res. 2009;19(9):1284-92.

12. Thorne S. Chapter 3: Scaffolding a Study. In: Interpretive Description - Qualitative Research for Applied Practice. 2nd ed. New York: Routledge; 2016. p. 59-80.

13. Richards L. Chapter 2: Making qualitative data. In: Handling Qualitative Data: A Practical Guide. London, England: SAGE Publications Inc.; 2015. p. 35-60.

14. Tufford L, Newman P. Bracketing in qualitative research. Qual Soc Work. 2012;11(1):8096.

15. Thorne S. Chapter 6: Entering the Field. In: Interpretive Description - Qualitative Research for Applied Practice. 2nd ed. New York: Routledge; 2016. p. 117-132.

16. Bazeley P. Chapter 6: Naming, organising, and refining codes. In: Qualitative Data Analysis: Practical Strategies. London, England: SAGE Publications Inc.; 2013. p. 15787.

17. Rosenbaum P. Communicating with Families: A Challenge We Can and Must Address! Phys Occup Ther Pediatr. 2011;31(2):133-4. 
M.Sc. Thesis - L Nguyen; McMaster University - Rehabilitation Science

18. Thorne S. Chapter 2: Cultivating Questions in the Applied Practice Field. In: Interpretive Description - Qualitative Research for Applied Practice. 2nd ed. New York: Routledge; 2016. p. 43-58.

19. Hunter A, Lusardi P, Zucker D, Jacelon C, Chandler G. Making Meaning: The Creative Component in Qualitative Research. Qual Health Res. 2002;12(3):388-98.

20. Thorne S. Chapter 1: Qualitative Research in the Applied Disciplines. In: Interpretive Description - Qualitative Research for Applied Practice. 2nd ed. New York: Routledge; 2016. p. 25-41.

21. Domecq JP, Prutsky G, Elraiyah T, Wang Z, Nabhan M, Shippee N, et al. Patient engagement in research: a systematic review. BMC Health Serv Res. 2014;14(1):89.

22. Gagliardi AR, Berta W, Kothari A, Boyko J, Urquhart R. Integrated knowledge translation (IKT) in health care: a scoping review. Implement Sci. Implementation Science; 2015;11(1):38.

23. Shen S, Doyle-Thomas KAR, Beesley L, Karmali A, Williams L, Tanel N, et al. How and why should we engage parents as co-researchers in health research? A scoping review of current practices. Heal Expect. 2017;20(4):543-54.

24. Marlett N, Shklarov S, Marshall D, Santana MJ, Wasylak T. Building new roles and relationships in research: a model of patient engagement research. Qual Life Res. 2015;24(5):1057-67.

25. Shevell A. Doing the "Talk": Disclosure of a Diagnosis of Cerebral Palsy. J Child Neurol. 2013;28(2):230-235.

26. Wiart L, Ray L, Darrah J, Magill-evans J. Parents ' perspectives on occupational therapy and physical therapy goals for children with cerebral palsy. Disabil Rehabil.

2010;32(3):248-58.

27. Hemsley JJ, Mason RM. Knowledge and Knowledge Management in the Social Media Age. J Organ Comput Electron Commer. 2013;23(1-2):138-67.

28. Siebes RC, Ketelaar M, Gorter JW, Alsem M, Jongmans MJ. Needs of Families with Children Who Have a Physical Disability: A Literature Review. Crit Rev Phys Rehabil Med. 2012;24:85-108.

29. Law M, Baptiste S, McColl M, Opzoomer A, Polatajko H, Pollock N. The Canadian occupational performance measure: an outcome measure for occupational therapy. Can $\mathrm{J}$ Occup Ther. 1990;57(2):82-7.

30. Kiresuk TJ, Sherman MR. Goal attainment scaling: A general method for evaluating comprehensive community mental health programs. Community Ment Health J. 1968;4(6):443-53.

31. Missiuna C, Pollock N, Law M, Walter S, Cavey N. Examination of the Perceived Efficacy and Goal Setting System (PEGS) With Children With Disabilities, Their Parents, and Teachers. Am J Occup Ther. 2006;60(2):204-14. 
M.Sc. Thesis - L Nguyen; McMaster University - Rehabilitation Science

\section{APPENDICES}

Appendix A: Supporting figures to provide background information in Chapter 1.

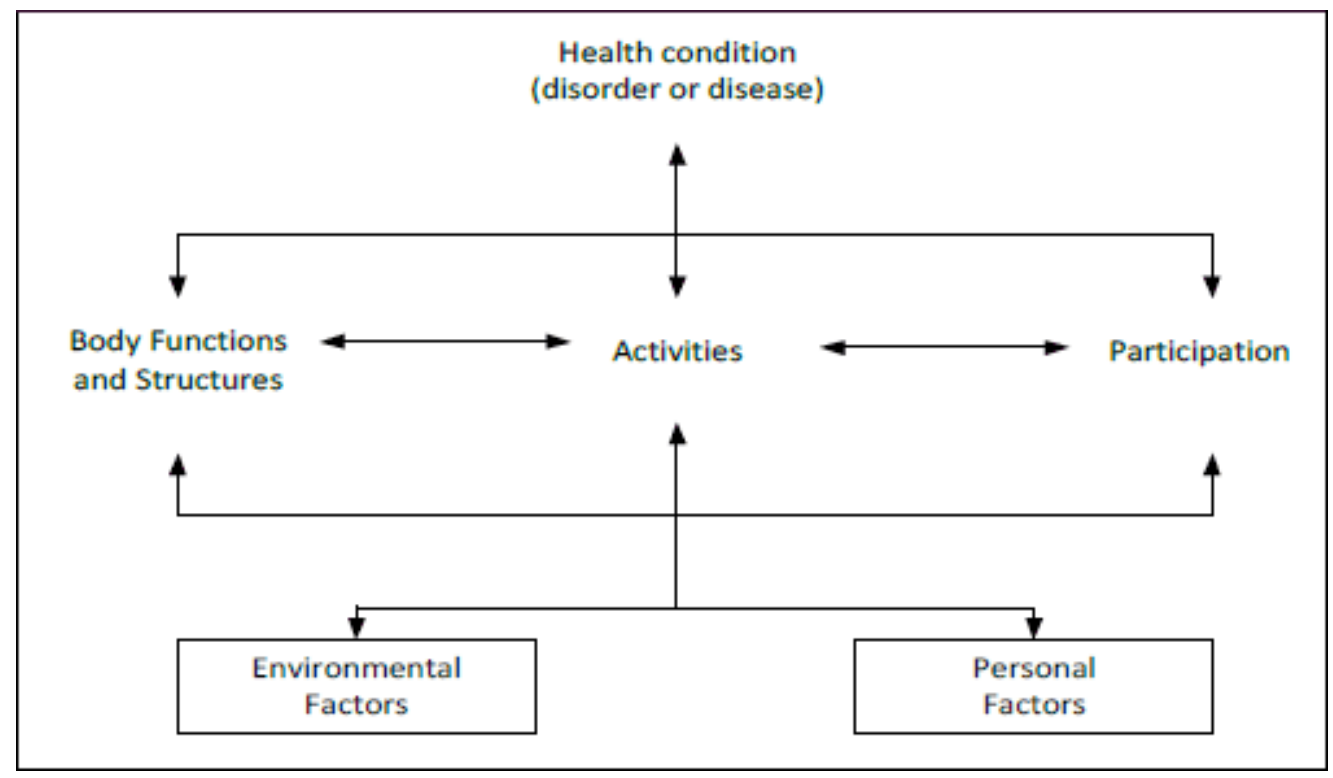

Figure 1. The International Classification of Functioning, Disability and Health (ICF). 
M.Sc. Thesis - L Nguyen; McMaster University - Rehabilitation Science

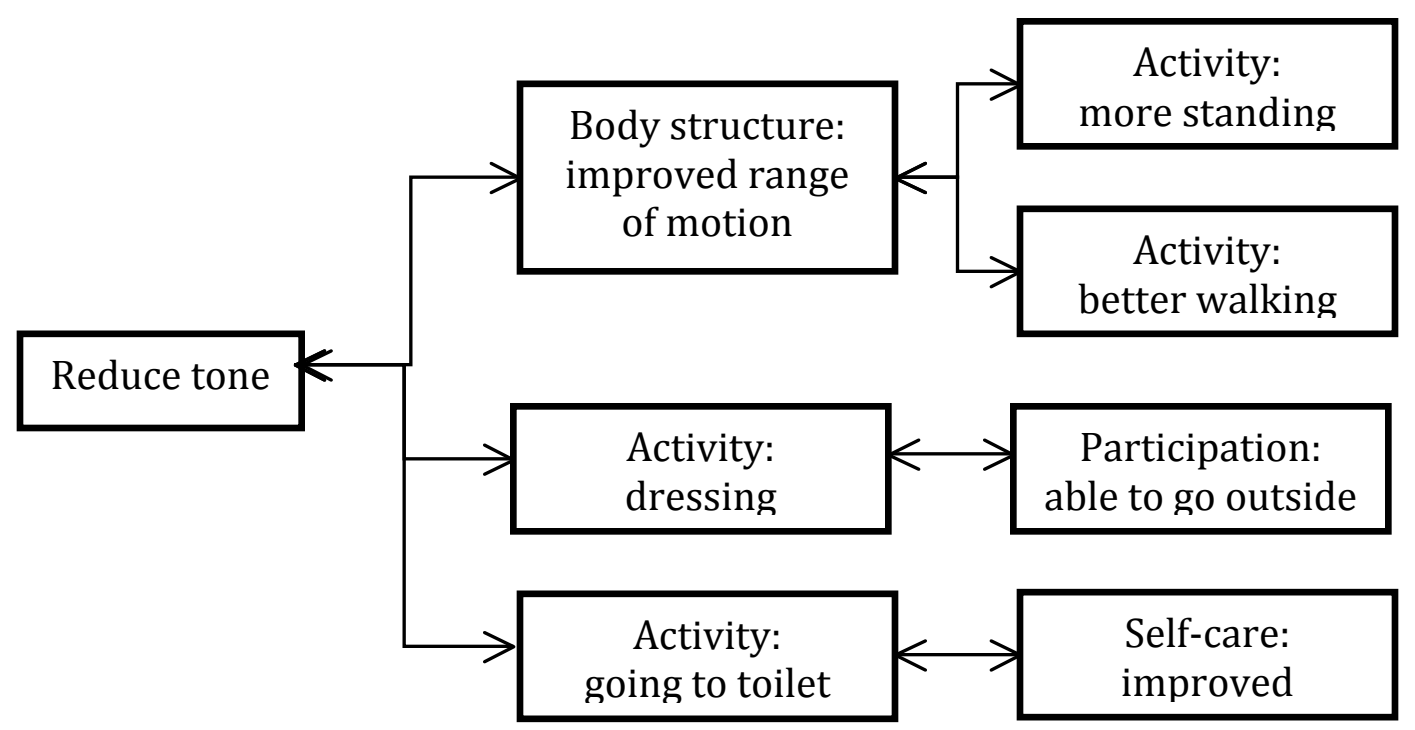

Figure 2. Conceptual relationships between the ICF categories. A conceptual diagram of possible relationships between body structures and function, activity, and participation. 


\section{McMaster Children's Hospital}

HAMILTON HEALTH SCIENCES

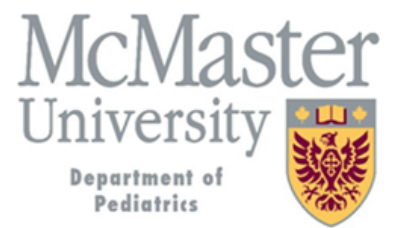

Participant's GMFCS Level:

Please read the following and mark the boxes beside the description that best represents the body structure and function, activity, and participation that you would you like your child to achieve after botulinum toxin treatment.

I would like the botulinum toxin treatment to help my child to...

\begin{tabular}{|c|c|c|}
\hline Body Structure / Function & Activity & Participation \\
\hline 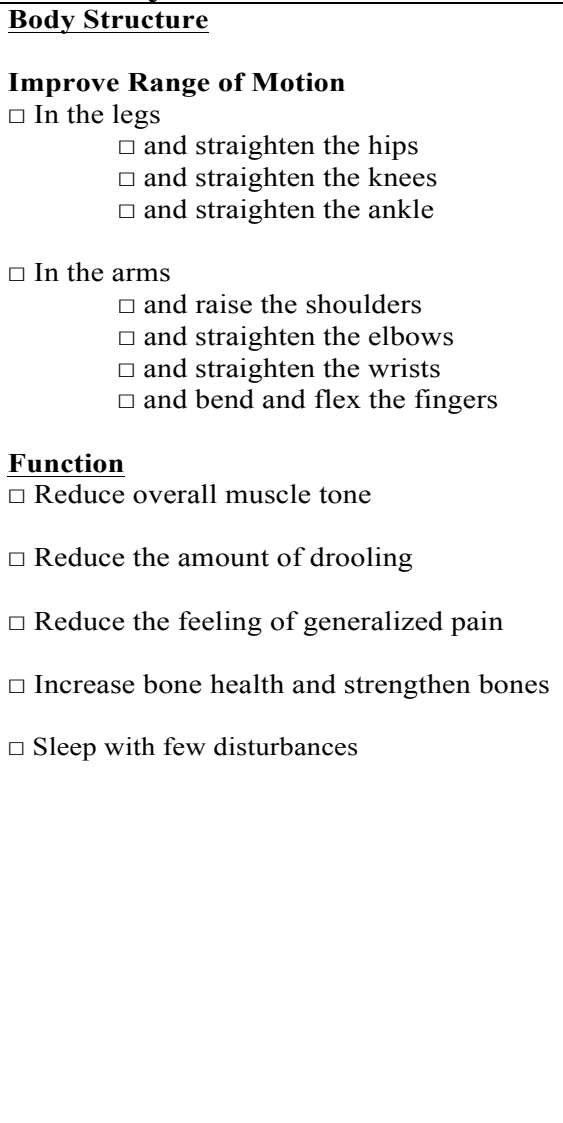 & 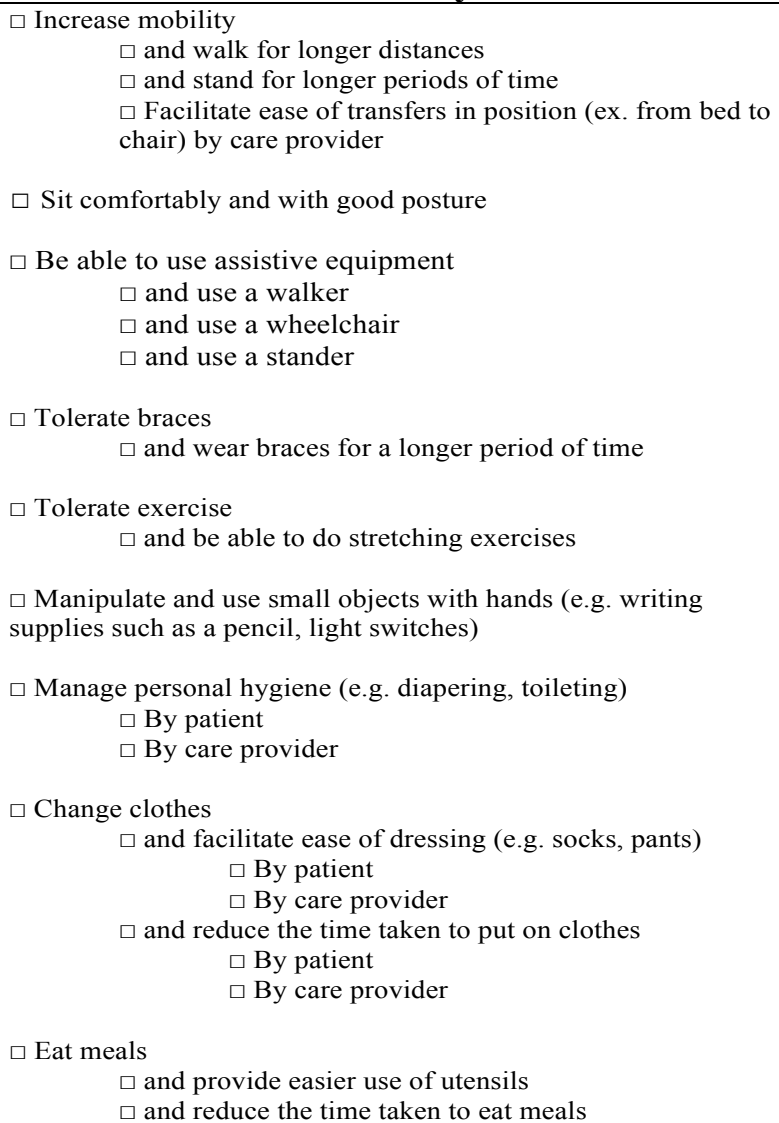 & $\begin{array}{l}\square \text { Be able to participate and compete } \\
\square \text { In wheelchair sports } \\
\square \text { Recreational activities } \\
\square \text { Swimming } \\
\square \text { Biking } \\
\square \text { Community groups } \\
\square \text { School activities } \\
\square \text { Religious activities }\end{array}$ \\
\hline
\end{tabular}




\section{Appendix C: Recruitment Poster}

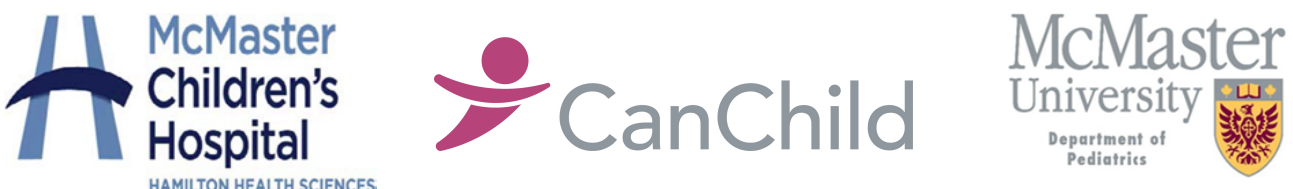

Recruitment Poster

\section{PARTICIPANTS NEEDED FOR RESEARCH IN BOTULINUM TOXIN TREATMENT FOR CHILDREN AND ADOLESCENTS WITH CEREBRAL PALSY}

We are looking for parents to take part in a study on the changes of botulinum toxin treatment in children and adolescents with cerebral palsy, classified as GMFCS Level IV or V, from the parents' perspectives.

You will be asked to share your story and answer a series of questions about the changes that you observed in your child after receiving botulinum toxin treatment.

Your participation would involve a one-time interview with a research assistant. The interview will be about 1 hour long.

You will have the option to have the interview: a) by telephone, Skype or

Google Hangout, or b) in-person at McMaster Children's Hospital.

We hope to create a list of the possible changes of botulinum toxin treatment, and share this list with families of children with cerebral palsy and healthcare professionals.

For more information about this study, or to volunteer for this study, please contact:

Linda Nguyen, MSc Student Department of Rehabilitation Sciences McMaster University Email: nguyel7@mcmaster.ca

This study has been reviewed by, and received ethics clearance by the Hamilton Integrated Research Ethics Board. 


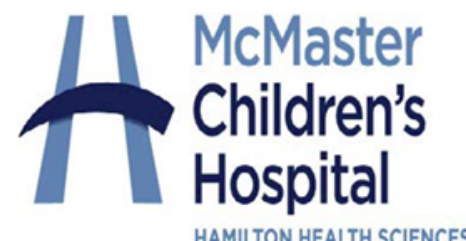

HAMILTON HEALTH SCIENCES.

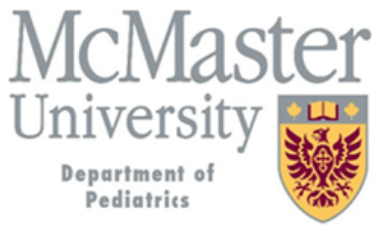

Information Sheet \& Consent Form

Principal Investigator: Dr. Jan Willem Gorter, MD, PhD, FRCPC, Department of Pediatrics, McMaster University

\section{Co-Investigators:}

Linda Nguyen, BHSc, MSc Student, CanChild Centre for Childhood Disability Research and

School of Rehabilitation, McMaster University

Dr. Peter Rosenbaum, MD, FRCPC, Department of Pediatrics, McMaster University

Dr. Briano Di Rezze, OT, PhD, School of Rehabilitation Science, McMaster University

Dr. Ronit Mesterman MD, FRCPC, Department of Pediatrics, McMaster University

\section{Dear Parents of}

We would like to invite you to participate in a research study. This study is looking at identifying the changes of botulinum toxin injections for your child and family. By documenting these changes that were found to be important to you and your child, we are hoping to create a list of all possible relevant changes in the context of botulinum toxin treatment in children with cerebral palsy (CP). Children with CP can be classified according to the Gross Motor Function Classification System (GMFCS), which is a tool that categorizes children with CP into five levels from level I (least affected) to level V (most affected). We hope to create a list that will help us guide other patients and their professional teams in becoming aware about the possible changes of botulinum toxin treatment in children with $\mathrm{CP}$ and classified as GMFCS level IV or V.

Children with cerebral palsy often have spasticity and increased tone in their muscles. Botulinum toxin treatment is widely used to treat patients with CP to help relax their muscle. Relaxing the muscles may be the direct effect of botulinum toxin treatment, but there may be other possible changes from botulinum toxin treatment that could affect the level of activity and participation in the child. 
There is very limited research available in the use of botulinum toxin treatment for children and youth with CP GMFCS levels IV and V. As a starting point, we would like to identify all possible changes of botulinum toxin treatment that are mentioned by parents of children with $\mathrm{CP}$ and classified as GMFCS level IV or V. The identification of these changes will allow future studies to assess if botulinum toxin treatment is helpful to families of children with CP. It is our hope that the documentation of these changes will contribute to the development of an inventory of goals, and increase awareness about these changes among healthcare professionals.

If you agree to participate in this research project, you will be asked to attend an interview with a trained research assistant. The time needed to complete the interview is approximately an hour. During the interview, you will be asked to respond to a series of questions about the changes that you observed in your child after receiving botulinum toxin injections. You will have the option to have the interview: a) by telephone, Skype or Google Hangout; or b) in-person at McMaster Children's Hospital (Hamilton, ON). The interview will be recorded using a digital recorder and transcribed. At no time will you be made to answer questions you are not comfortable with.

All information obtained as part of the study will be kept confidential and only used for research purposes. Information will be stored in a secure manner to respect patient privacy and confidentiality.

Being in this study - or not - will not affect your child's or family's services in any way. The botulinum toxin injections or other treatments given in the appointment are not part of the study. These are treatments that would be chosen by you and your therapists and doctors independent of the study. Even if you do not wish to participate in this study your child will receive any treatments that your therapist and doctors believe are important for them. As part of your appointment, you will also continue to set goals with the doctors and therapists for your child when he/she is being treated with botulinum toxin injections.

If you have any questions or need more information about the study itself, please contact Dr Jan Willem Gorter at 905-521-9140 Ext 26852.

This study has been reviewed by the Hamilton Integrated Research Ethics Board. If you have any questions about your rights as a research participant, you may contact the Office of the Chair of the Hamilton Integrated Research Ethics Board at 905-521-2100, Ext 42013.

Thank you in advance for your willingness to help in this very important project.

Yours truly,

Jan Willem Gorter, MD, PhD, FRCPC

Professor Department of Pediatrics and the School of Rehabilitation Science 
M.Sc. Thesis - L Nguyen; McMaster University - Rehabilitation Science

\section{CONSENT}

I have read the information presented in the information letter about the study: "Effects of Botulinum Toxin Treatment in Children and Adolescents with Cerebral Palsy GMFCS Level IV or V: Understanding the Parents' Perspectives" being conducted by Dr Jan Willem Gorter of McMaster University.

I have had the opportunity to ask questions about the involvement of my child (name of minor) additional details I requested. in this study and to receive

I understand that if I agree to participate in this study, I may withdraw from the study at any time.

I will be given a signed copy of this form. I agree to participate in the study.

$\square \quad$ I would like to receive a summary of the study's results.

Please send them to this email address:

or

to this mailing address:

$\square$ No, I do not want to receive a summary of the study's results

Name of participant (printed):

Signature of participant:

Witness Name (study team member):

Witness Signature (study team member):

Date: 


\section{Appendix E: Semi-structured Interview Guide}

\section{To explore the effects of botulinum toxin treatment for children with cerebral palsy in GMFCS level IV or V from the perspectives of parents}

Children with cerebral palsy often have spasticity and increased tone in their muscles, which can limit their movements. Botulinum toxin (BoNT-A) is often administered to children with cerebral palsy to help them relax their muscles.

In this study, I would like to know about the changes that you have observed in your child after he/she has received BoNT-A treatment, and whether this treatment has helped you and your child. Do I have your consent to record this interview?

1. Please tell me about your child?

Probes:

- Child's diagnosis

- Current problems

- Provision of treatments and rehabilitation therapies

2. Has your child received BoNT-A treatment before?

Probes:

- When was the last time that your child received BoNT-A treatment?

- Has your child frequently received BoNT-A treatment?

- How many times has your child received BoNT-A treatment (in total, per year)?

3. How did you hear about BoNT-A treatment?

Probes:

- What kind of information did you receive?

- Where did you receive this information (e.g. written and oral information, social media, Internet, parents)?

4. Before your child received BoNT-A treatment, why did you think BoNT-A treatment might be helpful?

Probes:

- Improvements in functional movements, pain, and comfort, involvement in therapy activities, ease of caregiving

5. What differences have you observed after your child was treated with BoNT-A treatment based on the last treatment session?

Probes:

- Did you notice any functional changes, such as improved range of motion or being able to engage in stretching exercises?

- Was it easier or more difficult to complete certain items, such as bathing, dressing, or transfers? 
M.Sc. Thesis - L Nguyen; McMaster University - Rehabilitation Science

- Engagement in social and community activities, play activities, recreational sports, use of assistive devices, ease of caregiving, personal hygiene

6. Were there any changes that you observed in your child after BoNT-A treatment that you did not expect to see?

Probes:

- What are the positive changes?

- What were the negative changes?

7. Were there any changes in your family's life that you observed after your child received BoNT-A treatment?

Probes:

- Were there any changes in your sleeping schedule or quality of sleep?

- What kinds of activities did your family participate in after your child received BoNT-A treatment?

- How did you feel after your child received BoNT-A treatment?

8. Were the changes that you observed part of your goals that you had for your child in the context of BoNT-A treatment?

- Did you set these goals?

- Did you share these goals with healthcare professionals?

- Have you had different goals each time your child received BoNT-A treatment? Have your goals changed over time?

9. Overall, could you describe the extent to which your expectations were met with BoNT-A treatment? Please expand.

Probes:

- If your expectations were not met, why did you think was the reason for this?

10. Would you go back and have BoNT-A treatment for your child again, or recommend it to other parents of young people like yours?

Probes:

- Reasons for recommendations 


\section{Appendix F: Codebook.}

\begin{tabular}{|c|c|c|c|c|}
\hline Category & Description & Code Words & Code Word Meaning & Examples \\
\hline $\begin{array}{l}\text { Body structures } \\
\text { and function }\end{array}$ & $\begin{array}{l}\text { Body structures: } \\
\text { Anatomical parts of } \\
\text { the body, such as } \\
\text { organs, limbs, and } \\
\text { their components } \\
\text { Body functions: } \\
\text { The physiological } \\
\text { functions of body } \\
\text { systems (including } \\
\text { psychological } \\
\text { functions) }\end{array}$ & $\begin{array}{l}\text { 3. Muscle tone } \\
\text { 4. Generalized pain }\end{array}$ & $\begin{array}{l}\text { 1. Movement of the hands, } \\
\text { arms, hips, legs, etc. } \\
\text { 2. Functions of the range and } \\
\text { ease of movement of a joint } \\
\text { 3. Presence of tension in } \\
\text { resting muscles and the } \\
\text { resistance offered when trying } \\
\text { to move the muscles passively } \\
\text { 4. Sensation of unpleasant } \\
\text { feeling indicating potential or } \\
\text { actual damage to some body } \\
\text { structure felt all over, or } \\
\text { throughout the body }\end{array}$ & $\begin{array}{l}\text { 1. Being able to straighten the } \\
\text { hips or knees } \\
\text { 2. Bend and flex the fingers, } \\
\text { raise the shoulders } \\
\text { 3. Reduce overall muscle tone } \\
\text { 4. Reduce level of pain }\end{array}$ \\
\hline Activity & $\begin{array}{l}\text { Execution of a task } \\
\text { or action by an } \\
\text { individual }\end{array}$ & $\begin{array}{l}\text { 1. Communication } \\
\text { 2. Changing basic } \\
\text { body position } \\
\text { 3. Maintaining a } \\
\text { body position } \\
\text { 4. Transferring } \\
\text { oneself }\end{array}$ & $\begin{array}{l}\text { 1. Using communication } \\
\text { devices and techniques } \\
\text { 2. Getting into and out of a } \\
\text { body position, and moving } \\
\text { from one location to another } \\
\text { 3. Staying in the same body } \\
\text { position } \\
\text { 4. Moving from one surface to } \\
\text { another }\end{array}$ & $\begin{array}{l}\text { 1. iPads } \\
\text { 2. Sitting, standing, lying down } \\
\text { 3. Sitting or standing for a long } \\
\text { period of time }\end{array}$ \\
\hline
\end{tabular}




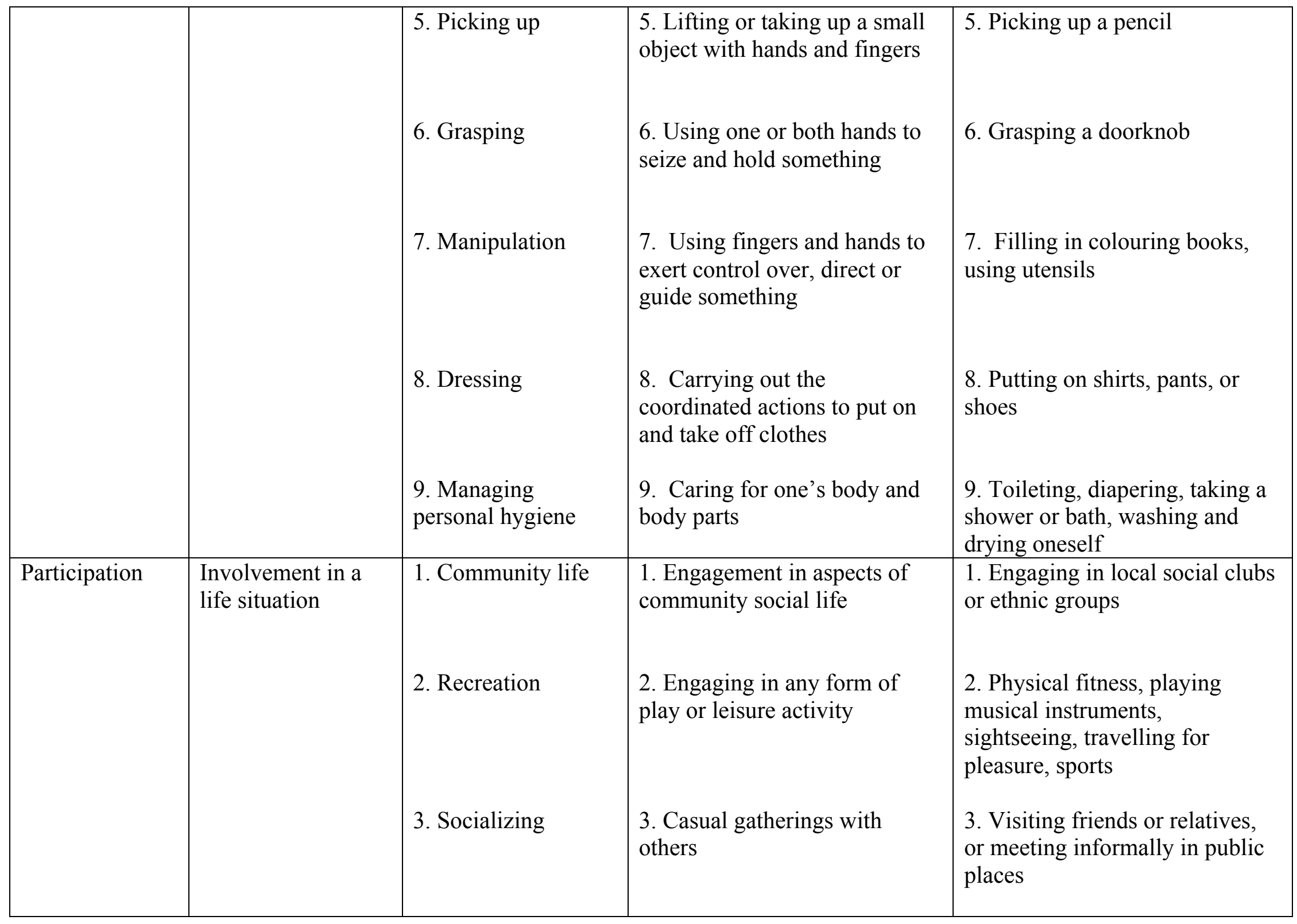




\begin{tabular}{|c|c|c|c|c|}
\hline $\begin{array}{l}\text { Environmental } \\
\text { Factors }\end{array}$ & $\begin{array}{l}\text { The physical, } \\
\text { social, and } \\
\text { attitudinal } \\
\text { environment in } \\
\text { which people live } \\
\text { and conduct their } \\
\text { lives }\end{array}$ & $\begin{array}{l}\text { 1. Adapted products } \\
\text { and technologies for } \\
\text { play } \\
\text { 2. Assistive products } \\
\text { and technology for } \\
\text { mobility and } \\
\text { transportation }\end{array}$ & $\begin{array}{l}\text { 1. Objects, material, toys and } \\
\text { other products adapted or } \\
\text { specially designed to assist } \\
\text { play } \\
\text { 2. Adapted or specially } \\
\text { designed equipment, products } \\
\text { and technologies that assist } \\
\text { people to move inside and } \\
\text { outside buildings }\end{array}$ & $\begin{array}{l}\text { 1. Remote control cards or } \\
\text { modified playground equipment } \\
\text { 2. Walking devices, special cars } \\
\text { and vans, adaptations to } \\
\text { vehicles, wheelchairs }\end{array}$ \\
\hline $\begin{array}{l}\text { Personal } \\
\text { Factors }\end{array}$ & $\begin{array}{l}\text { The particular } \\
\text { background of an } \\
\text { individual's life } \\
\text { and living, } \\
\text { composed of } \\
\text { features of the } \\
\text { individual that are } \\
\text { not part of a health } \\
\text { condition or health } \\
\text { state }\end{array}$ & $\begin{array}{l}\text { 2. Trust } \\
\text { 3. Comfort }\end{array}$ & $\begin{array}{l}\text { 1. A mental or emotional state } \\
\text { defined by pleasant and } \\
\text { positive emotions }\end{array}$ & $\begin{array}{l}\text { 1. Enjoyment in activities, loves } \\
\text { going to school } \\
\text { 2. Trusting other doctors, } \\
\text { connecting with parents of } \\
\text { children with disabilities }\end{array}$ \\
\hline $\begin{array}{l}\text { Process of } \\
\text { Learning }\end{array}$ & $\begin{array}{l}\text { Parents' reflection } \\
\text { of their experience } \\
\text { in understanding } \\
\text { the changes of } \\
\text { BoNT-A treatment } \\
\text { for their child }\end{array}$ & $\begin{array}{l}\text { 1. Experiences of } \\
\text { direct effects }\end{array}$ & $\begin{array}{l}\text { 1. Thinking about the impact } \\
\text { and difference the direct effects } \\
\text { has had on the life of the child } \\
\text { and family } \\
\text { 2. Describing the positive and } \\
\text { negative effects of BoNT-A } \\
\text { treatment }\end{array}$ & $\begin{array}{l}\text { 1. Seeing direct and immediate } \\
\text { effects of BoNT-A treatment, } \\
\text { and comparing differences in the } \\
\text { child before and after treatment } \\
\text { 2. Pain is a negative aspect of } \\
\text { BoNT-A treatment, and parents } \\
\text { identified that the positive } \\
\text { effects, such as ease of }\end{array}$ \\
\hline
\end{tabular}


M.Sc. Thesis - L Nguyen; McMaster University - Rehabilitation Science

\begin{tabular}{|l|l|l|l|}
\hline & & $\begin{array}{l}\text { caregiving, outweighed the } \\
\text { negative effects }\end{array}$ \\
& $\begin{array}{l}\text { 3. Developmental } \\
\text { stages }\end{array}$ & $\begin{array}{l}\text { 3. Description of the child's } \\
\text { abilities at different ages }\end{array}$ & $\begin{array}{l}\text { 3. Parents are focused on } \\
\text { exploring and recognizing their } \\
\text { child's ability when the child is } \\
\text { young. }\end{array}$ \\
BoNT-A treatment becomes a \\
routine for older children.
\end{tabular}


M.Sc. Thesis - L Nguyen; McMaster University - Rehabilitation Science

Appendix G: Summary of Key Themes and Subthemes

FINDING THE RIGHT PATH TO DO WHAT IS BEST FOR MY CHILD

Parents' Hopes

Parents' Goals

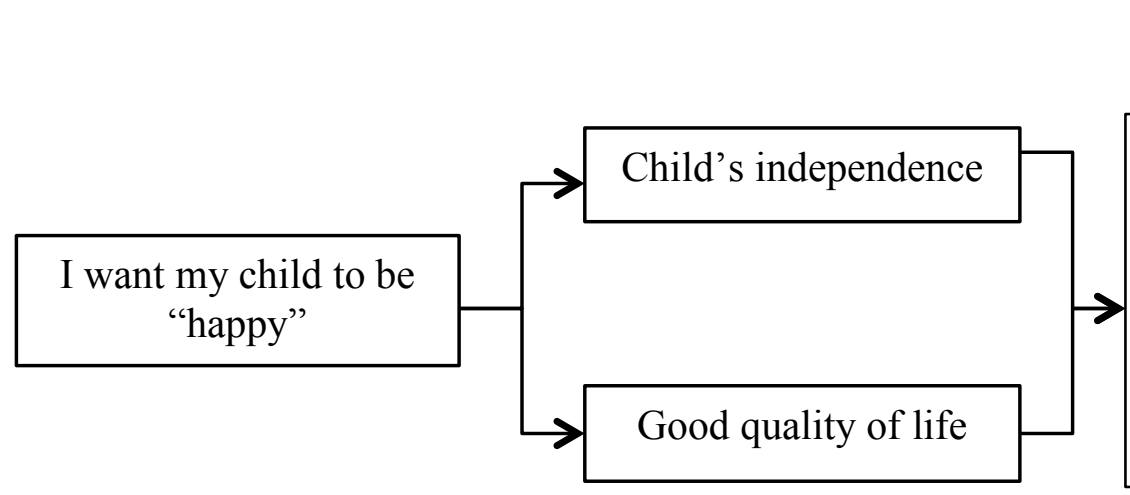

\section{Analytic Strategies}

Data immersion and understanding parents' stories

- Reflexive memos:

- Word frequency

- Word clouds

\section{(Zooming out)}

\begin{tabular}{|ll|}
\hline \multicolumn{2}{|c|}{ Coding } \\
$\bullet$ & Abductive \\
& reasoning coding \\
& process \\
- & ICF framework \\
- & Word frequency \\
- & Word clouds \\
& \\
(Zooming in)
\end{tabular}

Parents Learning

What Works

\section{Parents' \\ Reflections}

- Direct effects of BoNT-A treatment

Expectations of BoNT-A treatment

- Focusing on the specific changes observed by parents with BoNT-A treatment
- Making trade-offs and balancing the negative and positive effects of BoNT-A

- Recognizing the developmental stage of their child
Parents' Destination

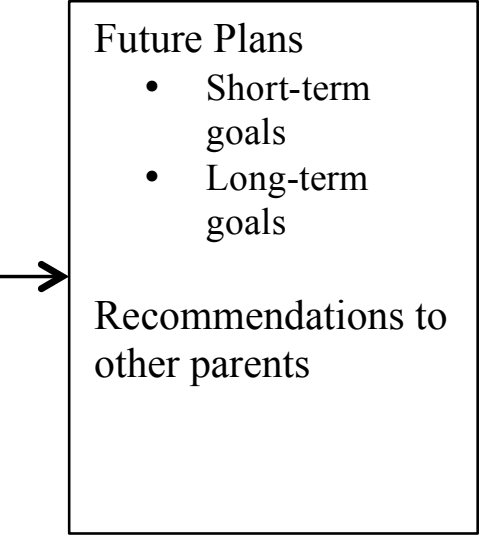

Abbreviations: 1. BoNT-A: botulinum toxin, 2. ICF: International Classification of Functioning, Disability and Health

The diagram provides an illustration of the analytic strategies that were used to demonstrate the parents' journey in learning about BoNT-A treatment and its impact on the child and family. It was important to consider the specific changes observed in each family (zooming in), but also the broader message that all parents were conveying in their journey (zooming out). 


\section{Appendix H: Word Clouds and Supporting Quotes.}

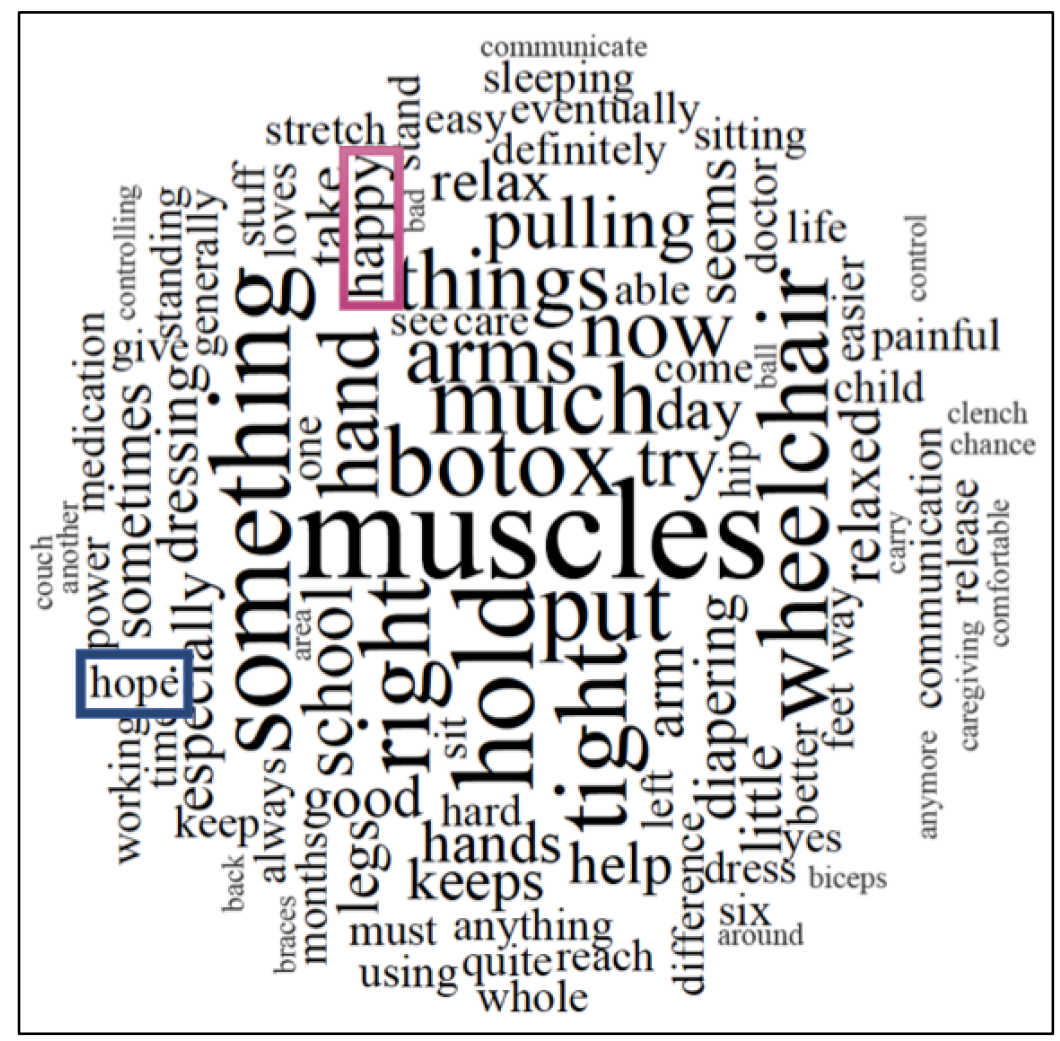

Figure 1. Word cloud of all parent interviews. The word cloud was generated from all parents' responses in the interviews to gain a better understanding of the key theme. All parents hope that their child will be as happy as possible. BoNT-A treatment was one option that could help children and adolescents with CP engage in meaningful activities that will make them happy. 
M.Sc. Thesis - L Nguyen; McMaster University - Rehabilitation Science

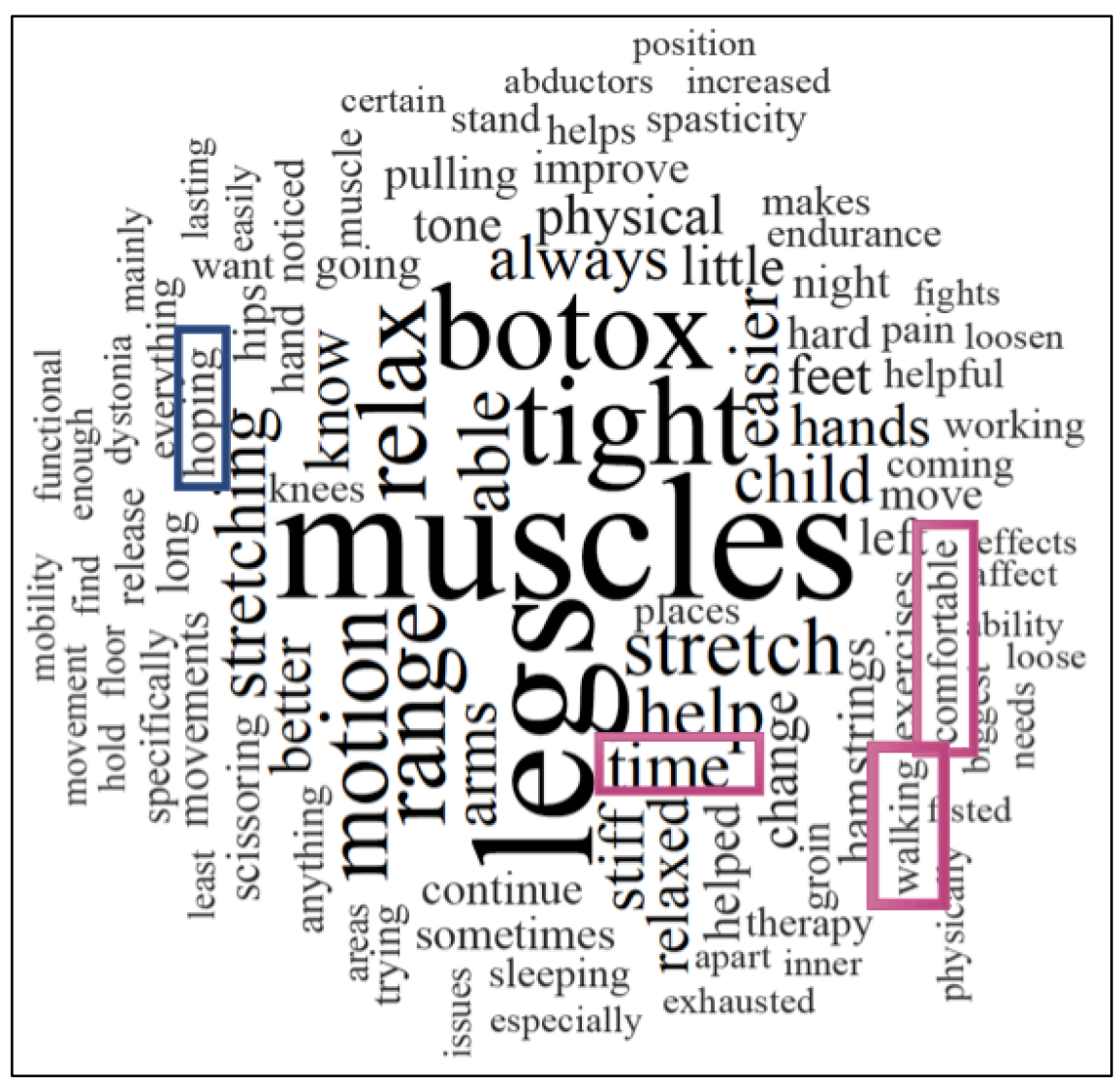

Figure 2. Body structures and function. Children and adolescents with CP received BoNT-A injections in different muscles areas, but most injections were for the legs. Parents were hoping to observe different effects, such as relaxing the muscles and increasing range of motion (highlighted in blue).

Other interesting effects that parents mentioned are highlighted in red. Parents also mentioned that they were targeting different muscle areas at different times. They wanted their child to be able to walk, but also ensure that their child was as comfortable as possible.

Below are parents' quotes to highlight the effects of BoNT-A treatment on body structures and function:

"She also wears gaiters and a wedge every other night on her legs. I think it's more comfortable for her when her legs are more relaxed to get that goods stretched with the wedge in there." (Mother of an 11-year-old girl, GMFCS level IV)

"She was sort of tight in the shoulders and at the elbows that she had a hard time manipulating it. So if any effect- make them more comfortable for range of motion, exercises, and keep the range of motion and that's important." (Mother of a 10-year-old girl, GMFCS level IV) 
M.Sc. Thesis - L Nguyen; McMaster University - Rehabilitation Science

"And he had a lot of scissoring while he was walking, and that's much better now. So I do think it helped with that, for sure." (Mother of a 10-year-old boy, GMFCS level IV)

Mother: "Well, eventually I mean, the botox wears off or it serves its system and he'll need injections again."

Interviewer: "Yeah."

Mother: "Usually it's every three, four months I think."

Interviewer: "So you would say that you would keep working on his different goals, increased range of motion, reducing tone, over a period of time with botox?"

Mother: "Yes."

(Mother of a 17-year-old adolescent male, GMFCS level V) 
M.Sc. Thesis - L Nguyen; McMaster University - Rehabilitation Science

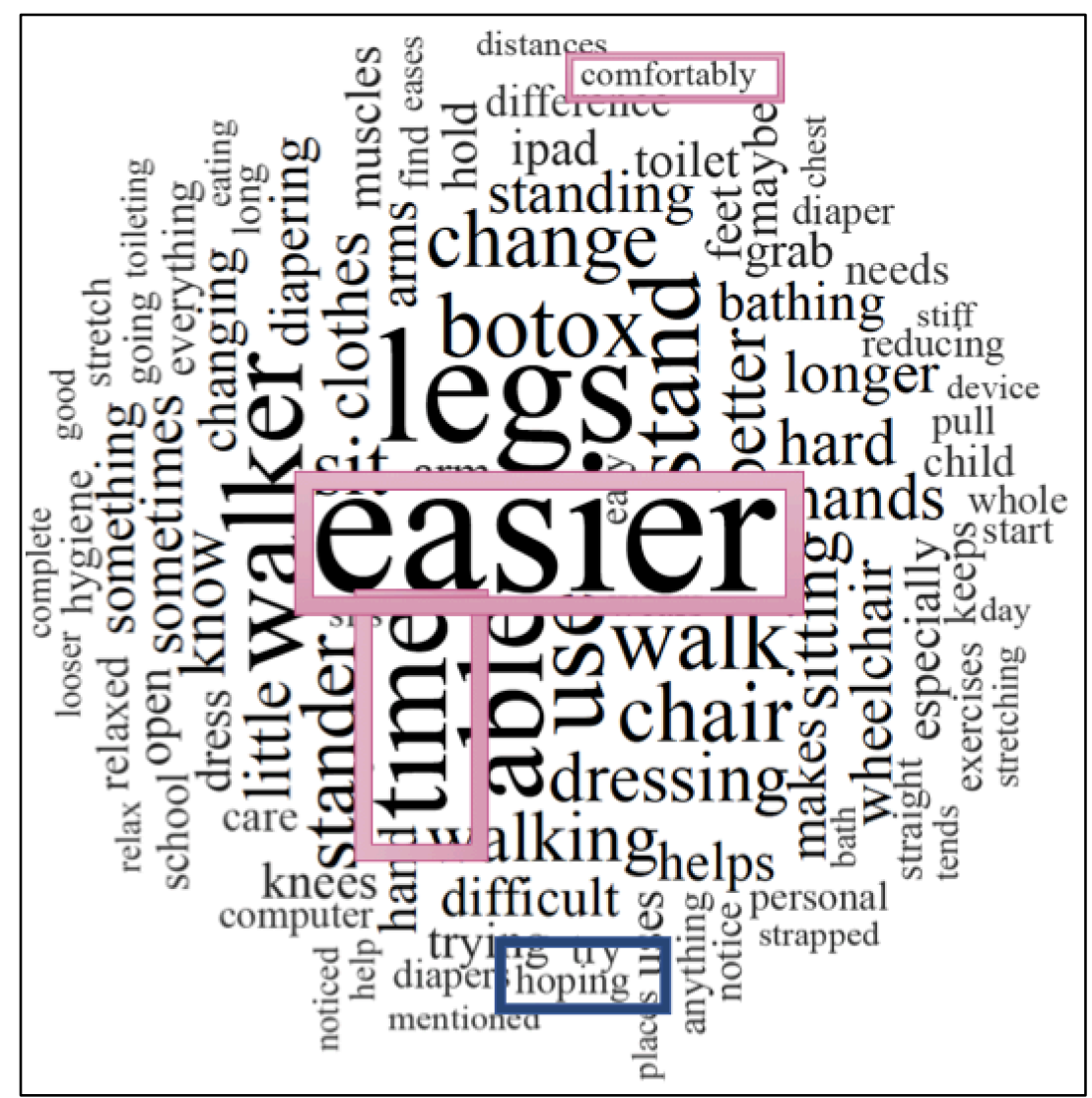

Figure 3. Activity. Parents were hoping that BoNT-A treatment would make it easier for their child to complete activities. While completing these activities, parents wanted their child to be as comfortable as possible. The child's ability to complete these activities depended on the time of the child's developmental stage.

Below are parents' quotes to illustrate their experiences of BoNT-A treatment for helping their child to complete activities.

"... with greater ease, I guess, you know, in his muscle groups so that he can walk a little bit easier. Stand a little bit easier. And, you know, crawl around a little bit easier with his younger brother, his parents." (Father of a 5-year-old boy, GMFCS level IV)

“... much easier to dress, um, uh. Better for [her] too because when we're having to pull her legs down or pull that one arm down, it's uncomfortable for her while we're doing it, so um, ultimately, um, during that time period where the botox is working and um, less painful for [her], for us too." (Mother of an 11-year-old girl, GMFCS level IV)

"I was just expecting for it [BoNT-A treatment] to allow [her] to stand comfortably." (Mother of an 8-year-old girl, GMFCS level IV) 
M.Sc. Thesis - L Nguyen; McMaster University - Rehabilitation Science

"The other thing was walking too. She had a walker at the time and when she received these treatments, it allowed for her legs, it seemed that her messages from her brain was easily sent to her legs. Um... walking was always been really difficult for her." (Mother of an 8-year-old girl, GMFCS level IV).

"And I think that was the first time she had it because we were hoping that it would give more mobility with her hands to be able to manipulate toys and things." (Mother of a 10-year-old girl, GMFCS level IV)

"Just to relax his muscle tone. Especially with sitting in a wheelchair all the time. Release his muscle tone in his legs and knees and thigh. Just to that-just to relax him. And it also helps withbecause he's in a timeframe where he's growing quickly." (Mother of a 17-year-old adolescent male, GMFCS level V)

"I was just hoping to relax his muscles and his legs and hamstrings and his knees just so that he's more comfortable and it's easier to take care of him, and that's what I expected." (Mother of a 17-year-old adolescent male, GMFCS level V) 


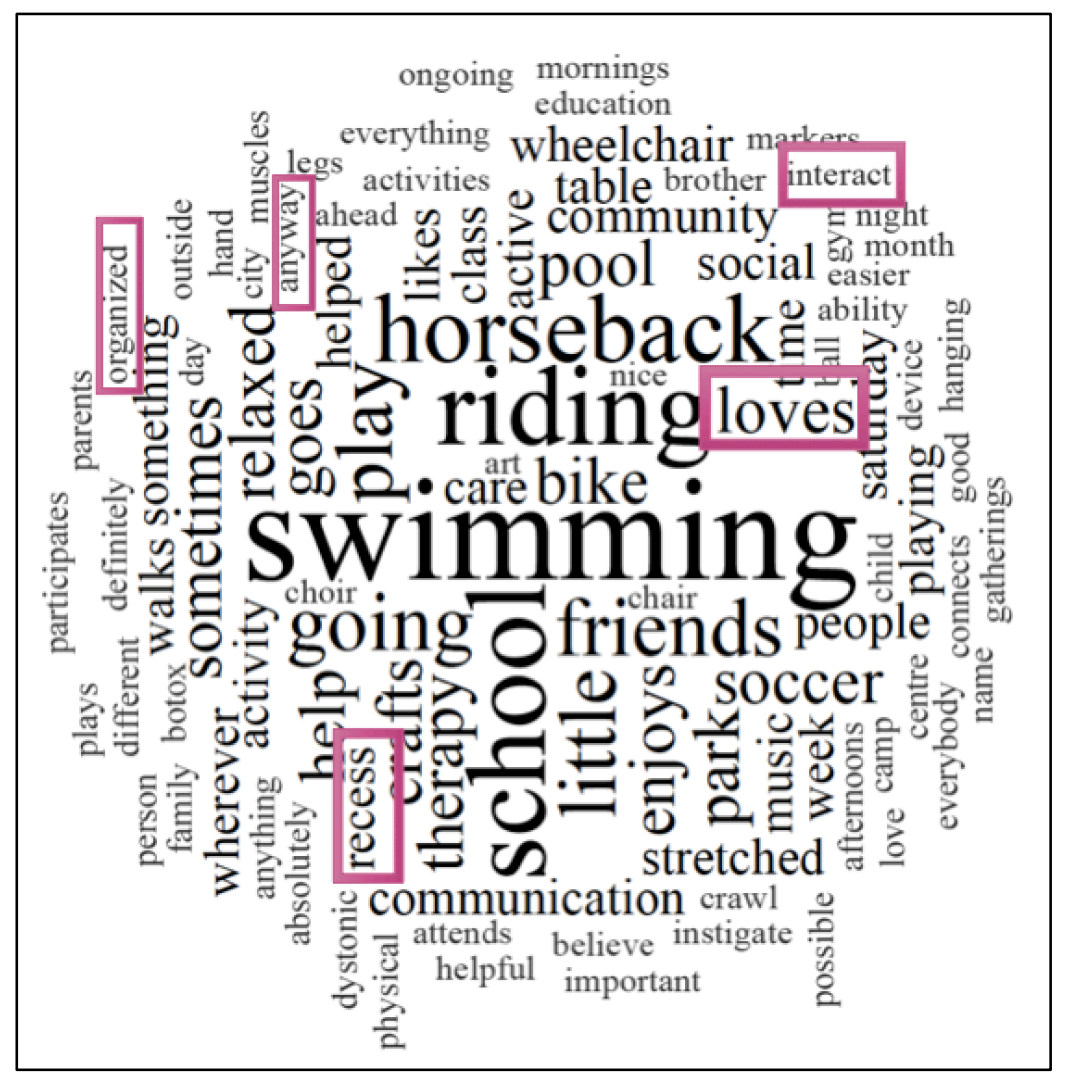

Figure 4. Participation. In the context of BoNT-A treatment, parents did not indicate that they were hoping for certain BoNT-A effects that would affect their child's participation. Parents were already encouraging their child and family to participate in the community anyway. The types of participation activities that children and adolescents were engaged in were based on their interests. There were certain activities that children and adolescents loved to do, such as socializing and interacting with people. Children and adolescents were engaged in both organized activities, such as horseback riding or swimming. They were also participating in informal activities, such as playing with friends at recess. These key terms were indicated by parents (highlighted in red).

Below are parents' quotes to illustrate how BoNT-A had an impact on their child's participation in various activities.

"We try not to let those [be] obstructions or barriers for going out for [him]. " (Father of a 5year-old boy, GMFCS level IV)

"Well we still do it [horseback riding and swimming] anyway, it's an ongoing activity." (Mother of a 17-year-old adolescent male) 
M.Sc. Thesis - L Nguyen; McMaster University - Rehabilitation Science

Interviewer: "Okay. Does he participate in any sports activities?"

Mother: "Um, no organized sports. No."

Interviewer: "What do you mean by informal sports? Could you describe some of it?"

Mother: "Well, like, playing soccer in the park."

(Mother of an 11-year-old boy, GMFCS level IV)

"She loves hanging out with the girls at the crafts table." (Mother of a 6-year-old girl, GMFCS level V)

"Yeah, she does swimming... and crafts night. She goes for three hours, from six to nine... She loves it. She connects well with a lot of people." (Mother of a 17-year-old adolescent female, GMFCS level IV). 


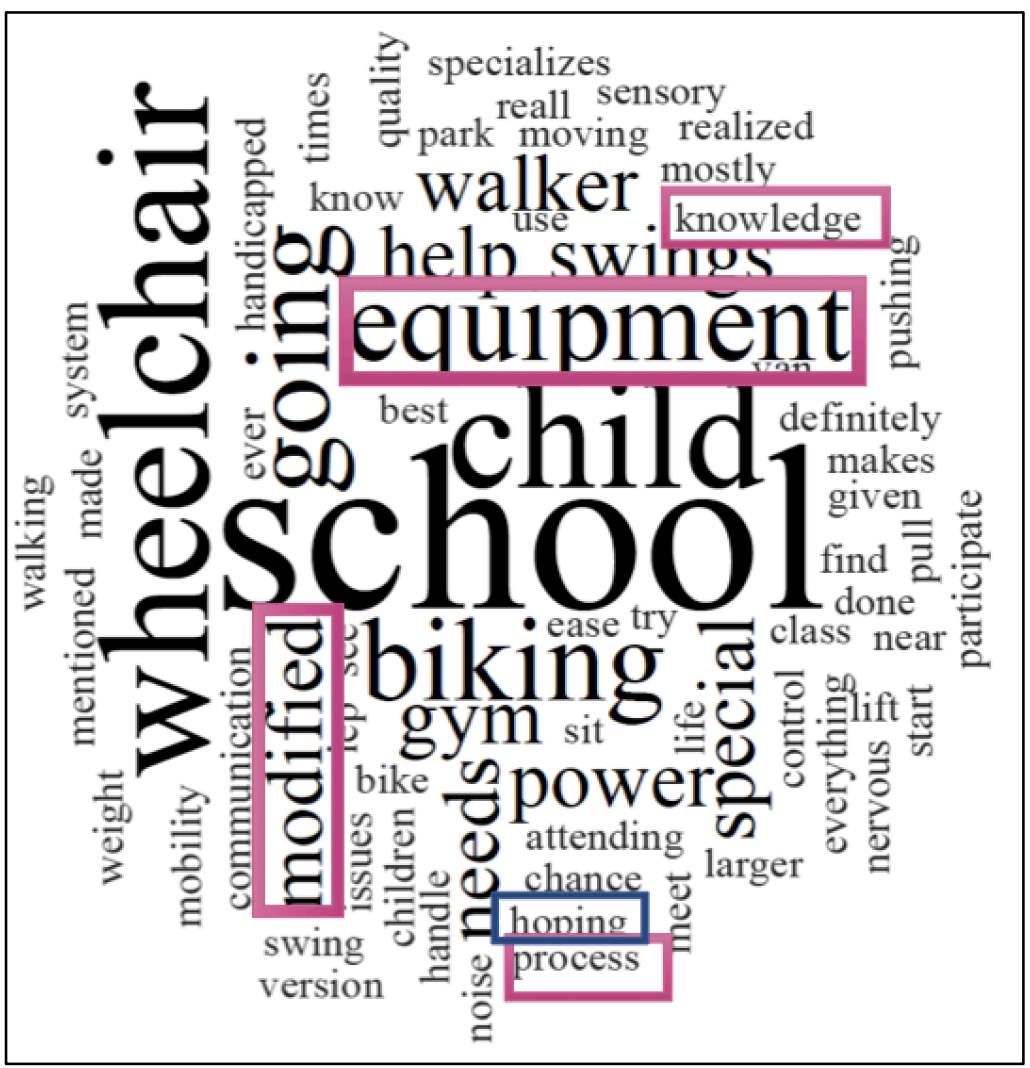

Figure 5. Environment. Parents indicated that BoNT-A treatment was helpful for their child to participate in activities, but modifications also needed to be made in the environment to facilitate their child's participation. Parents were hoping to arrange and set up equipment to facilitate their child's participation: "We're in a process of getting a lift system for our van too and we're hoping to get that going really soon” (Father of a 9-year-old boy, GMFCS level V).

A father also commented that he needed to learn from the knowledge of school educators who would be able to help his child participate in school: "So he'll be attending a school that specializes in special needs kids... because they all the equipment there [and] the knowledge to meet [his] needs" (Father of a 9-year-old boy, GMFCS level V). 


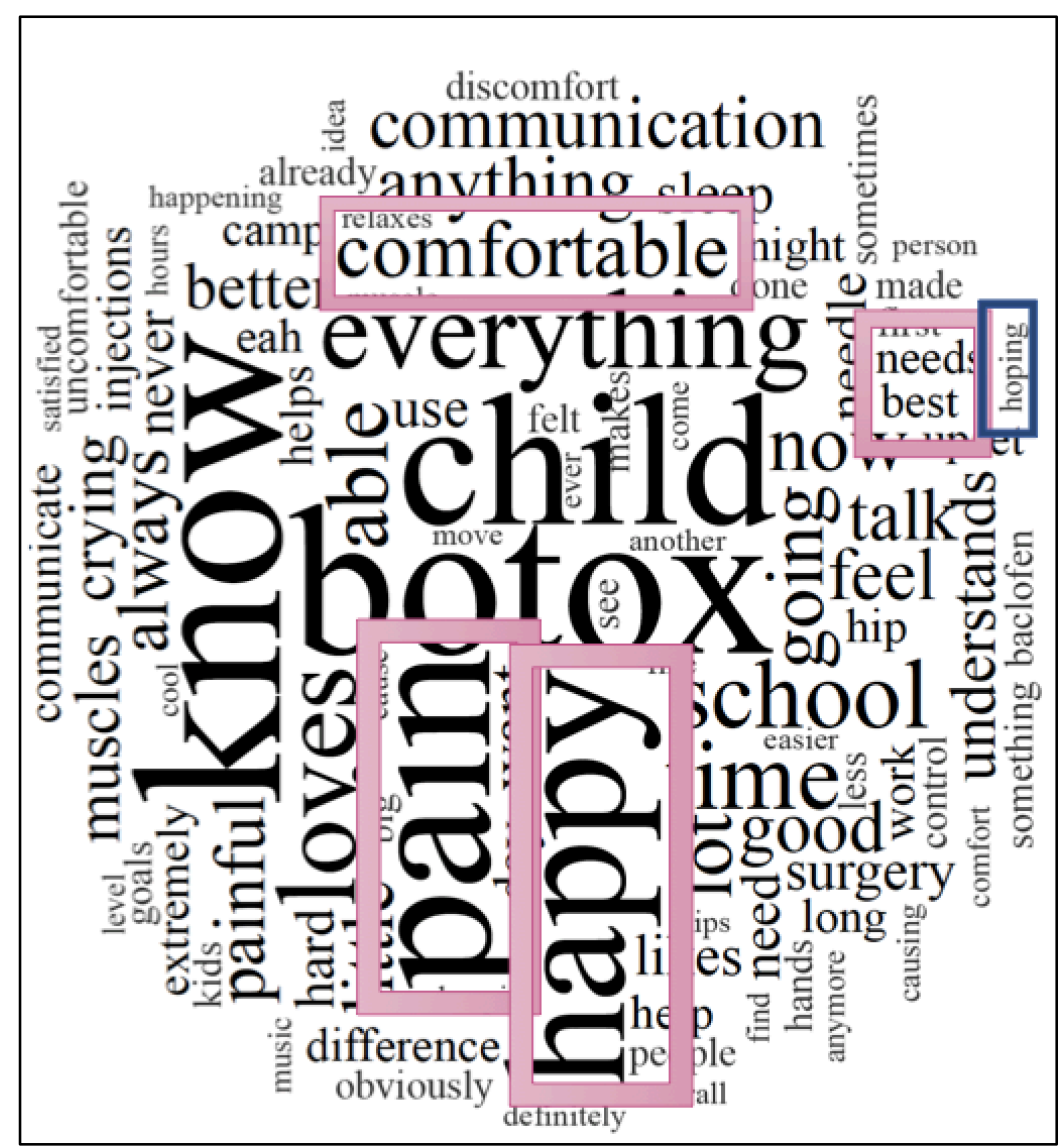

Figure 6. Personal factors. The child's happiness and level of comfort were personal factors that parents took into consideration when making decisions about pursuing further BoNT-A treatment sessions. Parents were hoping that BoNT-A continued to maintain their child's level of happiness and comfort. Some parents identified that it was painful for their child to receive BoNT-A injections, but parents needed do what was best for their child.

Below are parents' quotes to illustrate the personal factors that parents considered in the decision-making process of BoNT-A treatment.

"We want him to be happy and to be able to do the things that he loves to do easily. So, botox helps with that. So, we're happy to do that." (Mother of an 11-year-old boy, GMFCS level IV)

"Like obviously, physically she has a lot of complications. You know, we're doing the best that we're can. She's happy, so we 're happy." (Mother of an 8-year-old girl, GMFCS level IV)

"We noticed a bit of a difference but because she got so upset and it was so painful, we didn't think that it was worth getting done again. But we got it done again when she started getting stiffer, and the second time, the last time we did it, it really seemed to help." (Mother of an 11year-old girl, GMFCS level IV) 
M.Sc. Thesis - L Nguyen; McMaster University - Rehabilitation Science

"So we're hoping that the school system will give us a better hand of how to work with him in terms of communication, establish a communication, and then work with him from there." (Father of a 9-year-old boy, GMFCS level V)

"She just seems more comfortable in general... and not so much scissoring. The scissoring was making her uncomfortable and we don't see that anymore." (Mother of a 10-year-old girl, GMFCS level IV) 
M.Sc. Thesis - L Nguyen; McMaster University - Rehabilitation Science

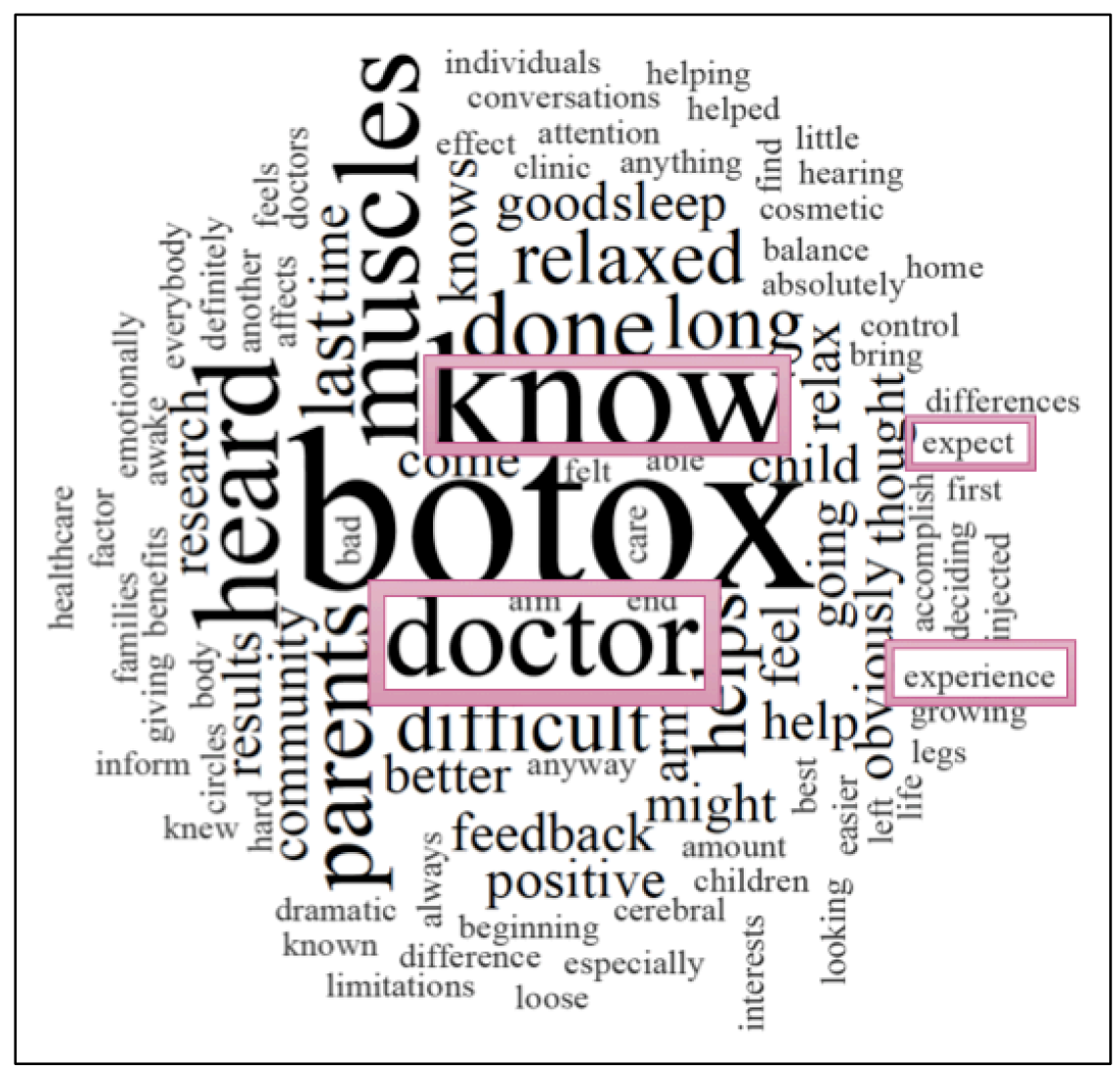

Figure 7. Learning process. It was a learning process for parents to identify the effects of BoNTA treatment for their child. Parents consulted with their healthcare professionals to make decisions about pursuing further BoNT-A treatment: "Yeah, I felt safe with that. We knew the doctor wouldn't recommend it [BoNT-A treatment] if she didn't feel it was in her best interests" (Mother of a 10-year-old girl, GMFCS level IV). Parents also consulted with other parents and heard positive feedback about BoNT-A treatment: "I know there's a few individuals that are sort of in and out of our circles with children who have received botox... positive feedback generally speaking, but... every child reacts a little differently to each treatment" (Father of a 5-year-old boy, GMFCS level IV). After several BoNT-A treatment sessions, parents had expectations of how BoNT-A treatment could help their child based on their previous experiences: "We've done it before and we kind of, you know, what to expect" (Mother of an 11-year-old girl, GMFCS level $I V$ ). Therefore, parents learned about whether BoNT-A treatment was effective for their treatment based on consultations with healthcare professionals and other parents, as well as their own personal experiences. 


\section{Appendix I: Member Checking Document}

Dear_ [parent]:

As promised, we would like to follow-up with information from our study entitled "Effects of Botulinum Toxin Treatment in Children and Adolescents with Cerebral Palsy GMFCS Level IV or V: Understanding the Parents' Perspectives".

Since August 2016, we have been fortunate to have parents share their story with us about their experiences of botulinum toxin treatment for their child. We appreciated your willingness to participate in our study and speak with us about the changes that you have observed in your child after botulinum toxin treatment.

In total, we interviewed 15 parents about their experiences. We interviewed both mothers and fathers. There were 7 boys and 8 girls, ranging in age from 5 to 17 years old. All of the interviews were typed and any information that could identify your child has been removed such as names and places. Our research team met to discuss how the information could be organized and identify common themes. These themes provide an overall topic to organize the key information that was raised in the interviews.

We would like to share with you a short summary of what we have learned so far. We want to make sure that the information that we thought were important is reflective of the information that you shared with us.

When you are reading through the summary, you may find that you recognize and connect with the themes. You might see that these themes are reflective of your experiences. However, you might also notice that these themes do not reflect your experiences. We would like you to make a note of these themes by putting a star beside them. We have also provided you with space to provide comments about these themes.

If you have any questions, please feel free to email me at nguyel7@,mcmaster.ca. We look forward to connecting with you.

Sincerely,

Linda Nguyen, MSc Student

CanChild Centre for Childhood Disability Research

School of Rehabilitation Science

McMaster University 
M.Sc. Thesis - L Nguyen; McMaster University - Rehabilitation Science

\section{Effects of Botulinum Toxin Treatment in Children and Adolescents with Cerebral Palsy GMFCS Level IV or V: Understanding the Parents' Perspectives}

\section{Summary of Study Findings}

Children with cerebral palsy (CP) often have increased tone in their muscles (called spasticity) that can limit their movements. Botulinum toxin treatment is often administered to children with CP to help their muscles relax. Here is a brief summary of the key themes based on the stories that parents shared during the interviews. Please put a star $(*)$ beside the themes that stand out to you. We have also left space on the last page for you to write your own thoughts and comments about these themes.

\section{Finding The Right Path to Do What Is Best for My Child}

We learned that parents are travelling the road on an unknown journey. It may be difficult to decide whether botulinum toxin treatment is the best decision for them. Children are already receiving various treatments and services, including physiotherapy and occupational therapy. Botulinum toxin treatment was also offered as a potential option to help care for a child with cerebral palsy.

"I think if it's an option for people, they should investigate it. You know it's a safer try, it's been beneficial for us."

It is important to connect with other parents and hear about their stories on the impact of botulinum toxin treatment.

"I did ask a couple of other moms with kids similar to [her]. And yeah, they had good experiences with it. And then when you hear, a mom tell you that has a kid very similar to [her], that's great. I would trust that."

We understood that every child wants to be happy, and that it important to take the steps to make every child as happy as possible. Children often enjoy going to school and socializing with friends. A child's happiness also depends on their level of comfort. We heard that a child is more comfortable when their muscles are relaxed.

"She just seems more comfortable in general. The scissoring was making her uncomfortable and we don't see that anymore."

"He is far more comfortable than he was before. He could sit in his car seat and wheelchair very comfortably."

\section{A Journey of Learning}

Botulinum toxin treatment was offered as an option to help their child manage their muscle tightness. We heard that every child is different and that it takes time to learn about the changes that took place in the child after each botulinum toxin treatment session. Botulinum toxin 
treatment impacted different aspects of the child's life, including body function and structures, activities, and participation.

- Body function and structures refers to the different parts of the body.

- Observed changes include: more relaxed muscle tone, decreased muscle tightness, release of tension, improved range of motion.

- Activities refer to everyday activities that the child is able to complete.

- Observed changes include: stretching exercises, ease of dressing such as wearing jackets, and ease of transfers in position.

- Participation refers to the child's involvement in social situations.

○ Observed changes include: drawing with friends at school, swimming, dancing, and horseback riding.

We also discussed about the reevaluation of treatment plans and goals based on these observations, and the hopes for what the child could achieve in the future.

"We were hoping that it would more mobility with her hands to be able to manipulate toys and things.”

"Because she wanted to do horseback riding and wanted her inner legs to be stretched out more, and she needs to stand so her legs are almost crossing. We're trying to stretch her out, so we need to focus on one area."

\section{The Future: Doing What Is Necessary}

Parents described how they would continue to have botulinum toxin treatment sessions for their child. Although some children experienced negative aspects of the treatment, the benefits outweighed the negative aspects.

"The discomfort of receiving the botox, the stress there [but] nothing that lasts beyond the moment of injection."

"The pain and the anxiety because she understands what is happening. It's very stressful for her."

"If you don't get a return on it, then I'm not doing it again. But definitely not. It's still very much worth it, for her and for me."

We heard that botulinum toxin treatment is still the best course of treatment for the child because of its benefits, such as improved quality of life for both parents and the child. It was easier for parents to care for their child, and to help their child complete certain activities. Parents reported "He's a little more relaxed, so getting him dressed is easier. Bathing him is easier." and "It just helps me carry him and transfer him." For the short-term, we heard that parents want to better care for their child. 
M.Sc. Thesis - L Nguyen; McMaster University - Rehabilitation Science

In the long-term, it is important to foster a sense of independence and confidence for the child.

"She wants to be independent and she gets frustrated when she can't do it by herself too. It helps with doing what she wants and that makes her happy to be able to be independent."

Understanding what is best for the child can take time. The path to making the right decision on whether to pursue botulinum toxin treatment depends on a number of factors. Ultimately, it was emphasized that botulinum toxin treatment could be a potential option if it had a positive impact on the child's happiness, and could help the child achieve independence in the future.

After reading through this summary of findings, please indicate provide your comments about the themes or quotes that stood out to you. Do you agree or disagree with each theme or quote? 


\section{Appendix J: Reflection of My Journey}

\section{A Reflection: The Stages of My Journey as a Researcher}

\section{Research \\ Background and Hopes}

\section{Research \\ Goals}

\section{Research \\ Process}

\section{Reflections on \\ Strengths and \\ Challenges}

\section{Destination and \\ Future Directions}

\begin{tabular}{|c|c|c|c|c|}
\hline $\begin{array}{l}\text { Hope: } \\
\text { - To describe } \\
\text { parents' } \\
\text { experiences of } \\
\text { BoNT-A treatment } \\
\text { - By understanding } \\
\text { parents' } \\
\text { experiences, we } \\
\text { could identify how } \\
\text { these experiences } \\
\text { shaped parents' } \\
\text { future goals }\end{array}$ & $\begin{array}{l}\text { Goal: } \\
\text { - } \quad \text { To identify the } \\
\text { effects of BoNT-A } \\
\text { treatment in } \\
\text { children and } \\
\text { adolescents with } \\
\text { CP in GMFCS } \\
\text { level IV or V }\end{array}$ & $\begin{array}{l}\text { Philosophical } \\
\text { assumptions: } \\
\text { - Constructivist } \\
\text { paradigm, in which } \\
\text { there are multiple } \\
\text { realities } \\
\text { - Findings are co- } \\
\text { constructed between } \\
\text { the researcher and } \\
\text { individual }\end{array}$ & $\begin{array}{l}\text { Reflections: } \\
\text { - Use of analytic } \\
\text { strategies to } \\
\text { recognize } \\
\text { strengths and } \\
\text { overcome } \\
\text { challenges } \\
\text { - Development of } \\
\text { ability to } \\
\text { understand } \\
\text { parents' } \\
\text { perspectives }\end{array}$ & $\begin{array}{l}\text { Destination: } \\
\text { - } \quad \text { To capture parents' } \\
\text { experiences of } \\
\text { BoNT-A treatment } \\
\text { Future Directions: } \\
\text { - } \quad \text { Provision of } \\
\text { informational goal- } \\
\text { setting resources for } \\
\text { parents and } \\
\text { healthcare } \\
\text { professionals }\end{array}$ \\
\hline \multicolumn{5}{|l|}{ Study Design } \\
\hline $\begin{array}{l}\text { Interpretive } \\
\text { description used } \\
\text { as a qualitative } \\
\text { methodology, to } \\
\text { describe parents' } \\
\text { experiences and } \\
\text { interpret this } \\
\text { information into } \\
\text { a key message }\end{array}$ & $\begin{array}{l}\text { - Framework of } \\
\text { the ICF to } \\
\text { categorize } \\
\text { parents' effects } \\
\text { of BoNT-A } \\
\text { The impact of } \\
\text { BoNT-A effects } \\
\text { on the child and } \\
\text { family were } \\
\text { identified }\end{array}$ & $\begin{array}{l}\text { - Clinical expertise } \\
\text { as a starting point } \\
\text { Peer debriefing } \\
\text { with research team } \\
\text { members and } \\
\text { healthcare } \\
\text { professionals } \\
\text { Member } \\
\text { checking with } \\
\text { parents for } \\
\text { feedback }\end{array}$ & $\begin{array}{l}\text { Strength: } \\
\text { - } \quad \text { Ongoing } \\
\text { reflexive memos } \\
\text { Challenges: } \\
\text { - Analytic } \\
\text { strategies to } \\
\text { identify stages of } \\
\text { parents' journey }\end{array}$ & $\begin{array}{l}\text { Resources: } \\
\text { 1. Summary of } \\
\text { parents' } \\
\text { experiences } \\
\text { 2. Inventory list of } \\
\text { goals } \\
\text { Evaluate the impact } \\
\text { of these resources } \\
\text { on goal setting and } \\
\text { goal achievement }\end{array}$ \\
\hline
\end{tabular}

Abbreviations: 1. BoNT-A: botulinum toxin, 2. ICF: International Classification of Functioning, Disability and Health

The diagram provides an overview of my journey as a qualitative researcher, and the process of using certain design approaches and analytic strategies at each stage of the study. Future directions of the next stage in a subsequent study are also provided. 
Appendix K: Reflections on the Challenges and Strengths of this Study.

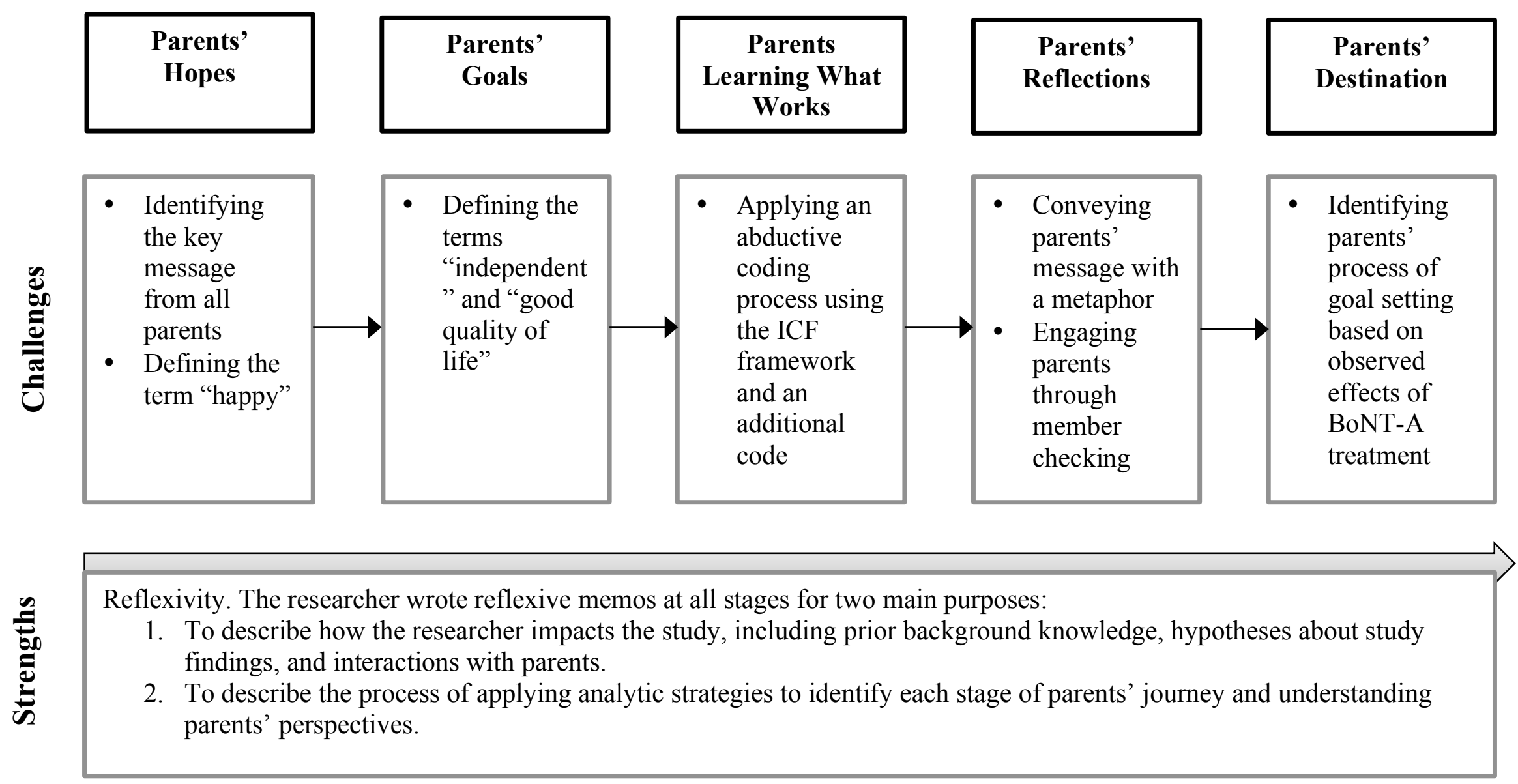

This diagram illustrates the challenges and strengths of this study. Challenges were experienced during the identification of each stage of parents' journey. The overall strength of this study was the use of reflexive memos to describe the impact of the researcher in the study and understand parents' perspectives. 